\title{
Multiple lesions and delayed diagnosis in breast cancer screening
}

Citation for published version (APA):

Lameijer, J. R. C. (2021). Multiple lesions and delayed diagnosis in breast cancer screening. [Doctoral Thesis, Maastricht University]. GVO drukkers \& vormgevers B.V. https://doi.org/10.26481/dis.20210112jl

Document status and date:

Published: 01/01/2021

DOI:

10.26481/dis.20210112jl

Document Version:

Publisher's PDF, also known as Version of record

\section{Please check the document version of this publication:}

- A submitted manuscript is the version of the article upon submission and before peer-review. There can be important differences between the submitted version and the official published version of record.

People interested in the research are advised to contact the author for the final version of the publication, or visit the DOI to the publisher's website.

- The final author version and the galley proof are versions of the publication after peer review.

- The final published version features the final layout of the paper including the volume, issue and page numbers.

Link to publication

\footnotetext{
General rights rights.

- You may freely distribute the URL identifying the publication in the public portal. please follow below link for the End User Agreement:

www.umlib.nl/taverne-license

Take down policy

If you believe that this document breaches copyright please contact us at:

repository@maastrichtuniversity.nl

providing details and we will investigate your claim.
}

Copyright and moral rights for the publications made accessible in the public portal are retained by the authors and/or other copyright owners and it is a condition of accessing publications that users recognise and abide by the legal requirements associated with these

- Users may download and print one copy of any publication from the public portal for the purpose of private study or research.

- You may not further distribute the material or use it for any profit-making activity or commercial gain

If the publication is distributed under the terms of Article $25 \mathrm{fa}$ of the Dutch Copyright Act, indicated by the "Taverne" license above, 


\section{Multiple lesions and delayed diagnosis in breast cancer screening}


Multiple lesions and delayed diagnosis

in breast cancer screening 
Copyright (C) Joost R.C. Lameijer 2021

All rights reserved. No part of this thesis may be reproduced or distributed in any form or by any means, without the prior written permission of the author or the publisher.

Cover: Patty T. Huijgens

Layout: Tiny Wouters

Printing: GVO drukkers \& vormgers B.V.

ISBN: 


\title{
Multiple lesions and delayed diagnosis in breast cancer screening
}

\author{
PROEFSCHRIFT \\ ter verkrijging van \\ de graad van doctor aan de Universiteit Maastricht, \\ op gezag van de Rector Magnificus, Prof. dr. Rianne M. Letschert, \\ volgens het besluit van het College van Decanen, \\ in het openbaar te verdedigen \\ op dinsdag 12 januari 2021 om 10.00 uur
}

door

Joost Rutger Constantijn Lameijer 
Promotor

Prof. dr. V.C.G. Tjan-Heijnen

\section{Copromotoren}

Dr. L.E.M. Duijm (Canisius Wilhelmina Ziekenhuis, Nijmegen)

Dr. A.C. Voogd

\section{Beoordelingscommissie}

Prof. dr. H.J.T. Rutten, voorzitter.

Prof. dr. G.H. de Bock (Universitair Medisch Centrum Groningen)

Prof. dr. G.J. Dinant

Prof. dr. D.K.M. de Ruysscher

Dr. A.B. Donkers-van Rossum (Catharina Ziekenhuis, Eindhoven) 


\section{Contents}

Chapter 1 General introduction

Chapter 2 Bilateral recall and bilateral cancers 19

2.1 Frequency and outcome of bilateral recall at screening 21 mammography

2.2 Tumour characteristics of bilateral screen-detected cancers and bilateral interval cancers in women participating at biennial screening mammography

Chapter 3 Additional findings

55

3.1 Frequency and characteristics of additionally detected ipsilateral breast lesions following recall at screening mammography

3.2 Frequency and characteristics of contralateral breast abnormalities following recall at screening mammography

Chapter 4 Delayed diagnosis

4.1 Trends in delayed breast cancer diagnosis after recall at screening mammography.

4.2 Delayed breast cancer diagnosis after repeated recall at biennial screening mammography, an observational follow-up study from the Netherlands 



\section{Chapter 1}

General introduction 
Breast cancer incidence in Dutch women is among the highest in Europe and has increased steadily over the years. ${ }^{1}$ This is partly explained by the introduction of breast cancer screening, as well as by the increased exposure to risk factors and increased awareness of breast cancer among women. In 2015, 17,000 women were newly diagnosed with breast cancer in the Netherlands, and of every seven women one will be diagnosed with breast cancer at some point in her life.

\section{Breast cancer screening in the Netherlands}

Screening programmes have been implemented in many countries to facilitate early diagnosis of asymptomatic breast cancer in order to prevent breast cancer related morbidity and mortality by early treatment of the disease. Breast cancer screening was introduced in the Netherlands in 1989. Several studies have shown the positive effect of breast cancer screening on breast cancer mortality rates in the Netherlands. ${ }^{2,3}$ However, it is difficult to estimate how much of the observed decrease in breast cancer mortality can be attributed to the introduction of breast cancer screening, knowing that many improvements in breast cancer care have taken place in the past three decades. Several studies have estimated that around $28-35 \%$ of the reduction in breast cancer related mortality over the past decades can be attributed to breast cancer screening, both in the Netherlands as well as in other countries. ${ }^{2-7}$ In a recent evaluation of the Dutch breast cancer screening programme over the period 2004-2014 a reduction of $58 \%$ in breast cancer related mortality was seen in screening participants versus nonparticipants. $^{8}$

The Dutch breast cancer screening programme is a biennial screening programme. At the time of introduction, it was offered to women aged 50-69 years. From 1998 onwards, women aged 70-75 have been included as well. Since the introduction of digital mammography in 2009-2010 in the southern region of the Netherlands, a standard two-view mammogram is obtained by certified screening technologists. ${ }^{9}$ The mammogram is independently read by two qualified screening radiologists according to European guidelines, and compared to earlier screening examinations when possible. ${ }^{9-11}$ Screening results are then sent to the general practitioner. In case of an abnormal screening examination, the woman is referred to a hospital where further diagnostic work-up will take place. The hospitals to which the women are referred are not hosting the screening units, as is the situation in other countries such as the United States and Canada. ${ }^{12}$

The Breast Imaging Reporting and Data System (BI-RADS) system is routinely used in the Dutch screening programme. ${ }^{13,14}$ Its use in the breast cancer screening programme has been assessed earlier, demonstrating that it can be used as a tool for stratification of women according to the suspicion of malignancy per BI-RADS category. ${ }^{15,16}$ In the Dutch screening programme, women with a BI-RADS score of 0, 4 and 5 are referred to dedicated breast units at hospitals in the region. BI-RADS score 3 
is not used in the Dutch screening programme as the programme does not provide short term follow-up. The BI-RADS 0 category represents a lesion that needs further work-up due to insufficient information from the screening mammogram alone. BI-RADS 4 represents an abnormality with a reasonable possibility of being malignant without classic features of malignancy, and BI-RADS 5 represents an abnormality which is highly suggestive of malignancy.

\section{Effectiveness and quality of screening programmes}

The effectiveness and quality of a screening programme is reflected by several parameters, including recall rate, cancer detection rate at screening, programme accuracy, false-positive rate and interval cancer rate.

A steep rise in recall rate has occurred in the past two decades. At the start of the screening programme in the Netherlands, a recall rate of 1\% (or 9.5 per 1000 screened women) was seen (1998). At that time, international recall rates generally varied between $4 \%$ and $10 \%$, and the Dutch optimization study group concluded that lowering the threshold for recall would improve breast cancer detection rate of the Dutch screening programme. ${ }^{11,17}$ Recall rates more than doubled after the application of a lower recall threshold, in addition to the implementation of digital and two-view mammography, from 9.5 per 1000 screened women in 1998 to 25 per 1000 screened women in 2014. . $^{8,9,11}$

The increased recall rates resulted in an increase of the cancer detection rate, from 4.8 per 1000 screened women in 1998 to 6.7 per 1000 screened women in 2014. ${ }^{8,11}$ Organizational and technical advancements, such as the introduction of digital mammography and improved reading strategies, have also helped to improve the accuracy of screening. ${ }^{9,18,19}$ Recently, promising reports have emerged on the introduction of digital breast tomosynthesis to the screening programmes worldwide, which may further improve screening accuracy in the near future if deemed feasible for the screening setting. ${ }^{9,20-26}$ Due to the increase in cancer detection rate, the programme sensitivity of the Dutch screening programme increased from $68.2 \%$ in 1998 to $74 \%$ in 2014. Despite the increase in recall rate, programme specificity was $98.6 \%$ in 2014 , which is high compared to screening programmes in other countries. ${ }^{6,8,27}$

One of the downsides of screening programmes, however, is the occurrence of false positive recalls, as these may cause anxiety among participants. The false-positive recall rate in the Dutch breast cancer screening programme has increased over the past decades from 9.0 per 1000 screened women in 2004 to 17.8 per 1000 screened women in 2014. This was seen in other countries as well, although the occurrence of falsepositive recall is lower in biennial screening programmes compared to annual screening programmes. ${ }^{8,28,29}$ Due to the rise in false positive recalls, the positive predictive value of screening has decreased over the past decade from $48.4 \%$ in 1998 to $31.0 \%$ in 2014 , despite increased numbers of screen-detected invasive and in situ carcinomas. ${ }^{8}$ 
When breast cancer is found in women within two years after a negative screen and prior to the next scheduled screening mammogram, this is called an interval cancer. Interval cancers are defined as "primary breast cancers that are diagnosed in women after a screening examination which has yielded a negative result, defined as no recommendation for referral or negative further assessment after referral, and before any subsequent screen is performed or within a time period equal to the screening interval ( 2 years)". ${ }^{10}$ These cancers can either be cancers missed at screening, or true interval cancers, i.e. cancers which are not visible at screening mammography. ${ }^{9,30}$ Interval cancers can occur both unilaterally and bilaterally, and are usually larger at detection and have a higher tumour grade as well as an increased likelihood of being oestrogen-receptor negative when compared to screen-detected cancers. They also show a higher frequency of lymph node involvement than screendetected cancers. ${ }^{31-33}$ Interval cancers account for approximately $25 \%$ of cancers detected in women participating in a biennial screening programme..$^{31,34,35}$ Over the past years, the interval cancer rate has been stable at around 2.2 per 1000 screened women, despite an increase of the recall and detection rates. The overall and diseasefree survival of women with interval cancers is worse than that of women with screendetected cancer. As mentioned before, a low rate of interval cancers is a key quality feature of a screening programme performance, which stresses the importance of monitoring this rate and keeping it as low as possible. ${ }^{36,37}$

\section{Bilateral recall and bilateral cancers}

Data on bilateral breast cancer and bilateral recall in screening mammography populations are scarse. The proportion of synchronous bilateral breast cancers among all breast cancers is modest and ranges, for example, from $2.2 \%$ in the Dutch screening population to $4.4 \%$ in a population derived from the National University of Ireland Galway breast cancer database in Ireland. ${ }^{38-41}$ Controversy exists regarding the prognosis of women with bilateral breast cancer. Several studies have reported a worse survival than for women diagnosed with unilateral breast cancer, but in other studies no differences were found between women with bilateral breast cancer and unilateral breast cancer. ${ }^{40,42-47}$ Despite these contrary findings, rapid detection of bilateral breast cancer seems paramount to optimize the effectiveness of the treatment for these women.

The increased detection of bilateral breast cancer is mostly attributed to the use of magnetic resonance imaging (MRI) after a diagnosis of primary breast cancer as a preoperative assessment This may yield additional lesions in the contralateral breast that require additional analyses. In a recent study, an additional cancer was found in the contralateral breast in $3 \%$ of the women who underwent MRI for pre-operative tumour assessment. ${ }^{38,39,48-51}$ 


\section{Additional findings}

The improved image quality and the new modalities being used in screening as well as in the diagnostic work-up after recall, have led to an increase in information obtained from these examinations. ${ }^{20,24-26}$

Technological advancements in imaging quality at screening not only provide the screening radiologist or clinical radiologist with more information on possible malignant lesions, they also have the ability to depict incidental lesions in the ipsilateral or contralateral breast, which may require multiple biopsies to exclude multifocal, multicentric or contralateral breast cancer. ${ }^{48,50,52}$ Additional malignant lesions may cause the surgeon to switch from breast conserving surgery to mastectomy, or may necessitate the use of (neo-)adjuvant chemo- and/or radiotherapy. ${ }^{42,48,50,53-55}$

\section{Delayed diagnosis}

Early detection of breast cancer does not solely involve detection of suspicious mammographic abnormalities at screening, but also requires a swift confirmation of malignancy after recall. Several studies have shown that up to $5 \%$ of recalled women experience a delay in the confirmation of their breast cancer. A delay in breast cancer diagnosis may worsen tumour characteristics, with progression of tumour size and a higher risk of metastatic lymph nodes. ${ }^{56-61}$

Studies have mostly focused on shorter diagnostic delays in symptomatic patients and very limited data are available on this subject in asymptomatic, screen-detected breast cancers. Several causes for a delayed breast cancer diagnosis after recall have been reported, including an improper classification of mammographic abnormalities at subsequent clinical breast imaging, communication errors between physicians, and sample errors at biopsy. ${ }^{56,62,63}$ With an increase in the information obtained from improved imaging techniques, as mentioned before, one may assume that the proportion of women who face a delay in their breast cancer diagnosis after recall at screening mammography has decreased over time. At the same time, a reduction in length of delay is expected due to increased diagnostic accuracy, also reducing the need for radiological follow-up in cases of equivocal findings at mammography or ultrasound. However, ambiguous findings at screening and recall may cause incorrect BI-RADS classifications, with subsequent false negative percutaneous biopsy or surgical excision. This could result in both short and long delays in breast cancer diagnosis.

\section{Database}

Since the implementation of the breast cancer screening programme in the region of Eindhoven (in the southern part of the Netherlands) in 1995, an Excel-database on 
screening outcome has been carefully maintained. The data from this database were used for the studies presented in this thesis.

The database is used for professional quality assurance as well as a wide variety of scientific purposes. The database contains information on patient characteristics and screening history. Recall data are recorded regarding the type of mammographic abnormality at screening as well as on the detection of additional lesions in the ipsilateral or contralateral breast. Type of biopsy performed, outcome of pathological analysis and data on tumour stage are also recorded, as are data on surgery and pathological analysis of the final surgical specimen. In case of an interval cancer, the previous screening mammograms were retrospectively assessed by two experienced screening radiologists in an independent fashion. Data is also recorded on breast density, family history of breast cancer, as well as data on earlier breast surgery (i.e. benign surgery or surgical biopsy).

\section{Aims and outline of this thesis}

The aims of this thesis were:

- to evaluate varying aspects of the breast cancer screening programme in the southern region of the Netherlands. These studies may contribute to an overview for screening and diagnostic radiologists and other personnel involved in the screening mammography programme on the outcome of various types of recall as well as additional findings found at recall.

- to improve our understanding of causes of delayed diagnosis of breast cancer after screening mammography, and hopefully providing means to further reduce these delayed diagnoses to improve the diagnostic accuracy and efficacy of this biennial screening mammography programme in the southern region of the Netherlands.

Chapter 2 determines trends and outcome of bilateral recall and the incidence of bilateral breast cancers, both at screening mammography and as interval cancers.

Chapter 3 evaluates additional findings detected after recall for an abnormal screening mammography, both in the ipsilateral recalled breast as well as lesions in the contralateral, non-recalled breast.

Chapter 4 analyses time trends, frequency and causes of short (4-24 months) and long delays (>24 months) in breast cancer diagnoses after recall at screening mammography. In chapter 6, the main results of the studies in this thesis are discussed, as well as their significance in improving the current and future breast cancer screening programme in the south of the Netherlands. 


\section{References}

1. Paap E, Broeders MJ, van Schoor G, Otten JD, Verbeek AL. Large increase in a Dutch woman's lifetime risk of developing breast cancer. Eur J Cancer. 2008;44:1485-7.

2. Otto SJ, Fracheboud J, Verbeek AL, Boer R, Reijerink-Verheij JC, Otten JD, Broeders MJ, de Koning HJ, National Evaluation Team for Breast Cancer S. Mammography screening and risk of breast cancer death: a population-based case-control study. Cancer Epidemiol Biomarkers Prev. 2012;21:66-73.

3. Sankatsing VDV, van Ravesteyn NT, Heijnsdijk EAM, Looman CWN, van Luijt PA, Fracheboud J, den Heeten GJ, Broeders MJM, de Koning HJ. The effect of population-based mammography screening in Dutch municipalities on breast cancer mortality: 20 years of follow-up. Int J Cancer. 2017;141:671-7.

4. Myers ER, Moorman P, Gierisch JM, Havrilesky LJ, Grimm LJ, Ghate S, Davidson B, Mongtomery RC, Crowley MJ, McCrory DC, Kendrick A, Sanders GD. Benefits and Harms of Breast Cancer Screening: A Systematic Review. JAMA. 2015;314:1615-34.

5. van Schoor G, Moss SM, Otten JD, Donders R, Paap E, den Heeten GJ, Holland R, Broeders MJ, Verbeek AL. Increasingly strong reduction in breast cancer mortality due to screening. Br J Cancer. 2011;104: 910-4.

6. Weedon-Fekjaer $\mathrm{H}$, Romundstad PR, Vatten LJ. Modern mammography screening and breast cancer mortality: population study. BMJ. 2014;348:g3701.

7. Morrell S, Taylor R, Roder D, Robson B, Gregory M, Craig K. Mammography service screening and breast cancer mortality in New Zealand: a National Cohort Study 1999-2011. Br J Cancer. 2017;116:828-39.

8. Landelijke evaluatie van bevolkingsonderzoek naar borstkanker in Nederland 2004-2014. Nijmegen: Landelijk Evaluatie Team voor bevolkingsonderzoek naar Borstkanker; 2019.

9. Nederend J, Duijm LE, Louwman MW, Groenewoud JH, Donkers-van Rossum AB, Voogd AC. Impact of transition from analog screening mammography to digital screening mammography on screening outcome in The Netherlands: a population-based study. Ann Oncol. 2012;23:3098-103.

10. Perry N, Broeders M, de Wolf C, Tornberg S, Holland R, von Karsa L. European guidelines for quality assurance in breast cancer screening and diagnosis. Fourth edition--summary document. Ann Oncol. 2008;19:614-22.

11. Landelijke evaluatie van bevolkingsonderzoek naar borstkanker in Nederland 1990-2011/2012. Nijmegen: Landelijk Evaluatie Team voor bevolkingsonderzoek naar Borstkanker; 2014.

12. Smith CR, Chiarelli AM, Holloway CM, Mirea L, O'Malley FP, Blackmore KM, Pandya A, Majpruz V, Harris CP, Hendry A, Hey A, Kornecki A, Lougheed G, Maier BA, Marchand P, McCready D, Rand C, Raphael S, Segal-Nadler R, Sehgal N, Muradali D. The impact of organized breast assessment on survival by stage for screened women diagnosed with invasive breast cancer. Breast. 2018;41:25-33.

13. American College of Radiology. BI-RADS Committee. ACR BI-RADS atlas: Breast Imaging Reporting and Data System. 4th ed. Reston, VA: American College of Radiology; 2003.

14. American College of Radiology. BI-RADS Committee. ACR BI-RADS atlas: Breast Imaging Reporting and Data System. 5th ed. Reston, VA: American College of Radiology; 2013.

15. Timmers JM, van Doorne-Nagtegaal HJ, Zonderland HM, van Tinteren $H$, Visser O, Verbeek AL, den Heeten GJ, Broeders MJ. The Breast Imaging Reporting and Data System (BI-RADS) in the Dutch breast cancer screening programme: its role as an assessment and stratification tool. Eur Radiol. 2012;22:1717-23.

16. Vanel D. The American College of Radiology (ACR) Breast Imaging and Reporting Data System (BI-RADS): a step towards a universal radiological language? Eur J Radiol. 2007;61:183.

17. Otten JD, Karssemeijer N, Hendriks JH, Groenewoud JH, Fracheboud J, Verbeek AL, de Koning HJ, Holland R. Effect of recall rate on earlier screen detection of breast cancers based on the Dutch performance indicators. J Natl Cancer Inst. 2005;97:748-54.

18. Bluekens AM, Broeders MJ, den Heeten GJ. Digital mammography in breast cancer screening: a step forward? Expert Rev Anticancer Ther. 2013;13:505-7.

19. Klompenhouwer EG, Voogd AC, den Heeten GJ, Strobbe LJ, de Haan AF, Wauters CA, Broeders MJ, Duijm LE. Blinded double reading yields a higher programme sensitivity than non-blinded double reading at digital screening mammography: a prospected population based study in the south of The Netherlands. Eur J Cancer. 2015;51:391-9.

20. Bernardi D, Macaskill P, Pellegrini M, Valentini M, Fanto C, Ostillio L, Tuttobene P, Luparia A, Houssami $\mathrm{N}$. Breast cancer screening with tomosynthesis (3D mammography) with acquired or synthetic 2D 
mammography compared with 2D mammography alone (STORM-2): a population-based prospective study. Lancet Oncol. 2016;17:1105-13. 2

21. Gilbert FJ, Tucker L, Gillan MG, Willsher P, Cooke J, Duncan KA, Michell MJ, Dobson HM, Lim YY, Purushothaman H, Strudley C, Astley SM, Morrish O, Young KC, Duffy SW. The TOMMY trial: a comparison of TOMosynthesis with digital MammographY in the UK NHS Breast Screening Programme-a multicentre retrospective reading study comparing the diagnostic performance of digital breast tomosynthesis and digital mammography with digital mammography alone. Health Technol Assess. 2015;19:i-xxv, 1-136.

22. Karssemeijer N, Bluekens AM, Beijerinck D, Deurenberg JJ, Beekman M, Visser R, van Engen R, BartelsKortland A, Broeders MJ. Breast cancer screening results 5 years after introduction of digital mammography in a population-based screening program. Radiology. 2009;253:353-8.

23. Hambly NM, McNicholas MM, Phelan N, Hargaden GC, O'Doherty A, Flanagan FL. Comparison of digital mammography and screen-film mammography in breast cancer screening: a review in the Irish breast screening program. AJR Am J Roentgenol. 2009;193:1010-8.

24. Skaane P, Bandos Al, Gullien R, Eben EB, Ekseth U, Haakenaasen U, Izadi M, Jebsen IN, Jahr G, Krager M, Niklason LT, Hofvind S, Gur D. Comparison of digital mammography alone and digital mammography plus tomosynthesis in a population-based screening program. Radiology. 2013;267:47-56.

25. Skaane P, Sebuodegard S, Bandos Al, Gur D, Osteras BH, Gullien R, Hofvind S. Performance of breast cancer screening using digital breast tomosynthesis: results from the prospective population-based Oslo Tomosynthesis Screening Trial. Breast Cancer Res Treat. 2018;169:489-96.

26. Zackrisson S, Lang K, Rosso A, Johnson K, Dustler M, Fornvik D, Fornvik H, Sartor H, Timberg P, Tingberg $A$, Andersson I. One-view breast tomosynthesis versus two-view mammography in the Malmo Breast Tomosynthesis Screening Trial (MBTST): a prospective, population-based, diagnostic accuracy study. Lancet Oncol. 2018;19:1493-503.

27. Harding C, Pompei F, Burmistrov D, Welch HG, Abebe R, Wilson R. Breast Cancer Screening, Incidence, and Mortality Across US Counties. JAMA Intern Med. 2015;175:1483-9.

28. Nelson HD, Pappas M, Cantor A, Griffin J, Daeges M, Humphrey L. Harms of Breast Cancer Screening: Systematic Review to Update the 2009 U.S. Preventive Services Task Force Recommendation. Ann Intern Med. 2016;164:256-67.

29. Nelson HD, Fu R, Cantor A, Pappas M, Daeges M, Humphrey L. Effectiveness of Breast Cancer Screening: Systematic Review and Meta-analysis to Update the 2009 U.S. Preventive Services Task Force Recommendation. Ann Intern Med. 2016;164:244-55.

30. van Bommel RMG, Voogd AC, Nederend J, Setz-Pels W, Louwman MWJ, Strobbe LJ, Venderink D, TjanHeijnen VCG, Duijm LEM. Incidence and tumour characteristics of bilateral and unilateral interval breast cancers at screening mammography. Breast. 2018;38:101-6.

31. Houssami N, Hunter K. The epidemiology, radiology and biological characteristics of interval breast cancers in population mammography screening. NPJ Breast Cancer. 2017;3:12.

32. Defossez G, Quillet A, Ingrand P. Aggressive primary treatments with favourable 5-year survival for screen-interval breast cancers. BMC Cancer. 2018;18:393.

33. Bellio G, Marion R, Giudici F, Kus S, Tonutti M, Zanconati F, Bortul M. Interval Breast Cancer Versus Screen-Detected Cancer: Comparison of Clinicopathologic Characteristics in a Single-Center Analysis. Clin Breast Cancer. 2017;17:564-71.

34. Tornberg S, Kemetli L, Ascunce N, Hofvind S, Anttila A, Seradour B, Paci E, Guldenfels C, Azavedo E, Frigerio A, Rodrigues V, Ponti A. A pooled analysis of interval cancer rates in six European countries. Eur J Cancer Prev. 2010;19:87-93.

35. Nederend J, Duijm LE, Voogd AC, Groenewoud JH, Jansen FH, Louwman MW. Trends in incidence and detection of advanced breast cancer at biennial screening mammography in The Netherlands: a population based study. Breast Cancer Res. 2012;14:R10.

36. Sala M, Domingo L, Louro J, Tora-Rocamora I, Bare M, Ferrer J, Carmona-Garcia MC, Barata T, Roman M, Macia F, Castells X, Group CS. Survival and Disease-Free Survival by Breast Density and Phenotype in Interval Breast Cancers. Cancer Epidemiol Biomarkers Prev. 2018;27:908-16.

37. Rayson D, Payne JI, Abdolell M, Barnes PJ, Maclntosh RF, Foley T, Younis T, Burns A, Caines J. Comparison of clinical-pathologic characteristics and outcomes of true interval and screen-detected invasive breast cancer among participants of a Canadian breast screening program: a nested casecontrol study. Clin Breast Cancer. 2011;11:27-32. 
38. Setz-Pels W, Duijm LE, Groenewoud JH, Voogd AC, Jansen FH, Hooijen MJ, Louwman MW. Detection of bilateral breast cancer at biennial screening mammography in the Netherlands: a population-based study. Radiology. 2011;260:357-63.

39. Setz-Pels W, Duijm LE, Groenewoud JH, Louwman MW, Jansen FH, van Beek M, Plaisier ML, Voogd AC. Patient and tumor characteristics of bilateral breast cancer at screening mammography in the Netherlands, a population-based study. Breast Cancer Res Treat. 2011;129:955-61.

40. Kheirelseid EA, Jumustafa H, Miller N, Curran C, Sweeney K, Malone C, McLaughlin R, Newell J, Kerin MJ. Bilateral breast cancer: analysis of incidence, outcome, survival and disease characteristics. Breast Cancer Res Treat. 2011;126:131-40.

41. Kim JY, Cho N, Koo HR, Yi A, Kim WH, Lee SH, Chang JM, Han W, Moon HG, Im SA, Noh DY, Moon WK. Unilateral breast cancer: screening of contralateral breast by using preoperative $M R$ imaging reduces incidence of metachronous cancer. Radiology. 2013;267:57-66.

42. O'Brien JA, Ho A, Wright GP, Stempel M, Patil S, Krause K, Morrow M, Gemignani ML. BreastConserving Surgery in Bilateral Breast Cancer. Ann Surg Oncol. 2015;22:3389-96.

43. Beckmann KR, Buckingham J, Craft P, Dahlstrom JE, Zhang Y, Roder D, Stuart-Harris R. Clinical characteristics and outcomes of bilateral breast cancer in an Australian cohort. Breast. 2011;20:158-64.

44. Hartman M, Czene K, Reilly M, Adolfsson J, Bergh J, Adami HO, Dickman PW, Hall P. Incidence and prognosis of synchronous and metachronous bilateral breast cancer. J Clin Oncol. 2007;25:4210-6.

45. Jobsen JJ, van der Palen J, Ong F, Riemersma S, Struikmans H. Bilateral breast cancer, synchronous and metachronous; differences and outcome. Breast Cancer Res Treat. 2015;153:277-83.

46. Kuo WH, Yen AM, Lee PH, Chen KM, Wang J, Chang KJ, Chen TH, Tsau HS. Cumulative survival in earlyonset unilateral and bilateral breast cancer: an analysis of 1907 Taiwanese women. $\mathrm{Br} \mathrm{J}$ Cancer. 2009;100:563-70.

47. Roder D, de Silva P, Zorbas H, Kollias J, Malycha P, Pyke C, Campbell I, Webster F. Survival from synchronous bilateral breast cancer: the experience of surgeons participating in the breast audit of the Society of Breast Surgeons of Australia and New Zealand. Asian Pac J Cancer Prev. 2012;13:1413-8.

48. El Sharouni MA, Postma EL, Menezes GL, van den Bosch MA, Pijnappel RM, Witkamp AJ, van der Pol CC, Verkooijen HM, van Diest PJ. High Prevalence of MRI-Detected Contralateral and Ipsilateral Malignant Findings in Patients With Invasive Ductolobular Breast Cancer: Impact on Surgical Management. Clin Breast Cancer. 2016;16:269-75.

49. Plana MN, Carreira C, Muriel A, Chiva M, Abraira V, Emparanza JI, Bonfill X, Zamora J. Magnetic resonance imaging in the preoperative assessment of patients with primary breast cancer: systematic review of diagnostic accuracy and meta-analysis. Eur Radiol. 2012;22:26-38.

50. Brennan ME, Houssami N, Lord S, Macaskill P, Irwig L, Dixon JM, Warren RM, Ciatto S. Magnetic resonance imaging screening of the contralateral breast in women with newly diagnosed breast cancer: systematic review and meta-analysis of incremental cancer detection and impact on surgical management. J Clin Oncol. 2009;27:5640-9.

51. Debruhl ND, Lee SJ, Mahoney MC, Hanna L, Tuite C, Gatsonis CA, Lehman C. MRI Evaluation of the Contralateral Breast in Women with Recently Diagnosed Breast Cancer: 2-Year Follow-up. J Breast Imaging. 2020;2:50-5.

52. Kim AH, Kim MJ, Kim EK, Park BW, Moon HJ. Positive predictive value of additional synchronous breast lesions in whole-breast ultrasonography at the diagnosis of breast cancer: clinical and imaging factors. Ultrasonography. 2014;33:170-7.

53. Kim J, Han W, Moon HG, Ahn SK, Shin HC, You JM, Chang JM, Cho N, Moon WK, Park IA, Noh DY. Low rates of additional cancer detection by magnetic resonance imaging in newly diagnosed breast cancer patients who undergo preoperative mammography and ultrasonography. J Breast Cancer. 2014;17:16773.

54. Susnik B, Schneider L, Swenson KK, Krueger J, Braatz C, Lillemoe T, Tsai M, DeFor TE, Knaack M, Rueth $\mathrm{N}$. Predictive value of breast magnetic resonance imaging in detecting mammographically occult contralateral breast cancer: Can we target women more likely to have contralateral breast cancer? J Surg Oncol. 2018;118:221-7.

55. Wang SY, Long JB, Killelea BK, Evans SB, Roberts KB, Silber A, Gross CP. Preoperative Breast Magnetic Resonance Imaging and Contralateral Breast Cancer Occurrence Among Older Women With Breast Cancer. J Clin Oncol. 2016;34:321-8. 
56. Duijm LE, Groenewoud JH, de Koning HJ, Coebergh JW, van Beek M, Hooijen MJ, van de Poll-Franse LV. Delayed diagnosis of breast cancer in women recalled for suspicious screening mammography. Eur J Cancer. 2009;45:774-81.

57. Duijm LE, Groenewoud JH, Jansen FH, Fracheboud J, van Beek M, de Koning HJ. Mammography screening in the Netherlands: delay in the diagnosis of breast cancer after breast cancer screening. $\mathrm{Br}$ Cancer. 2004;91:1795-9.

58. Smith EC, Ziogas A, Anton-Culver H. Delay in surgical treatment and survival after breast cancer diagnosis in young women by race/ethnicity. JAMA Surg. 2013;148:516-23.

59. Eriksson L, Bergh J, Humphreys K, Warnberg F, Tornberg S, Czene K. Time from breast cancer diagnosis to therapeutic surgery and breast cancer prognosis: A population-based cohort study. Int J Cancer. 2018;143:1093-104.

60. Neal RD, Tharmanathan P, France B, Din NU, Cotton S, Fallon-Ferguson J, Hamilton W, Hendry A, Hendry M, Lewis R, Macleod U, Mitchell ED, Pickett M, Rai T, Shaw K, Stuart N, Torring ML, Wilkinson C, Williams B, Williams N, Emery J. Is increased time to diagnosis and treatment in symptomatic cancer associated with poorer outcomes? Systematic review. Br J Cancer. 2015;112 Suppl 1:S92-107.

61. Torring ML, Frydenberg M, Hansen RP, Olesen F, Vedsted P. Evidence of increasing mortality with longer diagnostic intervals for five common cancers: a cohort study in primary care. Eur J Cancer. 2013;49:2187-98.

62. Ciatto S, Houssami N, Ambrogetti D, Bonardi R, Collini G, Del Turco MR. Minority report - false negative breast assessment in women recalled for suspicious screening mammography: imaging and pathological features, and associated delay in diagnosis. Breast Cancer Res Treat. 2007;105:37-43.

63. Duijm LE, Groenewoud JH, Roumen RM, de Koning HJ, Plaisier ML, Fracheboud J. A decade of breast cancer screening in The Netherlands: trends in the preoperative diagnosis of breast cancer. Breast Cancer Res Treat. 2007;106:113-9. 


\section{Chapter 2}

Bilateral recall and bilateral cancers 


\section{Chapter 2.1}

Frequency and diagnostic outcome of bilateral

recall at screening mammography

Lameijer JRC, Nederend J, Voogd AC, Tjan-Heijnen VCG, Duijm LEM

Int J Cancer 2020 


\section{Abstract}

This study was performed to determine the frequency of recall for bilateral breast lesions at screening mammography and compare its outcome with respect to unilateral recall.

We included 329132 screening mammograms (34889 initial screens and 294243 subsequent screens) from a Dutch screening mammography programme between January 2013 and January 2018. During 2-year follow-up, we collected radiological data, pathology reports and surgical reports of all recalled women. At bilateral recall, the lesion with the highest BI-RADS score was used as the index lesion when comparing screening mammography characteristics at bilateral versus unilateral recall.

A total of 9806 women were recalled at screening (recall rate, 3.0\%). Bilateral recall comprised $2.8 \%$ (271/9806) of all recalls. Biopsy was more frequently performed after bilateral recall than unilateral recall $(54.6 \%(148 / 271)$ versus $44.1 \%$ (4201/9535), $\mathrm{P}<0.001)$, yielding a lower positive predictive value (PPV) of biopsy after bilateral recall $(42.6 \%$ versus $51.7 \%, \mathrm{P}=0.029)$. The PPV of recall was comparable for both groups (23.2\% (63/271) versus $22.8 \%(2173 / 9535), P=0.85)$. Invasive cancers after bilateral recall were larger than those diagnosed after unilateral recall $(P=0.02)$, but histological subtype, histologic grading, receptor status and proportions of lymph node positive cancers were comparable.

Bilateral recall infrequently occurs at screening mammography. Biopsy is more frequently performed following bilateral recall but the PPV of recall is similar for unilateral and bilateral recall. Invasive cancers of both groups show comparable pathological features except of a larger tumour size after bilateral recall. 


\section{Introduction}

Breast cancer is the most commonly diagnosed cancer and the leading cause of cancer death among women, with an estimated 2.1 million new cases and 600000 deaths in 2018 worldwide. ${ }^{1}$ The proportion of bilateral breast cancer among all breast cancers is modest and ranges, for example, from $2.2 \%$ in a Dutch screening population to $4.4 \%$ in a population derived from the National University of Ireland Galway (NUIG) breast cancer database in Ireland. ${ }^{1-4}$ A worse survival has been reported for women with bilateral breast cancer than for women diagnosed with unilateral breast cancer. ${ }^{5-11}$

The detection of bilateral breast cancer has improved as a result of the ongoing developments in breast imaging over the past years. ${ }^{1,2,12-14}$ The increased detection of bilateral breast cancer is mostly attributed to the use of magnetic resonance imaging (MRI) after a diagnosis of primary breast cancer. ${ }^{12-14}$ Data on bilateral recall at screening mammography are very sparse. We previously reported a screening mammography sensitivity of only $19 \%$ for bilateral breast cancer detection in women screened between 1998 and 2008. ${ }^{1}$ However, in recent years much research has been done to improve the accuracy and detection of breast cancer at screening mammography, including studies on reading strategies and implementation of breast tomosynthesis. ${ }^{15-18}$ These developments may increase the number of recalls for bilateral lesions found at screening mammography and the subsequent detection of significant bilateral breast disease. ${ }^{15,16,18}$ As screening mammography focuses on early breast cancer detection, it may contribute to the improvement of survival of patients with bilateral breast cancer. Data on bilateral breast cancer in a screened population is sparse $^{1,2}$ and information on overall bilateral recall is lacking. We therefore assessed the frequency and characteristics of bilateral recall at screening mammography and compared its diagnostic outcome to unilateral recall.

\section{Methods}

\section{Study population}

This is an observational study with retrospective data collection of women aged 50-75 years who attended a biennial breast cancer screening programme conducted in the south of the Netherlands. Details of our screening programme have been described previously. ${ }^{19}$ In summary, women are personally invited by letter to attend the programme which has an attendance rate of about $80 \%$. Women being treated for breast cancer and those who still receive oncological follow-up after breast cancer treatment do not attend the screening programme. A consecutive series of 329132 fullfield digital mammography screening mammograms (34889 initial screening mammograms and 294243 subsequent screening mammograms) were included between January 1, 2013 and January 1, 2018. 
Women participating in the screening programme are offered the option to 'optout' of their data being used for quality assessment and scientific purposes. Ethical approval by our local Institutional Review Board was not required for this observational follow-up study, according to the Dutch Central Committee on Research involving Human Subjects (CCMO).

\section{Screening procedure and recall}

The screening mammograms were obtained at four specialized screening units (three mobile units and one fixed unit at Screening Programme South). All digital mammograms were acquired with a Lord Selenia FFDM system (Hologiclnc, Danbury, $\mathrm{CT}$ ), with a $70 \mu \mathrm{m}$ pixel size and a $232 \times 286 \mathrm{~mm}$ field of view. The examinations were obtained by specialized screening mammography radiographers and all screening mammograms were double read by a team of 12 certified screening radiologists. All screening radiologists read more than 10000 screening mammograms yearly. The screening radiologists first categorized abnormal mammographic findings into one of the following categories: suspicious mass, suspicious calcifications, suspicious mass combined with calcifications, asymmetry, architectural distortion, or other abnormalities not otherwise categorized. Then, each screen was classified according to the Breast Imaging Reporting and Data System (BI-RADS) lexicon and the radiologists annotated each recalled mammographic abnormality on a drawing which was part of the recall report. ${ }^{20}$ Women with a BI-RADS 1 (normal mammogram) or 2 (benign findings) were not recalled. Women with a BI-RADS 0 (incomplete, additional imaging evaluation needed), 4 (suspicious findings) or 5 (highly suggestive of malignancy) finding were referred to a dedicated breast unit of a hospital for further analysis. The BI-RADS category 3 (probably benign finding, follow-up suggested) is not used in the Dutch screening programme as this programme does not provide short-term follow-up.

\section{Diagnostic work-up after recall}

The diagnostic work-of most recalled women (97.6\%, 9567/9806) was performed in 6 hospitals (4 large teaching hospitals and 2 regional hospitals) located in our screening region. After physical examination by a surgical oncologist or dedicated breast nurse, additional breast imaging was performed at a radiology department. The screening mammogram was first reassessed by a radiologist, and the screening mammograms were routinely available for comparison and stored in the Picture Archiving and Communication System (PACS) of the hospital. Additional mammographic projections were obtained at the discretion of the attending radiologist. Full-field digital mammography was available in each of the 7 regional hospitals. Digital breast tomosynthesis (DBT) was present in 2 hospitals from the beginning of the inclusion period and became available in 3 other hospitals in 2015. Breast ultrasonography was used for the additional characterization of mammographic abnormalities and palpable breast lesions, for biopsy guidance and for target or second look purposes following 
breast MRI. In accordance with the Dutch guidelines, whole breast ultrasonography was not recommended. ${ }^{21}$ Breast MRI was also available in each hospital and performed if indicated, as defined by the guidelines of the European Society of Breast Imaging ${ }^{22}$ and the Dutch guidelines. ${ }^{21}$ Fine needle aspiration biopsy (FNAB), percutaneous core needle biopsy (CNB) and stereotactic biopsy were available in each hospital, whereas use of MRI guided biopsy procedures was concentrated in the larger hospitals. All biopsied recalls and women with equivocal findings after initial assessment were discussed by multidisciplinary teams that consisted of surgical oncologists, radiologists, medical oncologists, radiation oncologists, plastic surgeons, breast nurses and breast radiographers.

During two-year follow-up, clinical data and data from diagnostic breast imaging, biopsy specimen and surgical procedures were collected of all recalled women by one of the screening radiologists (LD) and several radiology residents. Information on previous breast surgery, mammographic breast density and family history of breast cancer were retrieved from questionnaires filled in by women prior to screening mammography, radiology reports and clinical data. Breast cancers were categorized into ductal carcinoma in-situ (DCIS) and invasive cancers. The TNM classification was used for malignant lesions. ${ }^{23}$

\section{Definition of index lesions}

In case of bilateral recall or recall for more than one ipsilateral breast lesion, the lesion with the highest BI-RADS score was used as the index lesion when comparing screening mammography characteristics at bilateral versus unilateral recall. In case of histologically proven multifocal, multicentric or bilateral breast cancer, the largest malignancy was considered the index lesion when comparing tumour characteristics.

\section{Statistical analysis}

All statistical analyses were performed using Statistical Package for Social Science 23.0 (SPSS Inc., IBM). The chi-square test was used to test for differences between women with unilateral or bilateral recall at screening mammography. A P-value of less than 0.05 was considered to indicate a statistically significant difference. P-values were twosided. Whenever applicable (due to small sample sizes), the Fisher's exact test was used. The independent samples T-test was used for comparison of mean age between unilateral and bilateral recall. In the case of median testing, the Median test was used. Whenever applicable, Bonferroni correction was applied for multiple testing.

Data were missing in less than $0.05 \%$ of the patients and in most cases involved the lack of estrogen or progesterone receptor status due to an insufficient tissue sample. In a few cases, recalled women refrained from follow-up $(n=20)$. These cases were also excluded from analysis. In the analysis of the categorical data, we treated the missing numbers (e.g., receptor status) as a separate category to allow a complete case analysis. 


\section{Results}

\section{Cohort characteristics}

The recall rate in our cohort was 3.0\% (9806/329132). Breast cancer was diagnosed in 2236 recalled women (including 19.9\% (445/2236) cases of ductal carcinomas in-situ), yielding an overall cancer detection rate of 6.8 per 1000 screening mammograms (8.1 per 1000 for initial screening mammograms (281/34899) and 6.6 per 1000 for subsequent screening mammograms (1955/294243). The overall positive predictive value (PPV) of recall was $22.8 \%$ (2236/9806) and was significantly lower for initial screening examinations than for subsequent screening examinations $(11.0 \%(281 / 2566)$ versus $27.0 \%$ (1955/7240), $\mathrm{P}<0.001)$.

\section{Baseline characteristics of recalled women}

Bilateral recalls comprised $2.8 \%(271 / 9806)$ of all recalls and the proportion of bilateral recalls was higher among women who were screened for the first time $(4.1 \%$ $(105 / 2566)$ versus $2.3 \%$ (166/7240), $\mathrm{P}<0.001)$. Median age, a history of previous breast surgery or a family history of breast cancer was comparable for bilateral and unilateral recalls, whereas bilateral recalls were more frequently initial screens $(P<0.001)$ and displayed less dense breasts at screening mammography $(P<0.001$, Table 2.1.1). Table 2.1.2 shows the distribution of the mammographic abnormalities at screening mammography for unilateral and bilateral recalls. Lesion characteristics were comparable for both groups, except of a larger proportion of suspicious calcifications among bilateral recalls $(P<0.001)$ and fewer masses $(P=0.016)$.

Table 2.1.1 Baseline characteristics of recalled women at screening mammography

\begin{tabular}{|c|c|c|c|c|}
\hline & $\begin{array}{l}\text { Overall } \\
N=9806\end{array}$ & $\begin{array}{l}\text { Bilateral recall } \\
\qquad \mathrm{N}=271\end{array}$ & $\begin{array}{l}\text { Unilateral recall } \\
\qquad \mathrm{N}=9535\end{array}$ & P-value* \\
\hline Median age (range), years & $58(50-75)$ & $58(50-75)$ & $58(50-75)$ & 0.93 \\
\hline Screening round, No (\%) & & & & $<0.001$ \\
\hline Initial & $2566(26.1)$ & $105(38.7)$ & $2461(25.8)$ & \\
\hline Subsequent & 7240 (73.9) & $166(61.3)$ & $7074(74.2)$ & \\
\hline Previous breast surgery, No (\%) & & & & 0.99 \\
\hline Yes & $686(7.0)$ & $19(7.0)$ & $667(7.0)$ & \\
\hline No & $9120(93.0)$ & $252(93.0)$ & $8868(93.0)$ & \\
\hline Breast density, No (\%) & & & & $<0.001$ \\
\hline ACR I+II (0\%-50\%) & $6197(63.2)$ & 211 (77.9) & $5986(62.8)$ & \\
\hline ACR III+IV (50\%-100\%) & 3609 (36.8) & $60(22.1)$ & 3549 (37.2) & \\
\hline Family history of breast cancer, No (\%) & & & & 0.25 \\
\hline Yes & $1189(12.2)$ & $39(14.4)$ & $1152(12.1)$ & \\
\hline No & $8617(87.8)$ & $232(85.6)$ & $8383(87.9)$ & \\
\hline
\end{tabular}

*Bilateral recall versus unilateral recall. $A C R=$ American College of Radiology 
Table 2.1.2 Mammographic abnormality of the index lesion at screening mammography*

$\begin{array}{lccc}\text { Mammographic abnormality, } & \text { Bilateral recall } & \text { Unilateral recall } & \text { P-value }^{ \pm} \\ \text {No (\%) } & \mathrm{N}=271 & \mathrm{~N}=9535 & 0.016 \\ \text { Mass } & 151(55.7) & 5996(62.9) & <0.001 \\ \text { Calcifications } & 67(24.7) & 1615(16.9) & 0.19 \\ \text { Mass with calcifications } & 14(5.2) & 348(3.6) & 0.52 \\ \text { Asymmetry } & 20(7.4) & 808(8.5) & 0.77 \\ \text { Architectural distortion } & 18(6.6) & 678(7.1) & 0.33 \\ \text { Other } & 1(0.4) & 90(0.9) & \end{array}$

*At bilateral recall, the lesion with the highest BI-RADS score was defined as the index lesion. \pm When Bonferroni-correction due to multiple testing is applied the P-value should be lower than 0.02 for a statistically significant result

\section{Diagnostic work-up after recall}

Women recalled for a unilateral mammographic abnormality more frequently underwent clinical breast imaging only, whereas a larger proportion of women with a bilateral recall received breast biopsy in addition to imaging $(54.6 \%(148 / 271)$ versus 44.1\% (4201/9535), $\mathrm{P}<0.001$, Table 2.1.3).

The positive predictive value of biopsy for breast cancer was lower for bilateral recalls $(42.6 \%$ versus $51.7 \%, \mathrm{P}=0.029)$.

Table 2.1.3 Type of additional assessment after recall and final outcome

\begin{tabular}{|c|c|c|c|}
\hline & $\begin{array}{l}\text { Bilateral recall } \\
\qquad \mathrm{N}=271\end{array}$ & $\begin{array}{l}\text { Unilateral recall } \\
\qquad \mathrm{N}=9535\end{array}$ & P-value \\
\hline Type of assessment after recall, No (\%) & & & $<0.001$ \\
\hline None or unknown & 0 & $25(0.3)$ & \\
\hline Clinical breast imaging only & $123(45.4)$ & $5309(55.7)$ & \\
\hline Clinical breast imaging + biopsy & $148(54.6)$ & $4201(44.1)$ & \\
\hline Final outcome, No (\%) & & & 0.85 \\
\hline No breast cancer & $208(76.8)$ & $7362(77.2)$ & \\
\hline Breast cancer & $63(23.2)$ & $2173(22.8)$ & \\
\hline Positive predictive value of biopsy, $\%$ & 42.6 & 51.7 & 0.029 \\
\hline Bilateral breast cancer, No (\%) & $20(7.4)$ & $34(0.4)$ & $<0.001$ \\
\hline
\end{tabular}

\section{Bilateral recall in prevalent cancers}

The proportion of bilateral recalls was larger among women with prevalent breast cancer (i.e., women who had attended the screening programme for the first time), namely $6.4 \%$ $(18 / 281)$ for first screens versus $2.3 \%(45 / 1955)$ for subsequent screens $(P<0.001)$.

\section{Characteristics of screen detected breast cancers and surgical treatment}

The proportion of DCIS among all true positive recalls was comparable for bilaterally or unilaterally recalled women $(25.4 \%(16 / 63)$ versus $19.7 \%(429 / 2173), P=0.26)$ and the distribution of the histological subtypes of invasive index cancers was comparable for both groups, with the majority of the invasive ductal type ( $P=0.54$, Table 2.1.4). 
Table 2.1.4 Tumour characteristics of the index breast cancers at bilateral and unilateral recall*

\begin{tabular}{|c|c|c|c|}
\hline & $\begin{array}{l}\text { Bilateral recall } \\
\qquad \mathrm{N}=63\end{array}$ & $\begin{array}{l}\text { Unilateral recall } \\
\qquad \mathrm{N}=2173\end{array}$ & P-value \\
\hline Type of cancer, No (\%) & & & 0.26 \\
\hline Ductal carcinoma in situ (DCIS) & $16(25.4)$ & $429(19.7)$ & \\
\hline Invasive & $47(74.6)$ & $1744(80.3)$ & \\
\hline Histology of invasive cancers, No (\%) & & & 0.54 \\
\hline Ductal & $41(87.2)$ & $1375(78.8)$ & \\
\hline Lobular & $4(8.5)$ & $222(12.7)$ & \\
\hline Ductolobular & $1(2.1)$ & $48(2.8)$ & \\
\hline Other & $1(2.1)$ & $99(5.7)$ & \\
\hline Tumour stage of invasive cancers, No (\%) & & & 0.005 \\
\hline $\mathrm{T} 1(\leq 20 \mathrm{~mm})$ & $30(63.8)$ & $1402(80.4)$ & \\
\hline $\mathrm{T} 2+(>20 \mathrm{~mm})$ & $17(36.2)$ & $338(19.4)$ & \\
\hline Unknown & 0 & $4(0.2)$ & \\
\hline Lymph node status of invasive cancers, No (\%) & & & 0.06 \\
\hline $\mathrm{N}+$ & $16(34.0)$ & $374(21.4)$ & \\
\hline $\mathrm{N}-$ & $31(66.0)$ & $1308(75.0)$ & \\
\hline Unknown & 0 & $62(3.6)$ & \\
\hline \multicolumn{4}{|l|}{ Bloom \& Richardson grade, No (\%) } \\
\hline I & $13(27.7)$ & $743(42.6)$ & $0.041^{ \pm}$ \\
\hline ॥ & $28(59.6)$ & $770(44.2)$ & $0.040^{ \pm}$ \\
\hline III & $6(12.8)$ & $218(12.5)$ & 0.95 \\
\hline Unknown & 0 & $13(0.7)$ & \\
\hline Estrogen receptor status, No (\%) & & & 0.79 \\
\hline Positive & $43(91.5)$ & $1571(90.1)$ & \\
\hline Negative & $4(8.5)$ & $168(9.6)$ & \\
\hline Unknown & 0 & $5(0.3)$ & \\
\hline Progesterone receptor status, No (\%) & & & 0.81 \\
\hline Positive & $33(70.2)$ & $1248(71.6)$ & \\
\hline Negative & $14(29.8)$ & $491(28.2)$ & \\
\hline Unknown & 0 & $5(0.3)$ & \\
\hline Her2/Neu receptor status, No (\%) & & & 0.15 \\
\hline Positive & 7 (14.9) & $154(8.8)$ & \\
\hline Negative & $40(85.1)$ & $1581(90.7)$ & \\
\hline Unknown & 0 & $9(0.5)$ & \\
\hline Final surgical treatment, No (\%) & & & $<0.001$ \\
\hline Breast conserving surgery & $48(76.2)$ & $1782(82.0)$ & \\
\hline Mastectomy & $14(22.2)$ & $366(16.8)$ & \\
\hline No surgery & $1(1.6)$ & $25(1.2)$ & \\
\hline
\end{tabular}

* In case of histologically proven multifocal, multicentric or bilateral breast cancer, the largest malignancy was considered the index lesion when comparing tumour characteristics. ${ }^{ \pm}$Not statistically significant after Bonferroni's adjustment for multiple testing

Tumour size of invasive index cancers was larger after bilateral recall, with fewer cancers sized $20 \mathrm{~mm}$ or less $(63.8 \%(30 / 47)$ versus $80.4 \%(1402 / 2173), \mathrm{P}=0.005)$. The proportion of lymph node positive invasive cancers was higher for bilateral recalls, but this difference was not statistically significant (34.0\% versus $21.4 \%, P=0.06$ ). The tumours after bilateral recall tended to be of lower Bloom and Richardson grade than tumours after unilateral recall, but this difference was not statistically significant after statistical correction was performed. Tumour receptor status was comparable for both groups. 
Bilateral breast cancer was diagnosed more frequently among bilateral recalls (7.4\% (20/271) versus $0.4 \%$ (34/9535), $\mathrm{P}<0.001)$. The 34 cancers, diagnosed in the nonrecalled breast after unilateral recall, were 4 ductal carcinoma in-situ (3 intermediate grade, 1 high grade) and 30 invasive cancers. The majority of the invasive cancers were of the ductal type $(76.7 \%, 23$ cancers), $<20 \mathrm{~mm}(86.7 \%, 26$ cancers), lymph node negative (73.3\%, 22 cancers) and Bloom and Richardson grade I (43.3\%, 13 cancers) or II (46.7\%, 14 cancers). The 20 non-index breast cancers in women diagnosed with bilateral breast cancer after a bilateral recall comprised 6 ductal carcinoma in-situ (all intermediate grade),10 invasive ductal cancers and 2 invasive lobular cancers. All but one of the 12 invasive cancers were sized $<20 \mathrm{~mm}$. Figure 2.1.1 and 2.1.2 show examples of bilateral recalls with subsequently confirmed bilateral breast cancer.

Figure 2.1.1 Two-view screening mammogram ( $A$ and $B$, medio-lateral oblique (MLO) view, and $C$ and $D$, cranio-caudal (CC) view) shows a BI-RADS 0 mass in the right breast (A and C, upper outer quadrant), and a BI-RADS 5 spiculated mass in the left breast (B and D, upper outer quadrant). Core needle biopsy (14 Gauge) revealed bilateral invasive ductal carcinoma. Tumour in the right breast: T2N1, tumour in the left breast: T1cN1. Treatment consisted of neo-adjuvant chemotherapy followed by bilateral breast conserving surgery and adjuvant radiotherapy

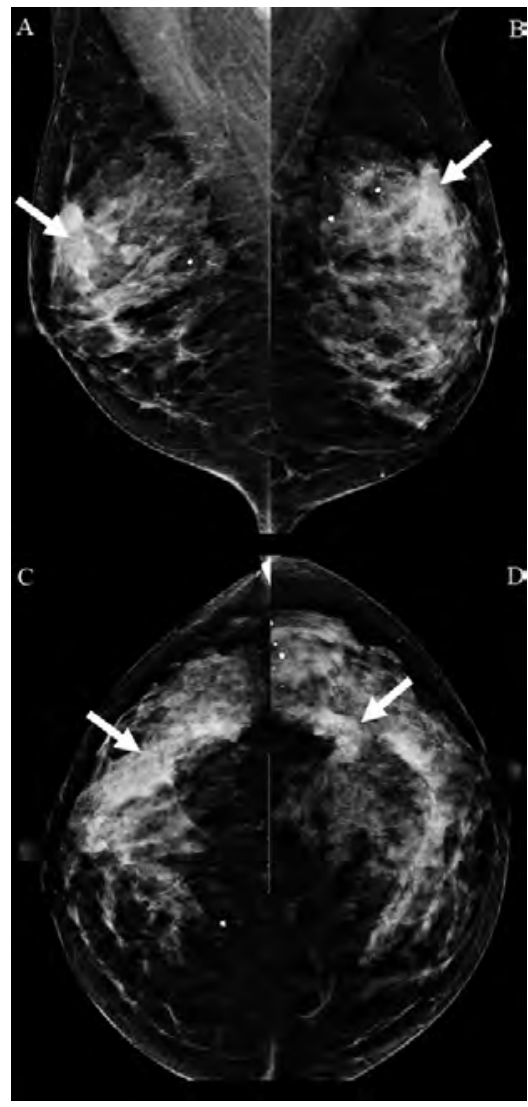


A majority of breast cancer patients underwent breast conserving surgery for their index cancer $(76.2 \%$ of cancers diagnosed after bilateral recall and $82.0 \%$ of cancers diagnosed after unilateral recall), whereas significantly more cancers were treated by mastectomy following bilateral recall $(22.2 \%$ versus $16.8 \%, \mathrm{P}<0.001)$.

Figure 2.1.2 Two-view screening mammogram ( $A$ and $B$, medio-lateral oblique (MLO) view, and $C$ and $D$, cranio-caudal (CC) view) shows a BI-RADS 4 architectural distortion in the right breast ( $A$ and C, upper outer quadrant) and an ill-defined BI-RADS 4 mass in the left breast (B and D, upper outer quadrant). Stereotactic core needle biopsy ( 9 Gauge) revealed high grade ductal carcinoma in-situ (DCIS) in the right breast and core needle biopsy (14 Gauge) yielded invasive ductal cancer in the left breast. The DCIS in the right breast had a maximum diameter of $\mathbf{5 0}$ $\mathrm{mm}$. The invasive ductal carcinoma in the left breast was a T2NO tumour. The patient underwent neoadjuvant chemotherapy followed by bilateral mastectomy and adjuvant antihormonal therapy.

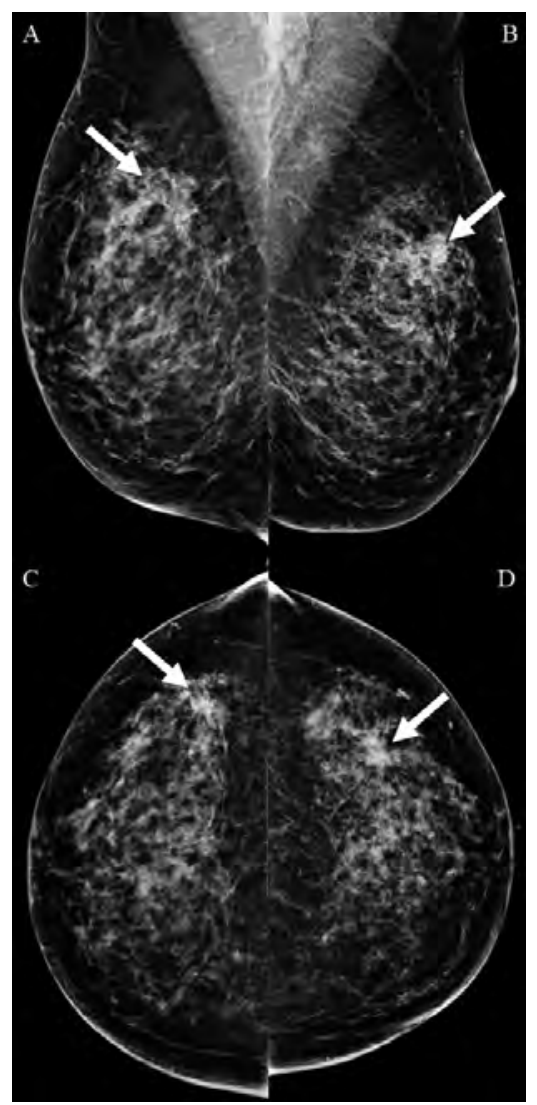

\section{False positive bilateral recalls}

The false positive recall rate (i.e., no diagnosis of breast cancer following recall) was similar for bilateral and unilateral recalls (76.8\% (208/271 versus 77.2\% (7362/9535, $\mathrm{P}=0.96)$. False positive recalls of non-index lesions after bilateral recall mostly 
comprised cysts, superposition of fibroglandular tissue or fibroadenomas. One case presented as bilateral non-Hodgkin lymphoma, which was not considered a primary breast cancer.

\section{Discussion}

This study describes the frequency and outcome of bilateral recall at screening mammography. We found that $2.7 \%$ of recalled women had their recall for a bilateral, suspicious mammographic screening abnormality. Bilateral recall was more frequently present in initial than in subsequent screening mammograms and in less dense breasts, and the distribution of mammographic abnormalities differed between unilateral and bilateral recalls. The overall proportion of true positive recalls (i.e., confirmation of breast cancer after recall) was similar for women after unilateral and bilateral recall. Although women with a bilateral recall more often underwent biopsy compared to women with a unilateral recall, a smaller proportion of these biopsies yielded cancer. The tumours after bilateral recall tended to be larger than those in women after unilateral recall, and we observed a larger mastectomy rate for breast cancers diagnosed after bilateral recall than diagnosed after unilateral recall.

Very limited data is available on the diagnosis of bilateral breast cancer in screened women. In our series, bilateral breast cancer was diagnosed in $0.4 \%$ of unilateral recalls and in $7.2 \%$ of bilateral recalls. Overall, bilateral breast cancer was confirmed in $2.4 \%$ $(51 / 2104)$ of women with a screen detected cancer in our study, which is comparable to the $2.2 \%$ we previously reported in women screened by screen-film mammography between 1998-2008. ${ }^{2}$

Although the transition from screen-film to digital screening mammography came along with increased recall rates, the Dutch screening mammography programme is still characterized by a low recall rate and we also observed a relatively low bilateral recall rate among all recalled women. ${ }^{24,25}$ Bilateral recall more frequently occurred in women screened for the first time, which may be due to a higher degree of vigilance and uncertainty among screening radiologists when a woman enters the screening programme, with no previous screening mammograms available for comparison. This assumption may also explain the higher frequency of bilateral recalls in women with a true positive recall after their initial (prevalent) screen. ${ }^{26,27}$

The higher biopsy rate after bilateral recall came along with a lower PPV of biopsy and a comparable overall PPV of recall for bilaterally or unilaterally recalled women. The radiologist may be more inclined to perform biopsy rather than imaging follow-up of equivocal findings at clinical breast imaging after bilateral recall. A recent UK reported a reduction of $33 \%$ in the number of benign biopsies after unilateral recall due to better characterization of lesions. ${ }^{28}$ However, it is not yet clear whether this may also be applicable in case of bilateral recall. 
Generalization of the UK findings to the Dutch screening setting may also be limited due to the higher UK recall rate and differences in clinical workup. A majority of Dutch hospitals have the availability of state of the art imaging modalities such as tomosynthesis and breast MRI, which may influence the frequency and PPV of biopsy, both at unilateral and bilateral recall.

We found a difference between unilateral and bilateral recall with respect to mammographic abnormalities at screening mammography. To our knowledge, no literature is available on this subject. Whilst in both bilateral and unilateral recall most lesions were characterized as masses, index lesions at bilateral recall were relatively more often characterized as suspicious calcifications compared to index lesions at unilateral recall. This may be due to a higher alertness among screening radiologists for calcifications than for other lesions, with a more intensified focus on calcifications in the index lesion than on the subtle abnormalities of non-index lesion in the contralateral breast which are, for example, asymmetries or architectural distortions.

It has been shown that especially invasive lobular cancers may be difficult to detect at screening mammography as these cancers frequently present as focal asymmetries, subtle architectural distortions or no mammographic abnormality at all. ${ }^{1,2,29}$ We found no significant differences in the histological types of invasive cancers when comparing unilateral and bilateral index cancers. A recent meta-analysis by Yun et al. (2018) suggests that the addition of new imaging modalities to digital screening mammography, such as digital breast tomosynthesis (DBT), may improve the detection of invasive lobular carcinomas. ${ }^{30}$ Contrast enhanced digital mammography (CEDM) also increases the detection of invasive lobular carcinomas and may therefore have additional benefits, but the use of this modality in a screening setting has not yet been proven to be feasible. ${ }^{31}$

Controversy exists regarding the prognosis and survival of bilateral breast cancer, with studies reporting an equivalent or poorer survival for bilateral breast cancer than for unilateral breast cancer. ${ }^{3,5-10}$ In case of bilateral breast cancer detected at screening mammography, the contralateral non-index cancer more frequently shows invasive lobular histology and less lymph node involvement, but other tumour characteristics such as tumour size, mitotic activity and receptor status are comparable to the index cancer (9). This study, performed in the era of screen-film mammography, also reported no significant differences in tumour characteristics between the index cancers of bilateral breast cancer and unilateral breast cancers. However, in our series of digital screening mammograms, we found that invasive index cancers after bilateral recall were larger than those diagnosed after unilateral recall and they showed a tendency towards a higher rate of lymph node invasion. This is a remarkable finding as digital screening mammography has a comparable or even higher sensitivity for breast cancer detection than screen-film mammography, especially for smaller cancers and cancer detection in more dense breasts. ${ }^{24,32}$ We don't have a biological explanation for the larger cancer size in women with a bilateral recall, with a tendency of these cancers for a worse $B \& R$ grading and more lymph node invasion. Invasive lobular cancers are 
known to have a larger mean tumour size at the time of detection than invasive ductal cancers, but the breast cancers in our study showed a comparable histological distribution after unilateral or bilateral recall. Cancers after bilateral recall more frequently showed lymph node metastases and more B\&R grade II tumours, but these differences were not statistically significant. Tumours in synchronous bilateral breast cancer may be considered as two biologically separate tumours and we have previously reported similar tumour characteristics for bilateral cancers and unilateral cancers. ${ }^{2,33}$

We found that the final surgical treatment for breast cancer more frequently consisted of mastectomy rather than breast conserving surgery after bilateral than after unilateral recall. This observation can be explained by the larger tumour size of the index cancers and the higher bilateral breast cancer rate after bilateral recall. Women may be inclined to choose for bilateral mastectomy rather than breast conserving surgery in case mastectomy is already indicated for the index lesion but not necessarily for the non-index lesion. It remains, however, a question of debate whether bilateral disease should be treated by bilateral mastectomy rather than by breast conserving surgery. Guidelines for the treatment of bilateral breast cancer are not readily available and more research is needed on the efficacy of breast conserving treatment in these women, with an emphasis on the risk of cancer recurrence.

Our study has certain limitations. As mentioned previously, the recall rate in the Dutch screening programme is lower than that of many other screening programmes, which could limit generalization of our results to other programs. ${ }^{2,15,17,34,35}$ Furthermore, small sample sizes of certain subgroups (mainly tumour characteristics of bilateral breast cancers) limit statistical analysis and warrant careful interpretation of the results in these subgroups. Differences in imaging modalities were present among hospitals that assessed the recalled women. In several hospitals, for example, tomosynthesis was available during the major or the whole part of the inclusion period, whereas this imaging modality became available at a later stage in other hospitals. Differences in diagnostic services may influence both imaging outcome and biopsy rates, for examples when one faces equivocal findings at digital mammography without being able to perform tomosynthesis or breast MRI for problem solving.

In summary, recall for bilateral lesions occurs infrequently at screening mammography. The PPV of recall is similar for unilateral and bilateral recall, although biopsy is more frequently performed following bilateral recall. Invasive index cancers are larger after bilateral recall.

Although the majority of bilateral recalls are false positive, screening radiologists should pay vigorous attention to the contralateral breast after having detected a screening mammographic abnormality in one breast, in order to facilitate a timely diagnosis of bilateral breast cancer. 


\section{References}

1. Setz-Pels W, Duijm LE, Groenewoud JH, Voogd AC, Jansen FH, Hooijen MJ, Louwman MW. Detection of bilateral breast cancer at biennial screening mammography in the Netherlands: a population-based study. Radiology 2011;260:357-63.

2. Setz-Pels W, Duijm LE, Groenewoud JH, Louwman MW, Jansen FH, van Beek M, Plaisier ML, Voogd AC. Patient and tumor characteristics of bilateral breast cancer at screening mammography in the Netherlands, a population-based study. Breast Cancer Res Treat 2011;129:955-61.

3. Kheirelseid EA, Jumustafa H, Miller N, Curran C, Sweeney K, Malone C, McLaughlin R, Newell J, Kerin MJ. Bilateral breast cancer: analysis of incidence, outcome, survival and disease characteristics. Breast Cancer Res Treat 2011;126:131-40.

4. Kim JY, Cho N, Koo HR, Yi A, Kim WH, Lee SH, Chang JM, Han W, Moon HG, Im SA, Noh DY, Moon WK. Unilateral breast cancer: screening of contralateral breast by using preoperative MR imaging reduces incidence of metachronous cancer. Radiology 2013;267:57-66.

5. Hartman M, Czene K, Reilly M, Adolfsson J, Bergh J, Adami HO, Dickman PW, Hall P. Incidence and prognosis of synchronous and metachronous bilateral breast cancer. J Clin Oncol 2007;25:4210-6.

6. Kuo WH, Yen AM, Lee PH, Chen KM, Wang J, Chang KJ, Chen TH, Tsau HS. Cumulative survival in earlyonset unilateral and bilateral breast cancer: an analysis of 1907 Taiwanese women. Br J Cancer 2009;100:563-70.

7. Holm M, Tjonneland A, Balslev E, Kroman N. Prognosis of synchronous bilateral breast cancer: a review and meta-analysis of observational studies. Breast Cancer Res Treat 2014;146:461-75.

8. Roder D, de Silva P, Zorbas H, Kollias J, Malycha P, Pyke C, Campbell I, Webster F. Survival from synchronous bilateral breast cancer: the experience of surgeons participating in the breast audit of the Society of Breast Surgeons of Australia and New Zealand. Asian Pac J Cancer Prev 2012;13:1413-8.

9. Beckmann KR, Buckingham J, Craft P, Dahlstrom JE, Zhang Y, Roder D, Stuart-Harris R. Clinical characteristics and outcomes of bilateral breast cancer in an Australian cohort. Breast 2011;20:158-64.

10. Mejdahl MK, Wohlfahrt J, Holm M, Balslev E, Knoop AS, Tjonneland A, Melbye M, Kroman N. Breast cancer mortality in synchronous bilateral breast cancer patients. Br J Cancer 2019;120:761-7.

11. Jobsen JJ, van der Palen J, Ong F, Riemersma S, Struikmans H. Bilateral breast cancer, synchronous and metachronous; differences and outcome. Breast Cancer Res Treat 2015;153:277-83.

12. El Sharouni MA, Postma EL, Menezes GL, van den Bosch MA, Pijnappel RM, Witkamp AJ, van der Pol CC, Verkooijen HM, van Diest PJ. High prevalence of MRI-detected contralateral and ipsilateral malignant findings in patients with invasive ductolobular breast cancer: impact on surgical management. Clin Breast Cancer 2016;16:269-75.

13. Plana MN, Carreira C, Muriel A, Chiva M, Abraira V, Emparanza JI, Bonfill X, Zamora J. Magnetic resonance imaging in the preoperative assessment of patients with primary breast cancer: systematic review of diagnostic accuracy and meta-analysis. Eur Radiol 2012;22:26-38.

14. Brennan ME, Houssami N, Lord S, Macaskill P, Irwig L, Dixon JM, Warren RM, Ciatto S. Magnetic resonance imaging screening of the contralateral breast in women with newly diagnosed breast cancer: systematic review and meta-analysis of incremental cancer detection and impact on surgical management. J Clin Oncol 2009;27:5640-9.

15. Bernardi D, Macaskill P, Pellegrini M, Valentini M, Fanto C, Ostillio L, Tuttobene P, Luparia A, Houssami $\mathrm{N}$. Breast cancer screening with tomosynthesis (3D mammography) with acquired or synthetic 2D mammography compared with 2D mammography alone (STORM-2): a population-based prospective study. Lancet Oncol 2016;17:1105-13.

16. Skaane $\mathrm{P}$, Bandos AI, Gullien R, Eben EB, Ekseth U, Haakenaasen U, Izadi M, Jebsen IN, Jahr G, Krager M, Niklason LT, Hofvind S, et al. Comparison of digital mammography alone and digital mammography plus tomosynthesis in a population-based screening program. Radiology 2013;267:47-56.

17. Skaane P, Sebuodegard S, Bandos Al, Gur D, Osteras BH, Gullien R, Hofvind S. Performance of breast cancer screening using digital breast tomosynthesis: results from the prospective population-based Oslo Tomosynthesis Screening Trial. Breast Cancer Res Treat 2018;169:489-96. 
18. Zackrisson S, Lang K, Rosso A, Johnson K, Dustler M, Fornvik D, Fornvik H, Sartor H, Timberg P, Tingberg A, Andersson I. One-view breast tomosynthesis versus two-view mammography in the Malmo Breast Tomosynthesis Screening Trial (MBTST): a prospective, population-based, diagnostic accuracy study. Lancet Oncol 2018;19:1493-503.

19. Lameijer JRC, Coolen AM, Voogd AC, Strobbe LJ, Louwman MWJ, Venderink D, Tjan-Heijnen VC, Duijm LEM. Frequency and characteristics of contralateral breast abnormalities following recall at screening mammography. Eur Radiol 2018;28:4205-14.

20. American College of Radiology. BI-RADS Committee. ACR BI-RADS atlas: Breast Imaging Reporting and Data System, 5th ed. Reston, VA: American College of Radiology, 2013.

21. NABON. Richtlijn Mammacarcinoom, vol. 2020: Het Nationaal Borstkanker Overleg Nederland (NABON), 2012.

22. Mann RM, Balleyguier C, Baltzer PA, Bick U, Colin C, Cornford E, Evans A, Fallenberg E, Forrai G, Fuchsjager $\mathrm{MH}$, Gilbert FJ, Helbich $\mathrm{TH}$, et al. Breast MRI: EUSOBI recommendations for women's information. Eur Radiol 2015;25:3669-78.

23. Sobin LH, Gospodarowicz MK, Wittekind C, International Union against Cancer. TNM classification of malignant tumours, 7th ed. Chichester, West Sussex, UK ; Hoboken, NJ: Wiley-Blackwell, 2010. xx, 310 p.

24. Nederend J, Duijm LE, Louwman MW, Groenewoud JH, Donkers-van Rossum AB, Voogd AC. Impact of transition from analog screening mammography to digital screening mammography on screening outcome in The Netherlands: a population-based study. Ann Oncol 2012;23:3098-103.

25. Sankatsing VDV, Fracheboud J, de Munck L, Broeders MJM, van Ravesteyn NT, Heijnsdijk EAM, Verbeek ALM, Otten JDM, Pijnappel RM, Siesling S, de Koning HJ, National Evaluation Team for Breast cancer screening N. Detection and interval cancer rates during the transition from screen-film to digital mammography in population-based screening. BMC Cancer 2018;18:256.

26. von Euler-Chelpin M, Lillholm M, Vejborg I, Nielsen M, Lynge E. Sensitivity of screening mammography by density and texture: a cohort study from a population-based screening program in Denmark. Breast Cancer Res 2019;21:111.

27. Weigel S, Heindel W, Heidrich J, Hense HW, Heidinger O. Digital mammography screening: sensitivity of the programme dependent on breast density. Eur Radiol 2017;27:2744-51.

28. Sharma N, McMahon M, Haigh I, Chen Y, Dall BJG. The potential impact of digital breast tomosynthesis on the benign biopsy rate in women recalled within the uk breast screening programme. Radiology 2019;291:310-7.

29. van Bommel RMG, Voogd AC, Nederend J, Setz-Pels W, Louwman MWJ, Strobbe LJ, Venderink D, TjanHeijnen VCG, Duijm LEM. Incidence and tumour characteristics of bilateral and unilateral interval breast cancers at screening mammography. Breast 2018;38:101-6.

30. Yun SJ, Ryu CW, Rhee SJ, Ryu JK, Oh JY. Benefit of adding digital breast tomosynthesis to digital mammography for breast cancer screening focused on cancer characteristics: a meta-analysis. Breast Cancer Res Treat 2017;164:557-69.

31. Patel BK, Davis J, Ferraro C, Kosiorek H, Hasselbach K, Ocal T, Pockaj B. Value added of preoperative contrast-enhanced digital mammography in patients with invasive lobular carcinoma of the breast. Clin Breast Cancer 2018;18:e1339-e45.

32. Pisano ED, Gatsonis C, Hendrick E, Yaffe M, Baum JK, Acharyya S, Conant EF, Fajardo LL, Bassett L, D'Orsi $C$, Jong $R$, Rebner $M$, et al. Diagnostic performance of digital versus film mammography for breast-cancer screening. N Engl J Med 2005;353:1773-83.

33. Fountzilas E, Kotoula V, Zagouri F, Giannoulatou E, Kouvatseas G, Pentheroudakis G, Koletsa T, Bobos M, Papadopoulou K, Samantas E, Demiri E, Miliaras S, et al. Disease evolution and heterogeneity in bilateral breast cancer. Am J Cancer Res 2016;6:2611-30.

34. Otto SJ, Fracheboud J, Looman CW, Broeders MJ, Boer R, Hendriks JH, Verbeek AL, de Koning HJ, National Evaluation Team for Breast Cancer S. Initiation of population-based mammography screening in Dutch municipalities and effect on breast-cancer mortality: a systematic review. Lancet 2003;361: 1411-7.

35. Sankatsing VDV, van Ravesteyn NT, Heijnsdijk EAM, Looman CWN, van Luijt PA, Fracheboud J, den Heeten GJ, Broeders MJM, de Koning HJ. The effect of population-based mammography screening in Dutch municipalities on breast cancer mortality: 20 years of follow-up. Int J Cancer 2017;141:671-7. 


\section{Chapter 2.2}

Tumour characteristics of bilateral screen-detected cancers and bilateral interval cancers in women participating at biennial screening mammography

van Bommel R, Lameijer JRC, Voogd AC, Nederend J, Louwman MW, Setz-Pels W, Klompenhouwer EG, Strobbe LJ, Tjan-Heijnen VCG, Duijm LEM

Eur J Radiol 2018;108:215-221 


\section{Abstract}

\section{Background}

Unilateral interval breast cancers show less favourable prognostic features than unilateral screendetected cancers, but data on tumour characteristics of bilateral interval cancers in a systematically screened population are sparse. Therefore, we compared tumour characteristics of bilateral interval cancers with those of bilateral screen-detected cancers.

\section{Methods}

We included all 468,720 screening mammograms of women who underwent biennial screening mammography in the South of the Netherlands between January 2005 and January 2015. We collected breast imaging reports, biopsy results and surgical reports of all recalled women and of all women who presented with interval breast cancer. In women with synchronous bilateral breast cancer, the tumour with the highest tumour stage was defined as the index cancer. For comparison of data between both groups Fisher exact test and Chisquare test were used.

Results

Synchronous bilateral cancer was diagnosed in $2.2 \%$ of screen-detected cancers (64/2947) and in $3.2 \%$ of interval cancers $(24 / 753)(P=0.1)$. Index tumours of bilateral screen-detected cancers and interval cancers showed similar characteristics, except for a larger proportion of T-stage 2 or worse (T2+) cancers among interval cancers $(16 / 24(66.7 \%)$ versus $23 / 58$ (39.7\%) $(P=0.03)$. Index cancers, compared to contralateral cancers, were less frequently stage $\mathrm{T} 1$ in both bilateral screen-detected cancers and bilateral interval cancers $(35 / 64(60.3 \%)$ versus $40 / 64 \quad(88.9 \%) \quad(P=0.001)$ and $8 / 24 \quad(33.3 \%)$ versus $18 / 24 \quad(85.7 \%) \quad(P<0.001)$, respectively). In bilateral screen-detected cancers, contralateral cancers were more often stage $1 \mathrm{a}-\mathrm{c}$ $(P<0.001)$ compared to index cancers. In bilateral index cancers, index cancers were more often of the lobular subtype $(P<0.001)$.

\section{Conclusions}

Index cancers of bilateral screen-detected cancers and bilateral interval cancers show significant differences in tumour size, whereas nodal status, receptor status and final surgical treatment are comparable. In bilateral screen-detected cancer, index cancers had a significantly higher tumour stage. In bilateral screen-detected cancer, index cancers were more often the ductal invasive subtype compared to contralateral cancers. 


\section{Introduction}

Breast cancer is one of the most common malignancies diagnosed in women nowadays. Many western countries have implemented regional or nationwide breast cancer screening programmes to detect breast cancer at a less advanced stage. Screening mammography, in combination with more effective treatments, results in decreased mortality of breast cancer. ${ }^{1-4}$

Despite the screening programmes, $20-25 \%$ of breast cancers in a systematically screened population are detected during the interval between two screening rounds, the so-called interval cancers. ${ }^{5,6}$ One of the challenges of breast cancer screening is to reduce the proportion of interval cancers, as they have proven to be relatively large, poorly differentiated tumours, with a worse disease-free and overall survival compared to screen-detected cancers. ${ }^{7}$

A subgroup of patients with breast cancer has synchronous bilateral cancer, with the contralateral cancer diagnosed within 3 months of the initially diagnosed breast malignancy. ${ }^{8,9}$ In symptomatic patients, $0.7-2.3 \%$ of breast cancers are bilateral ${ }^{9-11}$ and $2.2 \%$ of screen detected cancers are bilateral in a systematically screened population. ${ }^{8}$ Several studies in predominantly symptomatic patients, found that bilateral cancers show more favourable tumour characteristics than unilateral cancers, with a higher proportion of invasive lobular cancer, ${ }^{8}$ lower T-stage ${ }^{12}$ and a higher proportion of hormone receptor expression. ${ }^{10}$ This is mainly due to the smaller secondary detected tumour. $^{8,10,12}$ Despite these findings, many authors report a worse overall survival for bilateral breast cancer compared to unilateral breast cancer. ${ }^{13-16}$

Several studies have reported on tumour features of unilateral screen-detected cancers and interval cancers. ${ }^{7,17}$ However, data on bilateral breast cancer at screening mammography are sparse and data on bilateral interval cancer are, to our knowledge, almost lacking (Figure 2.2.1). In a previous study we focused on bilateral interval cancers and described how they differ from unilateral interval cancers. ${ }^{18}$ The quality and effect of screening mammography programmes are determined not only by the characteristics of screen-detected cancers (unilateral or bilateral) but also by those of unilateral and bilateral interval cancers. In the current study, we therefore investigated to what extent tumour characteristics of bilateral interval cancers differ from those of bilateral screen-detected cancers and we further explored differences between index tumours and contralateral tumours in bilateral screen-detected cancers and bilateral interval cancers. 
Figure 2.2.1 Almost 2 years after a negative first screen mammography, a woman was referred by her physician to a regional hospital for the evaluation of a palpable mass in the upper outer quadrant of the right breast. mammography (A) showed no suspicious findings. Ultrasound (B) showed a solid mass (calipers) biopsy revealed invasive lobular carcinoma. As the primary lesion was occult on mammography and biopsy yielded a lobular histology, breast MRI was performed. The MRI subtraction image shows a spiculated mass in the contralateral (left) breast (white arrow) and a small lesion located medially in the right breast (black arrow) (C). Biopsy yielded an invasive ductal carcinoma in the left breast and a fibroadenoma in the right breast

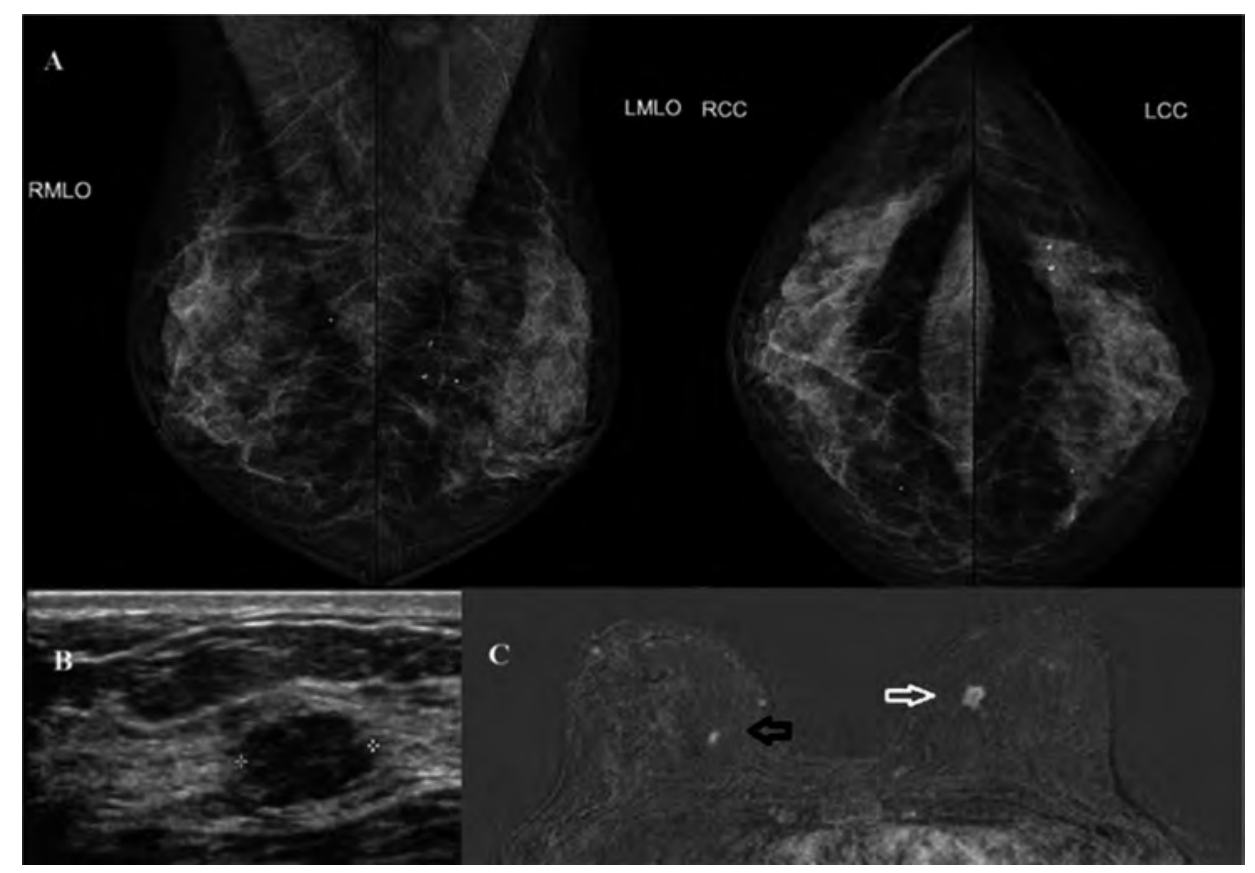

\section{Methods}

\section{Study population}

We included all screening examinations obtained in a breast cancer screening region in the south of the Netherlands, between January 1, 2005 and January 1, 2015. A total of 468,720 screening mammograms were obtained, both initial and subsequent screens. Both screen-film mammography (SFM) and full-field digital mammography (FFDM) were included in the study, since the transition from SFM to FFDM was made in 2009/2010. All women participating in the screening programme were asked to give written informed consent to use their screening data and follow-up data for scientific purposes. In total, four women refused usage of their data and were excluded from analysis. Ethical approval by our local Institutional Review Board was not required for 
this study, according to the Dutch Central Committee on Research involving Human Subjects (CCMO) in The Hague.

\section{Screening procedure}

Details of the Dutch nationwide breast cancer screening programme, offering biennial screening mammography for women aged 50-75 years, have been published elsewhere. ${ }^{19,20}$ In summary, all screening mammograms were obtained by a team of specialized mammography radiographers in one of four screening units (one fixed and three mobile units), and all screening mammograms were double read by two certified screening radiologists, with more than 20 years of experience with screening mammography and clinical breast imaging. During the study period, the screening group consisted of 15 radiologists and each radiologist evaluated at least 3000 mammograms yearly and all radiologists participated in clinical breast imaging. At the start of 2005, the mean length of experience of the 8 interpreting radiologists with screening mammography was 103 months (range, 63-119 months). Four more radiologists started interpreting screening mammograms between 2005-2010 and another 3 radiologists started interpreting screening mammograms between 2011-2013 Prior screening mammograms were always available for comparison at the time of subsequent screening. To facilitate this comparison, most recent screen-film mammograms were digitized using a film scanner and archiver designed for mammography (DigitalNow; R2/Hologic, Bedford, MA).

\section{Diagnostic work-up}

All recalled women received physical examination by the surgeon or the dedicated breast nurse at the breast unit of a hospital, and additional breast imaging was performed in the radiology department. Dependent on the findings at physical examination and mammography and dependent on local diagnostic work-up protocols, further diagnostic evaluation could include additional mammographic views, breast tomosynthesis, contrast-enhanced spectral mammography (CESM), (3D) breast ultrasound, magnetic resonance imaging (MRI), percutaneous fine needle aspiration cytology (FNAC), core needle biopsy (CNB), stereotactic biopsy, magnetic resonance guided biopsy or open surgical biopsy. All radiological findings were classified according to the fourth edition of the Breast Imaging Reporting and Data System lexicon, (BIRADS). ${ }^{21,22}$ Lesions classified as BI-RADS IV or V were routinely biopsied and BI-RADS III lesions were either biopsied or followed up, as discussed in the multidisciplinary breast team. Patients with radiological findings classified as BI-RADS I or II were again referred to the breast cancer screening programme. 


\section{Follow-up procedure}

For the detection of interval cancers and bilateral breast cancers, all women in our breast screening programme were followed during a period of about 2 years (until the next biennial screening mammography examination). Details on the methods of detecting interval cancers have been published previously. ${ }^{23-25}$ Most interval cancers were identified by linkage of the screening records to the Netherlands Cancer Registry (NCR), Netherlands Comprehensive Cancer Organization (IKNL) and regional pathology laboratories and radiotherapy centres. In all women recalled or diagnosed with interval cancer, we collected all available clinical and radiological data, including: screening mammography findings, clinical data, clinical breast imaging reports, biopsy results, and breast surgery reports.

In patients with interval cancer, all screening mammograms prior to the detection and the diagnostic mammogram which was obtained at the time of detection, were reviewed by three experienced screening radiologists. Breast density was categorized according to the BI-RADS lexicon. ${ }^{21,22}$ In bilateral breast cancers, the cancer with the more advanced stage (or, in cases where both tumours had the same stage, the largest tumour at pathology), was defined as the index tumour. ${ }^{9}$ We only included synchronous bilateral breast cancers, defined as histological confirmation of the contralateral tumour within three months after histological confirmation of the prior breast cancer. Clinical T-stage was defined prior to neoadjuvant therapy (either chemotherapy or endocrine therapy). In cases undergoing neoadjuvant therapy, local staging was usually investigated using MRI. Lobular carcinoma in situ was not considered to be a breast malignancy.

\section{Statistical analysis}

All data were entered into a computerized spreadsheet (Excel; Microsoft, Redmond, WA, USA), and statistics were performed using Statistical Package for Social Science 22.0 (SPSS Inc. Chicago, IL). The Chi-square or Fisher exact test was used to test differences in tumour characteristics between bilateral interval cancers and bilateral screen detected cancers and between index and contralateral tumours of both bilateral interval cancers and bilateral screen-detected cancers.

\section{Results}

\section{Overall screening results}

The overall screening results have already been published elsewhere [van Bommel, et al. 2018]. In summary, during a 10 year period between January 1, 2005 and January 1 , $2015,468,720$ screening mammograms were obtained $(160,776$ SFM screens and 307,944 FFDM screens). The recall rate was 26.5 per 1000 screened women 
$(12,398 / 468,720)$, with an overall cancer detection rate of 6.3 per 1000 screened women (2947/468,720, PPV 23.8\%). 753 women were diagnosed with interval cancer, representing $20.4 \%$ of all women diagnosed with breast cancer in the screened population, resulting in a programme sensitivity of $79.6 \%$.

\section{Bilateral cancer rate at screening mammography}

A total of sixty-four out of 2947 screen-detected cancers were bilateral and bilateral breast cancer was diagnosed in 24 out of 729 women with interval breast cancer $(2.2 \%$ versus $3.2 \%)$, $(P=0.08)$.

\section{Comparison of the index cancers of bilateral screen-detected cancers and bilateral interval cancers}

The distribution of breast density at the latest screening mammogram was comparable for bilateral screen-detected cancers and interval cancers ( $P=0.53$, Table 2.2.1). There were six ductal carcinoma in-situ cases (DCIS) in the screen-detected group $(9.4 \%, 6 / 64)$ and none among women with interval cancer. Index cancers of invasive, bilateral interval cancers were larger than those of bilateral screen-detected cancers, with a larger proportion of T2-4 cancers among interval index cancers $(66.7 \%(16 / 24)$ versus $39.7 \%(23 / 58),(P=0.03)$. There was no difference in nodal involvement between both groups, $39.7 \%(23 / 58)$ for screen-detected cancers versus $54.2 \%(13 / 24)$ for interval cancers $(P=0.23)$. We also found no significant differences in tumour histology distribution (e.g., invasive ductal or invasive lobular carcinoma), histological grade, oestrogen / progesterone / HER2 receptor expressions or final surgical treatment.

\section{Characteristics of index cancers versus contralateral cancers in women with bilateral screen-detected cancer}

Contralateral cancers comprised a higher percentage of ductal carcinoma in situ (DCIS) than index cancers $(25.0 \%(16 / 64)$ versus $9.4 \%(6 / 64),(P=0.006$, Table 2.2 .2$)$ in recalled women diagnosed with bilateral breast cancer. The majority of cancers in both groups were of the ductal type. There was a higher proportion of contralateral invasive lobular subtype cancer in women with an invasive index tumour of the lobular type than in women with an invasive ductal index tumour $(41.7 \%(5 / 12)$ versus $7.7 \%(3 / 39)$, $(P=0.01)$. Index cancers had a less favourable tumour size, with $39.7 \%(23 / 58)$ of invasive cancers showing T2-4 (>20 mm) versus $11.1 \%$ (5/45) of the contralateral breast cancers $(P=0.001)$. Differences in nodal involvement between index cancers and contralateral cancers were not statistically significant $(39.7 \%(23 / 58)$ versus $24.4 \%$ (11/45), $P=0.14)$. With respect to histological grading of invasive screen-detected cancers, contralateral cancers were more frequently grade I $(60.0 \%(27 / 45)$ versus $32.8 \%(19 / 58),(P=0.006))$. Receptor status and type of final surgical treatment were comparable for both groups. 
Table 2.2.1 Characteristics of index cancers of bilateral screen-detected cancers and bilateral interval cancers

\begin{tabular}{|c|c|c|c|}
\hline & $\begin{array}{c}\text { Index cancera } \\
\text { Screen- detected } \\
\text { N=64 }\end{array}$ & $\begin{array}{l}\text { Index cancer } \\
\text { Interval cancer } \\
\mathrm{N}=24\end{array}$ & P-value \\
\hline Breast density of latest screening mammogram, $n(\%)$ & & & 0.53 \\
\hline $0-50 \%(A C R A \& B)$ & $38(59.4)$ & $16(66.7)$ & \\
\hline $50-100 \%$ (ACR C\&D) & $26(40.6)$ & $8(33.3)$ & \\
\hline Type of cancer, $\mathrm{n}(\%)$ & & & 0.18 \\
\hline Ductal carcinoma in-situ & $6(9.4)$ & 0 & \\
\hline Invasive cancer & $58(90.6)$ & & \\
\hline Histological type of invasive cancers, $\mathrm{n}(\%)$ & & & 0.09 \\
\hline Ductal & $39(67.2)$ & $15(62.5)$ & \\
\hline Lobular & $12(20.7)$ & $9(37.5)$ & \\
\hline Other & $7(12.1)$ & 0 & \\
\hline Tumour stage of invasive cancers, $\mathrm{n}(\%)$ & & & 0.03 \\
\hline T1a-c & $35(60.3)$ & $8(33.3)$ & \\
\hline $\mathrm{T} 2-4$ & $23(39.7)$ & $16(66.7)$ & \\
\hline Lymph node status of invasive cancers, $\mathrm{n}(\%)$ & & & 0.13 \\
\hline $\mathrm{N}+$ & $23(39.7)$ & $13(54.2)$ & \\
\hline No & $35(60.3)$ & $11(45.8)$ & \\
\hline$B \& R$ grade of invasive cancers, $n(\%)$ & & & 0.49 \\
\hline 1 & $19(32.8)$ & $11(45.8)$ & \\
\hline II & 33 (56.9) & $10(41.7)$ & \\
\hline III & $5(8.6)$ & $2(8.3)$ & \\
\hline Unknown & $1(1.7)$ & & \\
\hline ER receptor status of invasive cancers, $\mathrm{n}(\%)$ & & & 0.69 \\
\hline Positive & $53(91.4)$ & $21(87.5)$ & \\
\hline Negative & $5(8.6)$ & $3(12.5)$ & \\
\hline $\mathrm{PR}$ receptor status of invasive cancers, $\mathrm{n}(\%)$ & & & 0.16 \\
\hline Positive & $45(77.6)$ & $15(62.5)$ & \\
\hline Negative & $13(22.4)$ & 9 (37.5) & \\
\hline Her2/Neu receptor status of invasive cancers, $\mathrm{n}(\%)$ & & & 0.54 \\
\hline Positive & $9(15.5)$ & $5(20.8)$ & \\
\hline Negative & $49(84.5)$ & $19(79.2)$ & \\
\hline Final surgical treatment, $\mathrm{n}(\%)$ & & & 0.40 \\
\hline Breast conserving surgery & $41(64.1)$ & $12(50.0)$ & \\
\hline Mastectomy & $21(32.8)$ & $11(45.8)$ & \\
\hline No surgery & $2(3.1)$ & $1(4.2)$ & \\
\hline
\end{tabular}




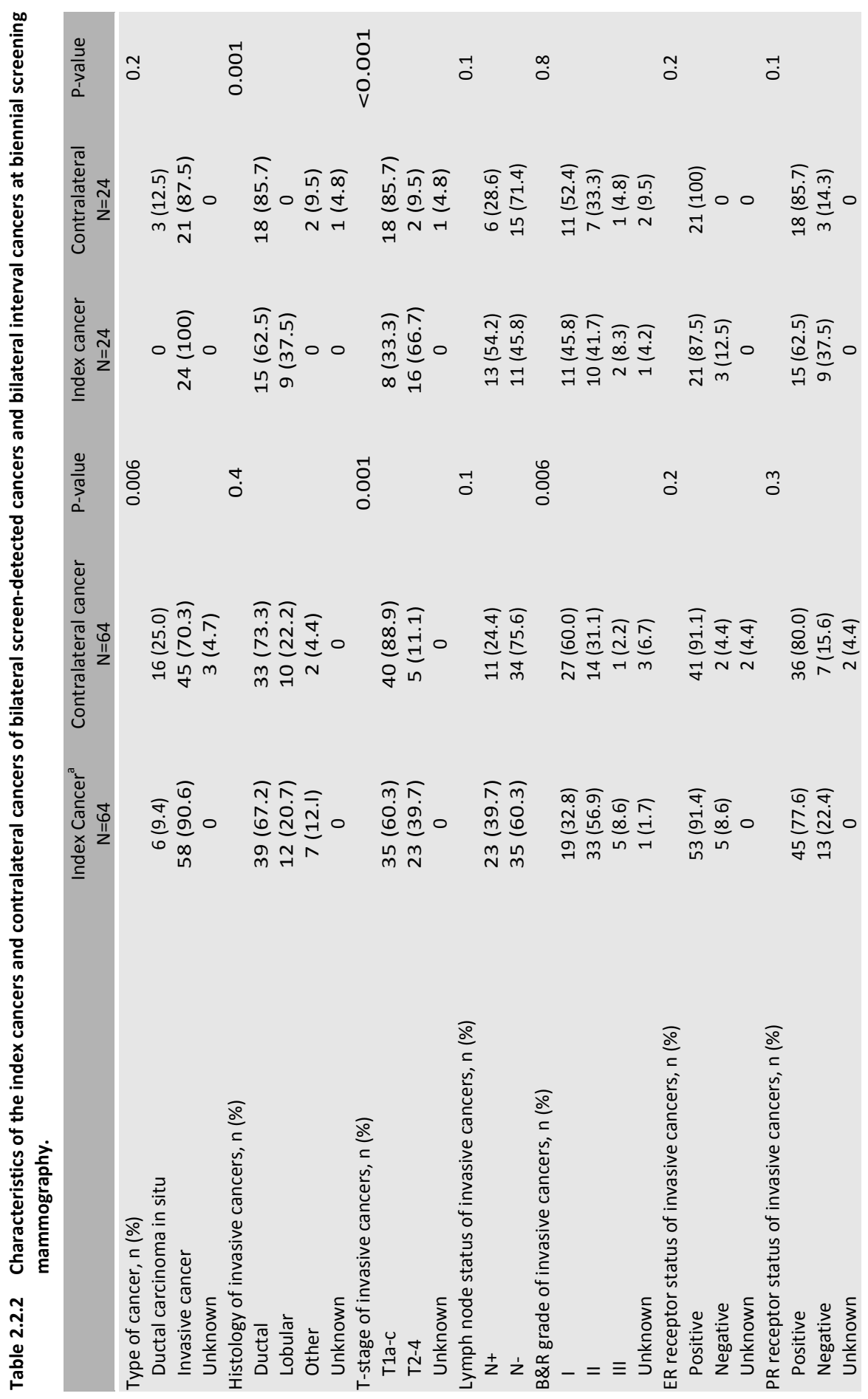




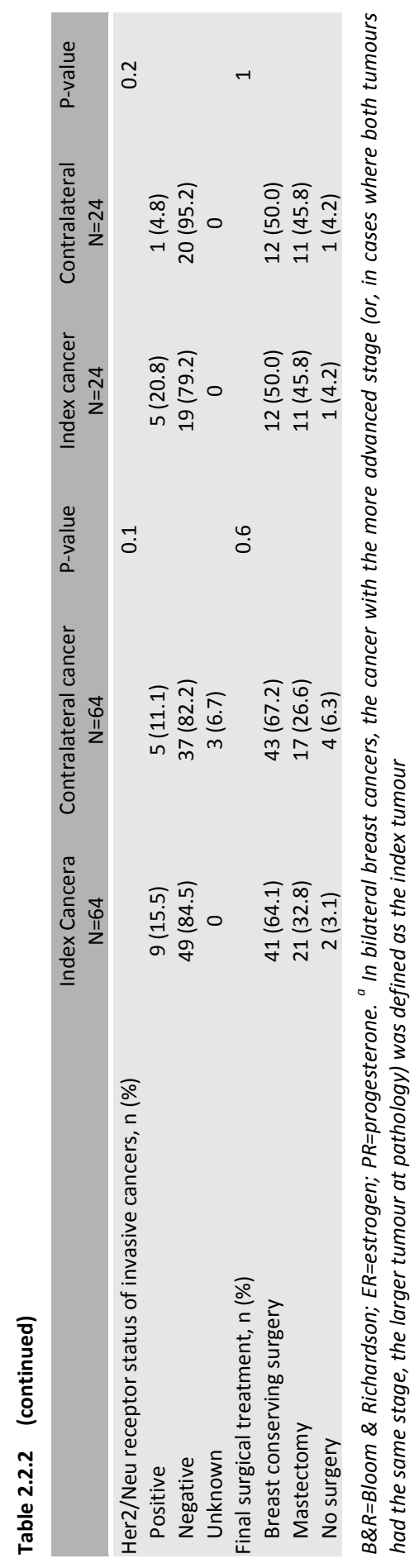




\section{Comparison of contralateral cancers in women with bilateral screen- detected cancers and bilateral interval cancers}

Contralateral cancers in women, either diagnosed with bilateral breast cancer after recall or diagnosed with bilateral interval cancer, showed comparable tumour characteristics, except of a higher percentage of invasive ductal cancers $(85.7 \%(18 / 21)$ versus $73.3 \%(33 / 45))$ and no invasive lobular cancers (0\% versus $22.2 \%(10 / 45)$ ) among contralateral interval cancers $(P=0.048$, Table 2.2.3).

Table 2.2.3 Characteristics of contralateral cancers of bilateral screen-detected and bilateral interval cancer

\begin{tabular}{|c|c|c|c|}
\hline & $\begin{array}{l}\text { Contralateral } \\
\text { cancera } \\
\text { Screen-detected } \\
N=64\end{array}$ & $\begin{array}{l}\text { Contralat } \\
\text { eral cancer } \\
\text { Interval cancer } \\
\mathrm{N}=24\end{array}$ & P-value \\
\hline Type of cancer, $\mathrm{n}(\%)$ & & & 0.3 \\
\hline Ductal carcinoma in-situ & $16(25.0)$ & $3(12.5)$ & \\
\hline Invasive cancer & $45(70.3)$ & 21 (87.5) & \\
\hline Unknown & $3(4.7)$ & 0 & \\
\hline Histological type of invasive cancers, n (\%) & & & 0.048 \\
\hline Ductal & $33(73.3)$ & $18(85.7)$ & \\
\hline Lobular & $10(22.2)$ & 0 & \\
\hline Other & $2(4.4)$ & $2(9.5)$ & \\
\hline Unknown & $1(4.8)$ & $1(4.8)$ & \\
\hline Tumour stage of invasive cancers, $\mathrm{n}(\%)$ & & & 0.5 \\
\hline T1a-c & 40 (88.9) & $18(85.7)$ & \\
\hline $\mathrm{T} 2-4$ & $5(11.1)$ & $2(9,5)$ & \\
\hline Unknown & 0 & $1(4,8)$ & \\
\hline Lymph node status of invasive cancers, $\mathrm{n}(\%)$ & & & 0.8 \\
\hline $\mathrm{N}+$ & $11(24.4)$ & $6(28.6)$ & \\
\hline No & $34(75.6)$ & $15(71.4)$ & \\
\hline Nottingham grading of invasive cancers, $\mathrm{n}(\%)$ & & & 0.8 \\
\hline 1 & $27(60.0)$ & $11(52.4)$ & \\
\hline II & $14(31.1)$ & $7(33.3)$ & \\
\hline III & $1(2.2)$ & $1(4,8)$ & \\
\hline Unknown & $3(6.7)$ & $2(9.5)$ & \\
\hline Estrogen receptor status of invasive cancers, $\mathrm{n}(\%)$ & & & 1 \\
\hline Positive & $41(91.1)$ & $21(100)$ & \\
\hline Negative & $2(4.4)$ & 0 & \\
\hline Unknown & $2(4.4)$ & 0 & \\
\hline Progesterone receptor status of invasive cancers, $n(\%)$ & & & 1 \\
\hline Positive & $36(80.0)$ & $18(85.7)$ & \\
\hline Negative & $7(15.6)$ & $3(14.3)$ & \\
\hline Unknown & $2(4.4)$ & 0 & \\
\hline Her2/Neu receptor status of invasive cancers, $\mathrm{n}(\%)$ & & & 0.5 \\
\hline Positive & $5(11.1)$ & $1(4.8)$ & \\
\hline Negative & $37(82.2)$ & $20(95.2)$ & \\
\hline Unknown & $3(6.7)$ & 0 & \\
\hline Final surgical treatment, $\mathrm{n}(\%)$ & & & 0.2 \\
\hline Breast conserving surgery & $43(67.2)$ & $12(50.0)$ & \\
\hline Mastectomy & $17(26.6)$ & $11(45.8)$ & \\
\hline No surgery & $4(6.3)$ & $1(4.2)$ & \\
\hline
\end{tabular}

Tumour at pathology) was defined as the index tumour. ${ }^{a}$ In bilateral interval breast cancers, the cancer with the more advanced stage (or, in cases where both tumours had the same stage, the larger 


\section{Characteristics of index cancers versus contralateral cancers in women diagnosed with bilateral interval cancer}

The comparison between index cancers and contralateral cancers in bilateral interval cancer has already been published elsewhere [van Bommel et al. 2018]. In summary, compared to contralateral cancers, invasive index cancers were more frequently of the lobular subtype $(37.5 \%(9 / 24)$ versus $0 \%(0 / 21),(P=0.001)$, Table 2.2 .2$)$ and showed a less favourable tumour size (T1a-C, 33.3\% (8/24) versus $85.7 \%(18 / 21),(P<0.001))$. We observed no significant differences in receptor status and final surgical treatment between index cancers and contralateral cancers (Table 2.2.2).

\section{Discussion}

To our knowledge, this is the first study comparing tumour characteristics of bilateral interval breast cancer with bilateral screen-detected breast cancer, in a biennial screened population. We found a comparable incidence of bilateral screen-detected cancer (2.2\%) and bilateral interval cancer (3.2\%) in our biennial screening mammography programme.

Index tumours of bilateral interval cancers were larger than those of bilateral screen-detected cancers. No differences in nodal stage, histological grade, receptor status or final surgical treatment were observed. In our previous study we showed that index cancers of bilateral interval cancers were more often of the invasive lobular subtype, had a less favourable tumour size (T-stage) and we suggested a trend towards higher hormone receptor expression in contralateral cancers. ${ }^{18}$ In this study we showed that in bilateral screen-detected cancers, contralateral cancers were more frequently $\mathrm{DCIS}$, and invasive contralateral cancers were smaller and better differentiated than index cancers.

Bilateral cancers are infrequently encountered in screening mammography programmes and their incidences are in the same range of the bilateral cancer incidence in a symptomatic population (0.7-3.2\%). ${ }^{26,27}$

Compared to the index tumours of bilateral screen-detected cancers, index tumours of bilateral interval cancers more frequently showed a locally advanced tumour stage (tumour stage T2 and higher). Unilateral interval cancers are known to be larger and usually have a more advanced nodal stage and less favourable tumour characteristics than screen-detected tumours ${ }^{28-31}$ and our findings have shown that this statement is also applicable to bilateral interval cancers.

In bilateral screen-detected cancers, about $10 \%$ of the index cancers and $25 \%$ of contralateral cancers were DCIS. In bilateral interval breast cancers, we observed only 3 cases of ductal carcinoma in-situ (none of them as index cancer) among the total of 48 interval cancers This shows that in systematically screening, not all findings have the same clinical significance. The sensitivity of screening mammography is better for the detection of unilateral, invasive ductal cancers than for invasive lobular cancers, 
probably resulting in a larger proportion of invasive interval cancers of the lobular subtype. ${ }^{6,15,30,32}$ We also observed a relatively large proportion of $37.5 \%$ of invasive lobular cancers among the index cancers of bilateral interval cancers. In our series, index cancers of bilateral interval cancers tended to be more frequently of the invasive lobular type than did the index cancers of bilateral screen-detected cancers, but this difference did not reach statistical significance. These findings are probably due to the relatively small sample size of bilateral cancers in our study.

We found a higher proportion of contralateral invasive lobular cancer in women with an invasive index tumour of the lobular type than in women with an invasive ductal index tumour. Invasive lobular cancer is known to be a diagnostic challenge at mammography and ultrasonography, ${ }^{33}$ whereas MRI has a high sensitivity for the detection of even small foci of invasive lobular cancer. ${ }^{34}$ Therefore, when dealing with an invasive lobular cancer (either screen-detected or presenting as interval breast cancer), pre-operative MRI should be considered in order to determine the extent of the tumour and to assess the contralateral breast. ${ }^{35}$

Our study has certain strengths and limitations. The large cohort of 468,720 screening mammograms and extensive follow-up enabled us to investigate bilateral breast cancers at screening mammography. The data provided us insight into many parameters, including mammographic features, tumour characteristics and surgical treatment. The follow-up period of two years, however, rendered it impossible to report on long term morbidity or mortality. The literature shows that, despite more favourable tumour characteristics (i.e., a higher proportion of invasive lobular cancers, smaller tumours and a higher proportion of positive receptor status), women with bilateral breast cancer have a worse prognosis than those with unilateral breast cancer. ${ }^{13-16,36}$ Obviously, both tumours have a risk of distant spread and thereby may compromise long term outcomes. Of note, we did not analyse the use of systemic therapy and whether the detection of bilateral cancer has changed the decision-making process in the use of systemic therapy.

The quality and effectiveness of screening mammography programmes is determined by the stage distribution and tumour characteristics of unilateral and bilateral screen-detected cancers and interval cancers. Although we found a low prevalence of bilateral breast malignancies in our screened population, their early detection may influence the therapeutical approach (breast conserving surgery versus mastectomy) and prognosis. Therefore, screening radiologists and clinical breast radiologists should vigorously examine both breasts to rule out or to confirm simultaneous bilateral disease.

Our study comprises a screening period of 10 years (2005-2014). In this period, much has changed in breast cancer screening and in clinical practice. For example, fullfield digital screening mammography replaced screen-film mammography in 20092010, and breast tomosynthesis and MR mammography are increasingly used at clinical workup. 
Therefore, more and smaller contralateral tumours might be found in the more recently screened patients than at an earlier time. Finally, although very limited data are available on bilateral screen-detected cancers and even less on bilateral interval cancers, we realize that we are reporting on a small subset of bilateral cancers. Due to the relatively small series of 64 bilateral screen-detected cancers and 24 bilateral interval cancers, differences between both groups may not have reached statistical significance and due to small numbers a multivariate analysis was not feasible.

In summary, bilateral screen-detected cancers and bilateral interval cancers are infrequently diagnosed. Index cancers and contralateral cancers of bilateral screendetected cancers and bilateral interval cancers show statistically significant differences in DCIS proportions, tumour histology and tumour size. 


\section{References}

1. Otto SJ, Fracheboud J, Looman CW, Broeder MJ, Boer R, Hendriks JH, Verbeek AL, de Koning H. National evaluation team for breast cancer screening. Initiation of population-based mammography screening in Dutch municipalities and effect on breast-cancer mortality: a systematic review. Lancet. 2003;361: 1411-7.

2. Dowling EC, Klabunde C, Patnick J, Ballard-Barbash R. Breast and cervical cancer screening programme implementation in 16 countries. J Med Screen. 2010;17:139-46.

3. Hellquist BN, Duffy SW, Abdsaleh S, Björneld L, Bordás P, Tabár L, Viták B, Zackrisson S, Nyström L, Jonsson $\mathrm{H}$, Effectiveness of population-based service screening with mammography for women ages 40 to 49 years: evaluation of the Swedish Mammography Screening in Young Women (SCRY) cohort. Cancer. 2011;117:714-22.

4. Van den Ende C, Oordt-Speets AM, Vroling H, van Agt HME. Benefits and harms of breast cancer screening with mammography in women aged 40-49 years: a systematic review. Int J Cancer. 2017; 141:1295-306.

5. Törnberg S, Kemetli L, Ascunce N, Hofvind S, Anttila A, Sèradour B, Paci E, Guldenfels C, Azavedo E, Frigerio A, Rodrigues $V$, Ponti A. A pooled analysis of interval cancer rates in six European countries. Eur J Cancer Prev. 2010;19:87-93.

6. Nederend J, Duijm LE, Voogd AC, Groenewoud JH, Jansen FH, Louwman MW. Trends in incidence and detection of advanced breast cancer at biennial screening mammography in The Netherlands: a population based study. Breast Cancer Res. 2012;14:R10.

7. Bellio G, Marion R, Giudici F, Kus S, Tonutti M, Zanconati F, Bortul M. Interval breast cancer versus screen-detected cancer: comparison of clinicopathologic characteristics in a single-center analysis. Clin Breast Cancer. 17 (2017) 564-71.

8. Setz-Pels W, Duijm LE, Groenewoud JH, Louwman MW, Jansen FH, van Beek M, Plaisier ML, Voogd AC. Patient and tumor characteristics of bilateral breast cancer at screening mammography in the Netherlands, a population-based study. Breast Cancer Res Treat. 2011;129:955-61.

9. Schmid SM, Pfefferkorn C, Myrick ME, Viehl CT, Obermann E, Schötzau A, Güth U. Prognosis of earlystage synchronous bilateral invasive breast cancer. Eur J Surg Oncol. 2011;37:623-8.

10. Kheirelseid EA, Jumustafa H, Miller N, Curran C, Sweeney K, Malone C, McLaughlin R, Newell J, Kerin MJ. Bilateral breast cancer: analysis of incidence, outcome, survival and disease characteristics. Breast Cancer Res. Treat. 2011;126:131-40.

11. Shi YX, Xia Q, Peng RJ, Yuan ZY, Wang SS, An X, Cao Y, Tan YT, Jin Y, Cai XY, Sun YL, Teng XY, Liu DG, Jiang WQ. Comparison of clinicopathological characteristics and prognoses between bilateral and unilateral breast cancer. J Cancer Res Clin Oncol. 2012;138:705-14.

12. Santiago L, Whitman G, Wang C, Dogan BE. Clinical and pathological features of clinically occult synchronous bilateral breast cancers. Curr Probl Diagn Radiol. 2018;47:305-10.

13. Carmichael AR, Bendall S, Lockerbie L, Prescott R, Bates T. The long-term outcome of synchronous bilateral breast cancer is worse than metachronous or unilateral tumours. Eur J Surg Oncol. 2002; 28:388-91.

14. Schaapveld M, Visser O, Louman WJ, Willemse PH, de Vries EG, van der Graaf WT, Otter R, Coebergh JW, van Leeuwen FE. The impact of adjuvant therapy on contralateral breast cancer risk and the prognostic significance of contralateral breast cancer: a population-based study in the Netherlands. Breast Cancer Res Treat. 2008;110:189-97.

15. Beckmann KR, Buckingham J, Craft P, Dahlstrom JE, Zhang Y, Roder D, Stuart-Harris R. Clinical characteristics and outcomes of bilateral breast cancer in an Australian cohort. Breast. 2010;20: 158-64.

16. Vuoto HD, García A, Candás GB, Zimmermann AG, Uriburu JL, Isetta JA, Cogorno L, Khoury M, Bernabó OL. Bilateral breast carcinoma: clinical characteristics and its impact on survival. Breast J. 2010;16: 625-32.

17. Rayson D, Payne JJ, Abdolell M, Barnes PJ, Maclntosh RF, Foley T, Younis T, Burns A, J. Caines J. Comparison of clinical-pathologic characteristics and outcomes of true interval and screen-detected invasive breast cancer among participants of a Canadian breast screening program: a nested casecontrol study. Clin Breast Cancer. 2011;11:27-32. 
18. Van Bommel RMG, Voogd AC, Nederend J, Setz-Pels W, Louwman MWJ, Strobbe LJ, Venderink D, TjanHeijnen VCG, Duijm LEM. Incidence and tumour characteristics of bilateral and unilateral interval breast cancers at screening mammography. Breast. 2018;38:101-6.

19 Duijm LE, Groenewoud JH, Hendriks JH, de Koning HJ. Independent double reading of screening mammograms in the Netherlands: effect of arbitration following reader disagreements. Radiology. 2004;231:564-70.

20. Klompenhouwer EG, Duijm LE, Voogd AC, den Heeten GJ, Strobbe L, Louwman MW, Coebergh JW, Venderink D, Broeders MJ. Re-attendance at biennial screening mammography following a repeated false positive recall. Breast Cancer Res Treat. 2014;145:429-37.

21. American College of Radiology, Breast Imaging Reporting and Data System (BIRADS), 4th ed.. American College of Radiology, Reston, Va, 2003.

22. Sickles EA, D'Orsi CJ, Bassett LW, et al. ACR BI-RADS Mammography. in: Breast Imaging Reporting and Data System: ACR BI-RADS - Breast Imaging Atlas, 5th ed.. American College o11f Radiology, Reston, Va, 2013.

23. Duijm LE, Groenewoud JH, de Koning HJ, Coebergh JW, van Beek M, Hoijen MJ, van de Poll-Franse LV. Delayed diagnosis of breast cancer in women recalled for suspicious screening mammography. Eur J Cancer. 2009;45:774-81.

24. Klompenhouwer EG, Voogd AC, den Heeten GJ, Strobbe LJ, de Haan AF, Wauters CA, Broeders MJ, Duijm LE. Blinded double reading yields a higher programme sensitivity than non-blinded double reading at digital screening mammography: a prospected population based study in the south of the Netherlands. Eur J Cancer. 2015;51c:391-9.

25. Van Bommel RMG, Weber R, Voogd AG, Nederend J, Louwman MWJ, Venderink D, Strobbe LJA, Rutten MJC, Plaisier ML, Lohle PN, Hooijen MJH, Tjan-Heijnen VCG, Duijm LEM. Interval breast cancer characteristics before, during and after the transition from screen-film to full-field digital screening mammography, BMC Cancer. 2017;17:315.

26. Nichol AM, Yerushalmi R, Tyldesley S, Lesperance M, Bajdik CK, Speers C, Gelmon KA, Olivotto IA. A case-match study comparing unilateral with synchronous bilateral breast cancer outcomes, J Clin Oncol. 2011;29:4763-68.

27. Holm M, Tjønneland A, Balslev E, Kroman N. Prognosis of synchronous bilateral breast cancer: a review and meta-analysis of observational studies, Breast Cancer Res Treat. 2014;146:461-75.

28. Burrell HC, Sibbering DM, Wilson AR, Pinder SE, Evans AJ, Yeoman LJ, Elston CW, Ellis IO, Blamey RW, Robertson JF. Screening interval breast cancers: mammographic features and prognosis factors, Radiology 1996;199:811-17.

29. Porter PL, El-Bastawissi AY, Mandelson MT, Lin MG, Khalid N, Watney EA, Cousens L, White D, Taplin S, White E. Breast tumor characteristics as predictors of mammographic detection: comparison of interval and screen-detected cancers, J Natl Cancer Inst. 1999;91:2020-8.

30. Vitak B, Olsen KE, Manson JC, Arnesson LG, Stal O. Tumour characteristics and survival in patients with invasive interval breast cancer classified according to mammographic findings at the latest screening: a comparison of true interval and missed interval cancers. Eur Radiol. 1999;9:460-9.

31. Musolino A, Michiara M, Conti GM, Boggiani D, Zatelli M, Palleschi D, Bella MA, Sgargi P, Di Blasio B, Ardizzoni A. Human epidermal growth factor receptor 2 status and interval breast cancer in a population-based cancer registry study. J Clin Oncol. 2012;30:2362-8.

32. Weber RJ, van Bommel RM, Louwman MW, Nederend J, Voogd AC, Jansen FH, Tjan-Heijnen VC, Duijm LE. Characteristics and prognosis of interval cancers after biennial screen-film or full-field digital screening mammography, Breast Cancer Res Treat. 2016;158:471-83.

33. Heidinger O, Heidrich J, Batzler WU, Krieg V, Weigel S, Heindel W, Hense HW. Digital mammography screening in Germany: impact of age and histological subtype on program sensitivity, Breast. 2015;24 191-6.

34. Carin AJ, Molière S, Gabriele V, Lodi M, Thiébaut N, Neuberger $\mathrm{K}$, Mathelin $\mathrm{C}$, Relevance of breast MRI in determining the size and focality of invasive breast cancer treated by mastectomy: a prospective study, World J Surg Oncol. 2017;15:128.

35. Debald M, Abramian A, Nemes L, Dobler M, Kaiser C, Keyver-Paik MD, et al. Who may benefit from preoperative breast MRI? A single-center analysis of 1102 consecutive patients with primary breast cancer, Breast Cancer Res Treat. 2015;153:531-7. 
36. Karakas Y, Kertmen N, Lacin S, Aslan A, Demir M, Ates O, Aksoy S, Altundag K. Comparison of prognosis and clinical features between synchronous bilateral and unilateral breast cancers, J BUON. 2017;22:623-7. 


\section{Chapter 3}

Additional findings 


\title{
Chapter 3.1
}

\author{
Frequency and characteristics of additionally \\ detected ipsilateral breast lesions following recall at \\ screening mammography
}

Lameijer JRC, Coolen AMP, Nederend J, Voogd AC, Tjan-Heijnen VCG, Duijm LEM The Breast 2018;42:94-101 


\section{Abstract}

Purpose

To determine the frequency and outcome of additionally detected ipsilateral breast abnormalities following recall at screening mammography.

Methods and materials

We included a consecutive series of 130,338 screening mammograms obtained between January 1, 2014 and January 1, 2016. During 2-year follow-up, clinical data were collected of all recalls. Women with a bilateral recall (115) and women recalled for multiple lesions in one breast (165) were excluded from the analyses. Screening outcome parameters were determined for recalled women with or without evaluation of additional ipsilateral breast abnormalities following recall.

\section{Results}

A total of 3995 women were recalled (recall rate, 3.1\%). In 258 (6.4\%) of these women, another lesion was detected in the ipsilateral breast than the one for which she had been recalled. Biopsy was more frequently performed of additionally detected ipsilateral lesions than of recalled lesions $(55.8 \%(144 / 258))$ versus $39.7 \%(1375 / 3457)$, $(p<0.001))$. The proportion of malignancy in recalled lesions and additionally detected lesions was comparable $(21.5 \%$ (743/3457) versus $19.0 \%(49 / 258), \mathrm{P}=0.34)$. Of all 144 biopsies of additionally detected ipsilateral lesions, 9 revealed a synchronous tumour in addition to a malignant recalled lesion, and 33 biopsies revealed multicentric or multifocal tumours. In 5 women, the recalled lesion turned out to be benign, whereas the additional lesion in a different quadrant was malignant at biopsy. A total of 97 biopsies showed benign findings.

\section{Conclusion}

A substantial proportion of women are analyzed for additional ipsilateral breast lesions following recall. These lesions are more frequently biopsied than recalled lesions, but have a comparable probability of being malignant. The majority of additionally detected cancerous lesions are part of multifocal or multicentric malignancies. 


\section{Introduction}

Screening mammography programmes have successfully been implemented in western countries over the past decades. Several studies have observed a reduction in breast cancer mortality, following the introduction of breast cancer screening, which is explained by detection of breast malignancy in an earlier stage and improved treatment. ${ }^{1-3}$

Over the years, improvements in breast imaging have increased the accuracy and detection rates at screening mammography. There is ongoing research to increase the detection of malignant breast lesions and to reduce false positive recalls of screening mammography programmes, for example by implementation of breast tomosynthesis. ${ }^{2-}$ ${ }^{11}$ In the diagnostic setting, additional imaging is usually performed to characterize a recalled lesion and additional ipsilateral or contralateral breast abnormalities may be detected. These additionally detected lesions are most frequently benign, but they also comprise malignant satellite lesions associated with the primary cancer and synchronous primary malignancies. ${ }^{12-16}$ Few results have been published on the detection of additional ipsilateral lesions by breast ultrasonography or mammography. ${ }^{15}$ It also remains unclear whether whole breast sonography, rather than targeted ultrasonography, should be used in the diagnostic workup after recall. Frequently, additional ipsilateral lesions are diagnosed by pre-operative magnetic resonance imaging (MRI) in women with breast cancer. ${ }^{16}$

To our knowledge, data on additionally detected breast lesions following recall of a different mammographic abnormality are lacking. Therefore, the purpose of the current study was to assess the frequency, characteristics and outcome of additionally detected ipsilateral breast lesions after recall in women who attended a biennial screening mammography programme in the South of the Netherlands.

\section{Materials and methods}

\section{Study population}

This is a prospective observational follow-up study of women aged 50-75 years who attended a biennial breast cancer screening programme conducted in the south of the Netherlands. Details of the design of our breast cancer screening programme have been described previously. ${ }^{17,18}$ Women are personally invited by letter to attend the screening programme and the attendance rate is more than $80 \%$. Women being treated for breast cancer or those attending clinical follow-up after treatment of breast cancer do not attend the screening programme. Also, women with breast implants masking most of the fibroglandular tissue at mammography are advised to refrain from the programme. Otherwise, there are no exclusion criteria for screening. A consecutive series of 130,338 full-field digital mammography screens $(13,762$ initial screens and 
116,576 subsequent screens) were included between January 1, 2014 and January 1, 2016. The screening mammograms were obtained at four specialized screening units (three mobile units and one fixed unit at Screening Program South).

Prior to participation, women are routinely asked for their permission for using their data for the evaluation of the screening programme and scientific purposes and all recalled women gave this permission. To minimize diagnostic bias, we excluded women who were recalled because of bilateral or multiple ipsilateral lesions, as additional diagnostic imaging procedures are more likely to be performed in these women than in women recalled for a unilateral lesion.

Ethical approval by our local Institutional Review Board was not required for this observational follow-up study, according to the Dutch Central Committee on Research involving Human Subjects (CCMO).

The flow chart of screened women and subsequent inclusion is depicted in Figure 3.1.1.

Figure 3.1.1 Flowchart of screened women and subsequent study inclusion

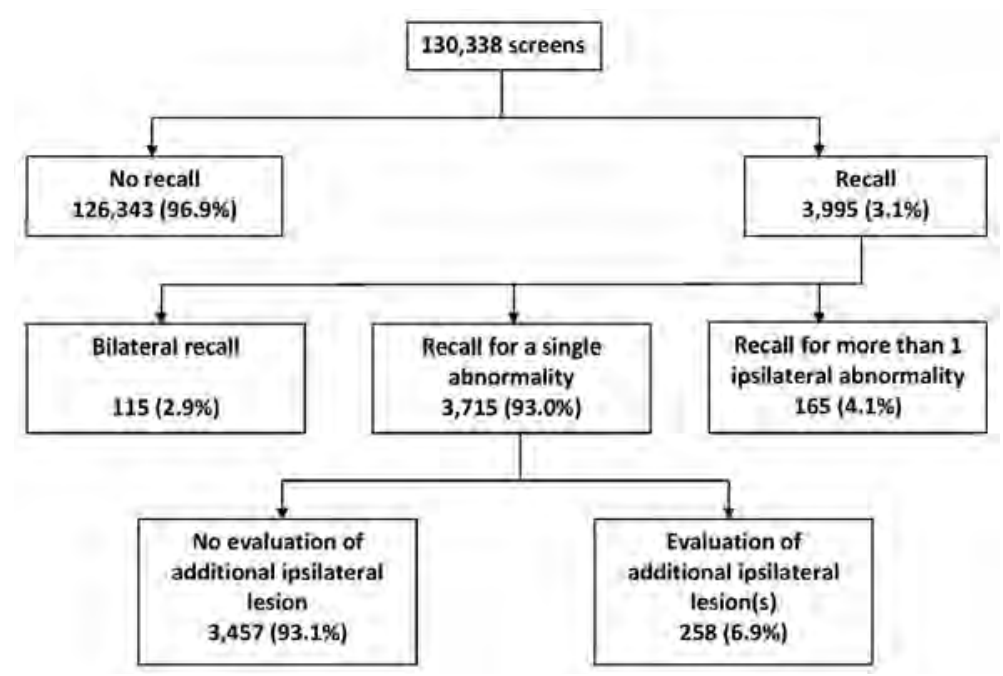

\section{Screening procedure and recall}

All digital mammograms were obtained with a Lord Selenia FFDM system (Hologiclnc, Danbury, CT), with a $70 \mathrm{~mm}$ pixel size and a $232 \times 286 \mathrm{~mm}$ field of view. The examinations were obtained by specialized screening mammography radiographers and all screening mammograms were double read in a blinded fashion by a team of 12 certified screening radiologists. All but one of the screening radiologists read more than 10000 screens yearly in the screening region we currently report on. The remaining radiologist reads 3000 screens in this specific region and an additional 10000 screens in another Dutch screening region. 
The screening radiologists first categorize abnormal mammographic findings into one of the following categories: suspicious mass, suspicious calcifications, suspicious mass combined with calcifications, architectural distortion, asymmetry or other abnormalities not otherwise categorized. Then, each screen is classified according to the Breast Imaging Reporting and Data System (BIRADS) lexicon and the radiologists annotate each recalled mammographic abnormality on a drawing which is part of the recall report. ${ }^{19}$ Women with a BI-RADS 1 or 2 were not recalled. Women with a BI-RADS 0,4 or 5 finding were referred to a dedicated breast unit of a hospital for further analysis. The BI-RADS category 3 is not used as short term follow-up is not available in the Dutch screening programme.

\section{Diagnostic work-up after recall}

Although a total of 20 hospitals were involved in the diagnostic work-up of recalled women, the diagnostic work up in the majority of women $(97.2 \%, 3883 / 3995)$ was performed in 7 regional hospitals in the south of the Netherlands. After physical examination by a surgical oncologist or dedicated breast nurse, additional breast imaging was performed at the radiology department. The screening mammogram was first reassessed by an experienced radiologist. The screening mammogram was routinely available and stored in the Picture Archiving and Communication System (PACS) of the hospital. Additional mammographic projections were obtained at the discretion of the radiologist. Full-field digital mammography was available in each of the 7 regional hospitals. Breast tomosynthesis was present in 2 hospitals from the beginning of the inclusion period and became available in 3 other hospitals in 2015 . Breast ultrasonography was used for the additional characterization of mammographic abnormalities and palpable breast lesions, for biopsy guidance and for target or second look purposes following breast MRI. Whole breast ultrasonography was not recommended, in accordance with the Dutch guidelines. ${ }^{20}$ Breast MRI was also available in each of the 7 hospitals and performed if indicated, as defined by the guidelines of the European Society of Breast Imaging ${ }^{21}$ and the Dutch guidelines. ${ }^{20}$ Fineneedle aspiration biopsy (FNAB), percutaneous core needle biopsy (CNB) and stereotactic biopsy were performed in each of the 7 hospitals, whereas MRI guided biopsy procedures were concentrated in the larger hospitals. All recalls were discussed by multidisciplinary teams that consisted of surgical oncologists, radiologists, medical oncologists, radiation oncologists, plastic surgeons, breast nurses and breast technologists.

During two-year follow-up, clinical data and data from diagnostic breast imaging, biopsy specimen and surgical procedures were collected of all recalled women by one of the screening radiologists (LD) and several radiology residents. The radiologist then entered all data in a database which had been constructed for quality assurance of the screening programme. Breast cancers were categorized into ductal carcinoma in-situ (DCIS) and invasive cancers; lobular carcinoma in-situ was considered a non-malignant lesion. The TNM (tumour, nodes and metastases) classification was used for malignant 
lesions. ${ }^{22}$ For all cancers treated by neoadjuvant therapy (either chemotherapy or antihormonal therapy), tumour size was derived from breast imaging (usually MRI) prior to the start of this therapy.

\section{Detection and assessment of ipsilateral breast lesions}

Any ipsilateral lesion for which a woman was nor recalled (i.e., not annotated by the screening radiologists) and that was evaluated after recall by any means of additional imaging and/or biopsy was considered to be an additionally evaluated lesion. One of the screening radiologists (LD) recorded for each recall whether additional, nonrecalled ipsilateral lesions had been diagnosed following recall. The methods of detection and subsequent assessment of ipsilateral breast lesions for which the woman had not been recalled were derived from the clinical records and clinical radiology reports. Similar to the workup up of screen-detected mammographic abnormalities, biopsy data and surgical reports of ipsilateral breast lesions were obtained.

\section{Statistical analysis}

All relevant data of screened and recalled women are stored in a database which is used for quality assurance of the screening programme and publication of studies. For the current study, the study population was similar to the one we used to determine the frequency and outcome of contralateral breast abnormalities following recall. ${ }^{18}$ Descriptive statistics were performed using Statistical Package for Social Science 23.0 (SPSS Inc., IBM, Chicago, IL). The chi-square test was used to test for differences between women without and with additional ipsilateral breast lesions detected following recall. A P-value of less than 0.05 was considered to indicate a statistically significant difference. P-values were two sided.

There was no loss to follow-up. In a small number of cases, data was missing (e.g., estrogen or progesterone receptor status missing due to an insufficient tissue sample). Because of the limited number of missing values, no statistical correction was performed. The Chi-square test with post hoc Bonferroni-correction was used to compare detection performance of the imaging modalities.

\section{Results}

\section{Overall screening results}

Out of 130,338 consecutively screened women, 3995 (3.1\%) were recalled for further assessment. Breast cancer was diagnosed in 905 recalled women (including 163 (18.0\%) ductal carcinomas in-situ), resulting in an overall cancer detection rate of 6.9 per 1000 screens. The cancer detection rate was 8.6 per $1000(118 / 13,762)$ for initial screens and 6.8 per $1000(787 / 116,576)$ for subsequent screens. The overall positive predictive 
value (PPV) of recall was $22.7 \%(905 / 3995 ; 11.4 \%(118 / 1037)$ for initial screens and $26.6 \%(787 / 2958)$ for subsequent screens).Women who were recalled for a bilateral lesion ( $n=115)$ and women with multiple recalled lesions in one breast $(n=165)$ were excluded from analysis (see also the flowchart, Figure 3.1.1). Patient characteristics were comparable for the remaining 3715 recalled women analyzed in this study, with a trend towards denser breasts in women with evaluation of an additional ipsilateral lesion. Patient characteristics are presented in Table 3.1.1.

Table 3.1.1 Baseline characteristics of women without or with assessment of additional, non-recalled ipsilateral breast lesions

\begin{tabular}{|c|c|c|c|c|}
\hline & $\begin{array}{l}\text { Overall } \\
\mathrm{N}=3,715\end{array}$ & $\begin{array}{c}\text { No additional } \\
\text { ipsilateral lesions } \\
\qquad N=3,457\end{array}$ & $\begin{array}{c}\text { Additional } \\
\text { ipsilateral lesions } \\
\mathrm{N}=258\end{array}$ & P-value* \\
\hline Median age, years & 58 & 58 & 57 & 0.89 \\
\hline \multicolumn{5}{|l|}{ Screening round, No (\%) } \\
\hline Initial & $944(25.4)$ & $887(25.4)$ & $57(22.0)$ & 0.22 \\
\hline Subsequent & $2771(74.6)$ & $2570(74.6)$ & $201(78.0)$ & \\
\hline \multicolumn{5}{|l|}{ Breast density, No (\%) } \\
\hline ACR I+II (0\%-50\%) & $2820(76,2)$ & $2637(76,2)$ & $183(71.0)$ & 0.06 \\
\hline ACR III+IV (50\%-100\%) & $895(23,8)$ & $820(23,8)$ & $75(29.0)$ & \\
\hline \multicolumn{5}{|c|}{ Previous breast surgery, No (\%) } \\
\hline Yes & $312(8,4)$ & $291(8,4)$ & $21(8.1)$ & 0.86 \\
\hline No & 3403 (91.6) & $3166(91.6)$ & 237 (91.9) & \\
\hline \multicolumn{5}{|c|}{ Hormone replacement therapy, No (\%) } \\
\hline Yes & $159(4.3)$ & $150(4.3)$ & $9(3,5)$ & 0.50 \\
\hline No & $3556(95.7)$ & 3307 (95.7) & $249(96.5)$ & \\
\hline \multicolumn{5}{|c|}{ Family history of breast cancer, No (\%) } \\
\hline Yes & $494(13,5)$ & $465(13,5)$ & $29(11.2)$ & 0.30 \\
\hline No & 3221 (86.5) & 2992 (86.5) & $229(88.8)$ & \\
\hline
\end{tabular}

ACR $=$ American College of Radiology.

*= women without assessment of additional ipsilateral lesions versus women with assessment of additional ipsilateral lesions

\section{Detection of additional ipsilateral lesions}

A total of 258 women, $6.4 \%$ of all recalls, were analyzed for an additional ipsilateral abnormality in the recalled breast.

In 182 women (70.5\%), the additional ipsilateral abnormality was first detected by review of the screening mammogram or additional mammographic views, with or without breast tomosynthesis. In 49 women (19.0\%), the lesions were found at ultrasound, whereas the remaining 27 lesions (10.5\%) were discovered at breast MRI. Breast MRI had been performed in 61 out of 258 women (23.6\%) with an additionally detected, ipsilateral breast abnormality. In 21 of these women (34.4\%), MRI was used for problem solving of an abnormality found at mammography or ultrasonography. In the remaining 40 women $(65.6 \%), \mathrm{MRI}$ was performed in a pre-operative setting to exclude or confirm (unilateral or bilateral) multicentricity or multifocality of breast cancer or to determine tumour size. Figure 3.1.2 shows at which type of imaging 
modality the additional ipsilateral breast lesions were initially detected. The four imaging modalities showed no statistically significant differences in the number of lesions detected per imaging modality.

Figure 3.1.2 Detection of additional breast lesions in the recalled breast per imaging modality

\section{Method of radiological detection of additional breast lesions in the recalled breast}

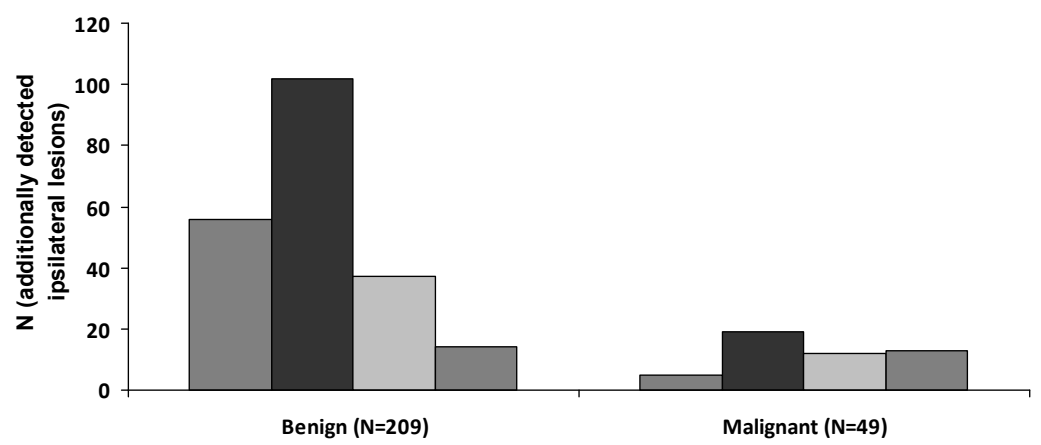

Benign additional lesions versus malignant additional lesions

$\square \mathrm{MG} \square \mathrm{MG}+\mathrm{DBT} \square \mathrm{US} \square \mathrm{MRI}$

\section{Workup of additionally detected lesions in the recalled breast}

The diagnostic workup is summarized in Table 3.1.2. Biopsy was performed in $55.8 \%$ $(144 / 258)$ of additionally detected ipsilateral lesions and in $39.7 \%$ (1375/3457) of recalled lesions $(P<0.001$, Table 3.1.3). The majority of biopsies consisted of percutaneous CNB $(99 / 144,68.8 \%)$ and the positive predictive value of biopsy was significantly lower for additionally detected lesions than for recalled lesions $(34.2 \%$ (49/144) versus 54\% (743/1375), $(P<0.001)$.

Positive predictive value of biopsy for additionally detected lesions changed when separate analysis was performed in women with a proven malignant index lesion $(42 / 71,59.2 \%)$ versus women with a proven benign index lesion $(5 / 73,6.85 \%$, $\mathrm{P}<0.001)$.

Table 3.1.2 Outcome of recalled lesions versus additionally detected lesions in the recalled breast

\begin{tabular}{lccc|} 
& $\begin{array}{c}\text { Recalled lesions } \\
\mathrm{N}=3,457\end{array}$ & $\begin{array}{c}\text { Additionally detected lesions } \\
\mathrm{N}=258\end{array}$ & P-value \\
\hline Outcome, No (\%) & & & 0.34 \\
$\quad$ False positive (no cancer) & $2714(78.5)$ & $209(81)$ & \\
$\quad$ True positive (cancer) & $743(21.5)$ & & \\
Type of assessment after recall, No (\%) & & $114(44.2)$ & $<0.001$ \\
$\quad$ Clinical breast imaging & $2071(59.9)$ & $144(55.8)$ & $<0.001$ \\
$\quad$ Clinical breast imaging + biopsy & $1375(39.7)$ & 34.0 & \\
Positive predictive value of biopsy, \% & 54.0 & &
\end{tabular}


Table 3.1.3 Biopsy procedures and outcome of additionally detected lesions in the recalled breast

\begin{tabular}{lcc} 
& \multicolumn{2}{c|}{ Final outcome } \\
\hline Type of biopsy, No (\%) & Benign (209) & Malignant (49) \\
No biopsy & $112(53.6)$ & \\
Ultrasound guided biopsy & & $2(4.1)$ \\
FNAB & $13(6.2)$ & $39(79.6)$ \\
CNB & $60(28.7)$ & $5(10.2)$ \\
SCNB & $17(8.1)$ & 0 \\
Percutaneous biopsy + excisional biopsy & $1(0.5)$ & $1(2.0)$ \\
Excisional biopsy & $4(1.9)$ & 0 \\
MRI biopsies N (\%) & $2(1.0)$ &
\end{tabular}

FNAB = fine needle aspiration biopsy; CNB = core needle biopsy; SCNB = stereotactic core needle biopsy

\section{Additionally detected lesions in the recalled breast}

Of the 258 additionally detected ipsilateral lesions, 209 proved to be benign at biopsy or radiological follow. These lesions included cysts (81) and fibroadenomas (24), and to a lesser extent intramammary lymph nodes (15) or areas of fibrosis (10) and fibrocystic changes (4).

In 49 of the 258 women (19.0\%) with an additional lesion detected in the recalled breast, the lesion proved to be malignant. The characteristics of these malignancies are presented in Table 3.1.4 and compared to those of recalled women without analysis of additional lesions. The proportions of DCIS and invasive cancers were comparable for both groups, but additionally detected, ipsilateral malignancies more frequently showed a lobular histology (28.5\% versus $11.8 \%, \mathrm{P}=0.001)$. Compared to screendetected cancers, the screen detected cancers with an additionally detected malignant lesion were more often stage $\mathrm{T} 2$ or higher $(\mathrm{P}<0.001)$. In all but one of the 17 additionally detected cancers with lymph node involvement, the cancer was either part of a multifocal (10) or multicentric (6) malignancy. Lymph node involvement was more frequently present in the screen-detected cancers with an additionally detected cancer $(40.1 \%$ versus $20.9 \%, \mathrm{P}=0.004)$. Mastectomy was more often performed in women diagnosed with an additional malignant ipsilateral lesion than in women with a unifocal, recalled malignancy $(55.1 \%$ versus $14.8 \%, \mathrm{P}<0.001)$.

\section{Multifocal and multicentric malignancies}

Ipsilateral multifocal or multicentric breast cancer was present in 52 women who were recalled for the evaluation of a single abnormality at screening mammography. In 35 of the 49 (71\%) additionally detected malignancies, the histological features of these lesions were comparable to those of the index lesions and they were considered to be part of multifocal $(24 / 35,69 \%)$ or multicentric disease $(11 / 35,31 \%)$. Multifocality or multicentricity of breast cancer was histologically proven prior to surgery in 33 out of 35 lesions. The remaining 2 lesions were considered malignant on imaging alone and their malignant nature was confirmed at the surgical specimen. 
The remaining 14 malignant lesions were either synchronous tumours $(n=9)$ or unifocal cancers in women whose recalled lesion turned out to be benign $(n=5)$. The synchronous cancers comprised six patients with DCIS, one invasive tubular cancer, one invasive ductolobular carcinoma and one invasive ductal carcinoma. These lesions showed a different histology than the ipsilateral, recalled malignancy. The histology of the five cancers diagnosed in women with a benign, recalled lesion in the ipsilateral breast was as follows: three invasive ductal carcinomas, one invasive lobular carcinoma and one DCIS.

Table 3.1.4 Tumour characteristics of unilateral, screen-detected cancers versus additional cancers diagnosed in the ipsilateral recalled breast

\begin{tabular}{|c|c|c|c|}
\hline & $\begin{array}{l}\text { Screen-detected } \\
\text { cancers } \\
n=743\end{array}$ & $\begin{array}{l}\text { Additionally detected } \\
\text { ipsilateral cancers } \\
\qquad n=49\end{array}$ & P-value \\
\hline Type of cancer, No (\%) & & & 0.44 \\
\hline Ductal carcinoma in situ (DCIS) & $139(18.7)$ & $7(14.3)$ & \\
\hline Invasive & $604(81.3)$ & $42(85.7)$ & \\
\hline Histology of invasive cancers, No (\%) & & & 0.001 \\
\hline Ductal & $470(77.8)$ & $28(66.7)$ & \\
\hline Lobular & $71(11.8)$ & $12(28.5)$ & \\
\hline Ductolobular & $20(3.3)$ & $1(2.4)$ & \\
\hline Other & $43(7.1)$ & $1(2.4)$ & \\
\hline Tumour stage of invasive cancers, No (\%) & & & $<0.001$ \\
\hline $\mathrm{T} 1$ & $486(80.5)$ & $22(52.4)$ & \\
\hline $\mathrm{T} 2+$ & 118 (19.5) & $20(47.6)$ & \\
\hline Lymph node status of invasive cancers, No (\%) & & & 0.004 \\
\hline $\mathrm{N}+$ & 126 (20.9) & $17(40.1)$ & \\
\hline $\mathrm{N}-$ & $472(78.1)$ & 25 (59.9) & \\
\hline Unknown & $6(1.0)$ & 0 & \\
\hline Bloom \& Richardson grade, No (\%) & & & 0.01 \\
\hline 1 & $283(46.9)$ & $12(28.5)$ & \\
\hline II & $252(41.7)$ & $25(59.5)$ & \\
\hline III & $68(11.3)$ & $5(12.0)$ & \\
\hline Unknown & $1(0.1)$ & 0 & \\
\hline Estrogen receptor status, No (\%) & & & 0.39 \\
\hline Positive & $546(90.3)$ & $36(85.8)$ & \\
\hline Negative & $55(9.2)$ & $6(14.2)$ & \\
\hline Unknown & $3(0.5)$ & 0 & \\
\hline Progesterone receptor status, No (\%) & & & 0.59 \\
\hline Positive & $427(70.7)$ & $32(76.2)$ & \\
\hline Negative & $175(29.0)$ & $10(23.8)$ & \\
\hline Unknown & $2(0.3)$ & 0 & \\
\hline Her2/Neu receptor status, No (\%) & & & 0.89 \\
\hline Positive & $61(10.1)$ & $4(9.5)$ & \\
\hline Negative & $539(89.2)$ & $38(90.5)$ & \\
\hline Unknown & $4(0.7)$ & 0 & \\
\hline Final surgical treatment, No (\%) & & & $<0.001$ \\
\hline Breast conserving surgery & $625(84.1)$ & $22(44.9)$ & \\
\hline Mastectomy & $110(14.8)$ & $27(55.1)$ & \\
\hline No surgery & $8(1.1)$ & 0 & \\
\hline
\end{tabular}




\section{Discussion}

To our knowledge, this is the first study which focuses on the analysis of additionally detected breast lesions following recall of a different mammographic abnormality. We found that additional ipsilateral lesions were detected in $6.4 \%$ of recalled women. Type of assessment (clinical imaging versus clinical imaging + biopsy) was comparable for recalled lesions and additionally detected lesions, whereas the positive predictive of biopsy was higher for recalled lesions. However, separate analysis showed that in the case of a malignant index lesion, the positive predictive value of biopsy for the additional lesion was higher compared to cases of benign index lesions $(P<0.001)$, which suggest that a low threshold for additional biopsy in proven malignant index lesions is warranted.

About $20 \%$ of the additionally detected lesions proved to be malignant and a majority of these malignancies were part of multifocal or multicentric disease. A majority of the additionally detected, malignant lesions were invasive ductal carcinomas. A recent metanalysis focusing on the detection of ipsilateral multifocal or multicentric cancer in women already diagnosed with breast cancer found comparable percentages of invasive cancers. ${ }^{23}$

In our series of 49 malignancies, additionally diagnosed in the recalled breast, 24 were histologically identical to the index lesion and located in the same breast quadrant (multifocal disease), whereas 11 malignancies with histological features identical to the index lesion were located in a different quadrant (multicentric disease). According to previous studies and a recent meta-analysis, multifocality may have a significant impact on 5 year survival rates, whereas the impact on disease free survival is subject to debate, with a previous meta-analysis showing a trend towards a poorer DFS (HR 1.96; $P=0.07$ ). ${ }^{23-26}$

The majority of additionally detected lesions in recalled breasts showed a benign outcome and they were mostly cysts and fibroadenomas. Recent studies show a comparable rate of additionally found benign lesions in recalled women, although a larger proportion of fibroadenomas were found at contrast enhanced mammography. ${ }^{15,27,28}$ In a majority of women, analysis by imaging alone was sufficient to confirm the benign nature of additionally detected lesions. Surgical excision of benign breast lesions should be kept to a minimum. Excisional biopsy may cause changes in the breast tissue, impairing a proper assessment of future screening mammograms. The latter may result in an increased false positive recall rate and a lower sensitivity of screening mammography. ${ }^{29}$

Almost half of the additional ipsilateral lesions were detected on digital mammography combined with breast tomosynthesis. With the increased use of tomosynthesis in a diagnostic setting, it can be expected that more additional lesions will be detected after recall. Tomosynthesis has not yet been implemented in the Dutch mammography screening programme. Several studies have shown that breast tomosynthesis in a screening setting, in addition to full field digital mammography, 
increases the cancer detection and may decrease false positive recall rates. ${ }^{6,7}$ On the other hand, an Italian screening study reported a higher false-positive recall rate when adding tomosynthesis to digital mammography. ${ }^{5}$ and a recent Swedish screening study also found a higher false positive recall rate for one view tomosynthesis compared to digital mammography. ${ }^{4}$ Higher recall rates and higher false positive rates may likely decrease again when radiologists gain more experience with tomosynthesis in a screening setting. $^{4-7}$ Certain types of breast cancer, especially invasive lobular carcinoma, can be difficult to detect as they may present as subtle architectural distortions which are more likely to be missed at screening mammography. At screening, tomosynthesis may be helpful to detect these distortions. In the diagnostic setting, it can be of value to find additional multicentric or multifocal lesions and guide ultrasound imaging when the index lesion presents with an architectural distortion. Vigilance is required and one should not be mislead by the satisfaction of having found one breast abnormality as additional malignant lesions may be present elsewhere in the breast. ${ }^{8-11,24,30}$

In our study, a majority of the additionally detected malignant lesions (64\%) were found in the same quadrant as the index lesion and a considerable number of these malignant lesions (30\%) were detected first at ultrasound. Breast ultrasonography of the quadrant harbouring the cancer is routinely performed, in adherence to the guidelines of the European Society of Breast Imaging ${ }^{21}$ and the Dutch guidelines ${ }^{20}$, whereas whole breast ultrasonography is not recommended as it may introduce many more increased false positive findings than the detection of additional cancers. Another substantial number of additional ipsilateral malignancies were found at breast MRI. According to the Dutch guidelines, indications for breast MRI include the evaluation of multicentric, multifocal or contralateral disease in case of invasive lobular cancer, and determination of tumour size in dense breasts. In select cases, MRI can be employed for problem solving of indeterminate lesions at mammography and/or

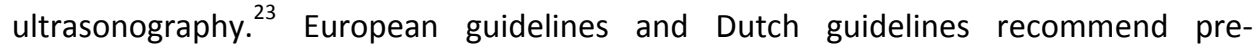
operative MRI imaging for most cases of invasive lobular carcinomas and they do not recommend a routine use of breast MRI for invasive ductal carcinoma or ductal carcinoma in situ. The higher proportion of invasive lobular cancer among additionally detected ipsilateral cancers may probably be explained by the more intensified use of MRI in invasive lobular cancer than invasive ductal cancer.

Synchronous malignancy was found in nine women with assessment of an additional ipsilateral lesion. The majority of these lesions were DCIS, ranging from lowgrade to high grade DCIS. Diagnosis and treatment of DCIS has been studied extensively, also with respect to the issue of overdiagnosis and overtreatment of early breast cancer. Consensus has yet to be reached on this topic. Research on the treatment of synchronous DCIS is sparse, but it will probably have a significant impact on the proposed treatment regimen. The treatment not only concerns surgical planning, but it also comprises decisions on radiation therapy. The woman's preference for mastectomy or breast conserving surgery should also be taken in account as this 
decision may as well be influenced by the presence of synchronous malignant lesions. ${ }^{31,32}$ In this study, women with an additional malignancy diagnosed in the breast already harbouring a recalled breast cancer were much more likely to undergo mastectomy than women with only a malignant recalled lesion (55.1\% versus $14.8 \%$, $\mathrm{P}<0.001)$. In these cases multifocality and multicentricity may warrant extensive surgery, without the possibility of breast conserving surgery.

An ipsilateral breast cancer was diagnosed in five women whose recalled mammographic abnormality proved benign. The lesions were either located in the same quadrant as the recalled lesion and detected at ultrasound (2/5), or located in a different quadrant and detected by mammography with $(2 / 5)$ or without tomosynthesis (1/5). We do not know whether the lesions, located in different quadrants, were visible at screening mammography, but previous research suggests that additional cancers may be missed at screening as a result of satisfaction of search.

Our study has certain limitations. Our results may not be representative for other regional or nation-wide screening mammography programmes. Programmes may show variations in reading strategies (single reading versus double reading), screening interval (1-3 years), radiological equipment, and differences in recall rates. Also, a nonuniform use of imaging modalities after recall may have influenced study outcome. and the moderate sample size of ipsilateral cancers may limit the external validation of the results.

Breast imaging techniques are continuously updated and new techniques are emerging and being implemented, which may increase the number of abnormalities detected at screening and the number of additional lesions in recalled women. Although one should aim for an increased cancer detection, this must not be accompanied by a significant increase in false positive findings that may introduce unnecessary diagnostic investigations, unnecessary treatment, and avoidable psychological impact.

In summary, additionally detected ipsilateral breast lesions are usually benign. The majority of malignant lesions are part of a multifocal or multicentric screen detected malignancy. Synchronous tumours comprise a minority of the additionally detected malignant lesions. Additional radiological imaging and biopsy is frequently required to determine the nature of lesions additionally detected in recalled breasts. 


\section{References}

1. Gotzsche PC, Jorgensen KJ. Screening for breast cancer with mammography. Cochrane Database Syst Rev 2013, CD001877.

2. Sankatsing VDV, van Ravesteyn NT, Heijnsdijk EAM, Looman CWN, van Luijt PA, Fracheboud J, den Heeten GJ, Broeders MJM, de Koning HJ. The effect of population-based mammography screening in Dutch municipalities on breast cancer mortality: 20 years of follow-up. Int J Canc 2017;141:671-7.

3. Otto SJ, Fracheboud J, Looman CW, Broeders MJ, Boer R, Hendriks JH, Verbeek AL, de Koning HJ. National Evaluation Team for Breast Cancer S. Initiation of population-based mammography screening in Dutch municipalities and effect on breast-cancer mortality: a systematic review. Lancet 2003;361:1411-7.

4. Lang K, Andersson I, Rosso A, Tingberg A, Timberg P, Zackrisson S. Performance of one-view breast tomosynthesis as a stand-alone breast cancer screening modality: results from the Malmo Breast Tomosynthesis Screening Trial, a population-based study. Eur Radiol 2016;26:184-90.

5. Bernardi D, Macaskill P, Pellegrini M, Valentini M, Fanto C, Ostillio L, Tuttobene P, Luparia A, Houssami $\mathrm{N}$. Breast cancer screening with tomosynthesis (3D mammography) with acquired or synthetic 2D mammography compared with 2D mammography alone (STORM-2): a population-based prospective study. Lancet Oncol 2016;17:1105-13.

6. Skaane P, Bandos AI, Gullien R, Eben EB, Ekseth U, Haakenaasen U, Izadi M, Jebsen IN, Jahr G, Krager M, Niklason LT, Hofvind S, et al. Comparison of digital mammography alone and digital mammography plus tomosynthesis in a population-based screening program. Radiology 2013;267:47-56.

7. Ciatto S, Houssami N, Bernardi D, Caumo F, Pellegrini M, Brunelli S, Tuttobene P, Bricolo P, Fanto C, Valentini M, Montemezzi S, Macaskill P. Integration of 3D digital mammography with tomosynthesis for population breast-cancer screening (STORM): a prospective comparison study. Lancet Oncol 2013;14:583-9.

8. McDonald ES, Oustimov A, Weinstein SP, Synnestvedt MB, Schnall M, Conant EF. Effectiveness of digital breast tomosynthesis compared with digital mammography: outcomes analysis from 3 years of breast cancer screening. JAMA Oncol 2016;2:737-43.

9. Maxwell AJ, Michell M, Lim YY, Astley SM, Wilson M, Hurley E, Evans DG, Howell A, Iqbal A, Kotre J, Duffy $S$, Morris J. A randomised trial of screening with digital breast tomosynthesis plus conventional digital 2D mammography versus 2D mammography alone in younger higher risk women. Eur J Radiol 2017;94:133-9.

10. Friedewald SM, Rafferty EA, Rose SL, Durand MA, Plecha DM, Greenberg JS, Hayes MK, Copit DS, Carlson KL, Cink TM, Barke LD, Greer LN, et al. Breast cancer screening using tomosynthesis in combination with digital mammography. J Am Med Assoc 2014;311:2499-507.

11. McCarthy AM, Kontos D, Synnestvedt M, Tan KS, Heitjan DF, Schnall M, Conant EF. Screening outcomes following implementation of digital breast tomosynthesis in a general-population screening program. J Natl Cancer Inst 2014;106.

12. El Sharouni MA, Postma EL, Menezes GL, van den Bosch MA, Pijnappel RM, Witkamp AJ, van der Pol CC, Verkooijen HM, van Diest PJ. High prevalence of MRI-detected contralateral and ipsilateral malignant findings in patients with invasive ductolobular breast cancer: impact on surgical management. Clin Breast Canc 2016;16:269-75.

13. Gutierrez. High cancer yield and positive predictive value: outcomes at a center routinely using preoperative breast MRI for staging. AJR Am J Roentgenol 2011;196:93-9.

14. Sardanelli. Overview of the role of pre-operative breast MRI in the absence of evidence on patient outcomes. Breast 2010;19:3-6.

15. He H, Plaxco JS, Wei W, Huo L, Candelaria RP, Kuerer HM, Yang WT. Incremental cancer detection using breast ultrasonography versus breast magnetic resonance imaging in the evaluation of newly diagnosed breast cancer patients. Br J Radiol 2016;89:20160401.

16. Plana MN, Carreira C, Muriel A, Chiva M, Abraira V, Emparanza JI, Bonfill X, Zamora J. Magnetic resonance imaging in the preoperative assessment of patients with primary breast cancer: systematic review of diagnostic accuracy and meta-analysis. Eur Radiol 2012;22:26-38. 
17. Duijm LE, Groenewoud JH, Jansen FH, Fracheboud J, van Beek M, de Koning HJ. Mammography screening in The Netherlands: delay in the diagnosis of breast cancer after breast cancer screening. $\mathrm{Br} \mathrm{J}$ Canc 2004;91:1795-9.

18. Lameijer JRC, Coolen AM, Voogd AC, Strobbe LJ, Louwman MWJ, Venderink D, Tjan-Heijnen VC, Duijm LEM. Frequency and characteristics of contralateral breast abnormalities following recall at screening mammography. Eur Radiol 2018;28(10):4205-14.

19. American College of Radiology. BI-RADS Committee. ACR BI-RADS atlas: breast imaging reporting and data system. fifth ed. Reston, VA: American College of Radiology; 2013.

20. NABON. Richtlijn Mammacarcinoom, vol. 2017; 2012.

21. Mann RM, Balleyguier C, Baltzer PA, Bick U, Colin C, Cornford E, Evans A, Fallenberg E, Forrai G, Fuchsjager $\mathrm{MH}$, Gilbert FJ, Helbich $\mathrm{TH}$, et al. Breast MRI: EUSOBI recommendations for women's information. Eur Radiol 2015;25:3669-78.

22. Sobin LH, Gospodarowicz MK, Wittekind C. International Union against Cancer. TNM classification of malignant tumours. seventh ed. Chichester, West Sussex, UK ; Hoboken, NJ: Wiley-Blackwell; 2010. p. 310. xx.

23. Kanumuri $P$, Hayse B, Killelea BK, Chagpar AB, Horowitz NR, Lannin DR. Characteristics of multifocal and multicentric breast cancers. Ann Surg Oncol 2015;22:2475-82.

24. Vera-Badillo FE, Napoleone M, Ocana A, Templeton AJ, Seruga B, Al-Mubarak M, AlHashem H, Tannock IF, Amir E. Effect of multifocality and multicentricity on outcome in early stage breast cancer: a systematic review and meta-analysis. Breast Canc Res Treat 2014;146:235-44.

25. Weissenbacher TM, Zschage M, Janni W, Jeschke U, Dimpfl T, Mayr D, Rack B, Schindlbeck C, Friese K, Dian D. Multicentric and multifocal versus unifocal breast cancer: is the tumor-node-metastasis classification justified? Breast Canc Res Treat 2010;122:27-34.

26. Houssami N, Ciatto S, Macaskill P, Lord SJ, Warren RM, Dixon JM, Irwig L. Accuracy and surgical impact of magnetic resonance imaging in breast cancer staging: systematic review and meta-analysis in detection of multifocal and multicentric cancer. J Clin Oncol 2008;26:3248-58.

27. Houben IPL, Van de Voorde P, Jeukens C, Wildberger JE, Kooreman LF, Smidt ML, Lobbes MBI. Contrastenhanced spectral mammography as workup tool in patients recalled from breast cancer screening has low risks and might hold clinical benefits. Eur J Radiol 2017;94:31-7.

28. Lobbes MB, Lalji U, Houwers J, Nijssen EC, Nelemans PJ, van Roozendaal L, Smidt ML, Heuts E, Wildberger JE. Contrast-enhanced spectral mammography in patients referred from the breast cancer screening programme. Eur Radiol 2014;24:1668-76.

29. van Breest Smallenburg V, Duijm LE, Voogd AC, Groenewoud JH, Jansen FH, van Beek M, Louwman MW. Lower sensitivity of screening mammography after previous benign breast surgery. Int J Canc 2012;130:122-8.

30. Bahl M, Gaffney S, McCarthy AM, Lowry KP, Dang PA, Lehman CD. Breast cancer characteristics associated with 2D Digital Mammography versus Digital Breast Tomosynthesis for screening-detected and interval cancers. Radiology 2017, 171148.

31. Groen EJ, Elshof LE, Visser LL, Rutgers EJT, Winter-Warnars HAO, Lips EH, Wesseling J. Finding the balance between over- and under-treatment of ductal carcinoma in situ (DCIS). Breast 2017;31:274-83.

32. Iacconi C, Galman L, Zheng J, Sacchini V, Sutton EJ, Dershaw D, Morris EA. Multicentric cancer detected at breast MR imaging and not at mammography: important or not? Radiology 2016;279:378- 84. 


\section{Chapter 3.2}

Frequency and characteristics of contralateral

breast abnormalities following recall at

screening mammography

Lameijer JRC, Coolen AMP, Voogd AC, Strobbe LJ, Louwman MWJ, Venderink D,

Tjan-Heijnen VCG, Duijm LEM

European Radiology 2018;28:4205-4214 


\section{Abstract}

Purpose

To determine the frequency and characteristics of contralateral, non-recalled breast abnormalities following recall at screening mammography.

Methods

We included a series of 130,338 screening mammograms performed between 1 January 2014 and 1 January 2016. During the 1-year follow-up, clinical data were collected for all recalls. Screening outcome was determined for recalled women with or without evaluation of contralateral breast abnormalities.

\section{Results}

Of 3,995 recalls (recall rate 3.1\%), 129 women (3.2\%) underwent assessment of a contralateral, non-recalled breast abnormality. Most lesions were detected at clinical mammography and/or breast tomosynthesis (101 women, 78.3\%). The biopsy rate was similar for recalled lesions and contralateral, non-recalled lesions, but the positive predictive value of biopsy was higher for recalled lesions $(P=0.01)$. A comparable proportion of the recalled lesions and contralateral, nonrecalled lesions were malignant $(P=0.1)$. The proportion of ductal carcinoma in situ was similar for both groups, as well as invasive cancer characteristics and type of surgical treatment.

\section{Conclusions}

About $3 \%$ of recalled women underwent evaluation of contralateral, non-recalled breast lesions. Evaluation of the contralateral breast after recall is important as we found that $15.5 \%$ of contralateral, non-recalled lesions were malignant. Contralateral cancers and screen-detected cancers show similar characteristics, stage and surgical treatment. 


\section{Introduction}

Many countries have introduced breast cancer screening programmes with the aim to detect breast cancers at an early stage, before these grow large enough to become symptomatic, and thus to decrease morbidity and improve breast cancer survival. Breast cancer mortality has decreased in the past 20 years in The Netherlands and this improved survival is due to a combination of breast cancer screening and improved treatment. ${ }^{1-3}$

Breast cancers detected at screening are often small and non-symptomatic. Improved radiological breast imaging techniques, including the replacement of screenfilm mammography by full-field digital mammography (FFDM) and the recent introduction of breast tomosynthesis (three-dimensional mammography), have resulted in a more accurate detection and characterisation of breast lesions at screening mammography. ${ }^{4,5}$ Breast tomosynthesis has not yet been implemented in our nation-wide screening mammography programme. Women are usually recalled for a unilateral lesion at screening mammography, but a small percentage of cases (1-2\%) is recalled for suspicious bilateral lesions. ${ }^{6}$

After recall, additional breast imaging is performed for the evaluation of the suspected lesion detected at screening mammography. In a diagnostic setting, the addition of breast tomosynthesis to digital mammography results in a higher sensitivity and specificity of breast cancer diagnosis than digital mammography alone. ${ }^{7-9}$ For example, Gilbert et al. ${ }^{9}$ reported a higher sensitivity for the detection of invasive cancers sized 11-20 $\mathrm{mm}$ when adding tomosynthesis to digital mammography in a diagnostic setting (93\% versus $86 \%, \mathrm{P}<0.001$ ). Specificity also increased, from $58 \%$ with digital mammography to $69 \%$ with digital mammography plus breast tomosynthesis. Lång et al. $^{10}$ found an increased lesion visualisation with breast tomosynthesis compared to digital mammography, especially for spiculated masses.

Additional breast cancers may be detected in the breast for which the woman has been recalled, or in the contralateral breast. Preoperative breast magnetic resonance imaging (MRI) in breast cancer patients has also been shown to detect additional malignancies in one or both breasts in a significant number of patients, and the MRI findings frequently result in more extensive surgery compared to the initially proposed treatment, such as additional contralateral mastectomy. ${ }^{11-13}$

To our knowledge, no previous studies have reported on additionally detected contralateral breast lesions in women recalled for a unilateral abnormality at screening mammography. We, therefore, assessed the frequency and characteristics of these contralateral lesions in women who attended a biennial screening mammogram programme in the South of the Netherlands. 


\section{Materials and methods}

\section{Study design end study population}

This is a prospective observational follow-up study of women aged 50-75 who attended a biennial breast cancer screening programme conducted in the south of The Netherlands. A consecutive series of 130,338 full-field digital mammography screens (13,762 initial screens and 116,576 subsequent screens) between 1 January 2014 and 1 January 2016 were included. The screening mammograms were obtained at four specialised screening units in a biennial screening mammography programme conducted in the south of The Netherlands.

Women are personally invited by letter to attend the screening programme. These letters are sent to the address of every woman aged between 50 and 75 years old registered in the municipal registration. Women being treated for breast cancer or those attending clinical follow-up after treatment of breast cancer do not attend the screening programme. Otherwise, there are no exclusion criteria for screening eligibility.

Women participating in our screening mammography programme were asked for permission to use their data for scientific purposes and for the evaluation of the screening programme. All women gave permission to use their screening and diagnostic data.

Possible exclusion criteria included no permission to use screen data, technical failure of screening equipment and insufficient image quality as assessed by an experienced screening radiologist. None of the women screened for study inclusion met these criteria.

A total of 3,995 women were recalled for further analysis. The hospitals involved in these recalls were visited and data as described below were obtained. Possible exclusion criteria after recall included insufficient follow-up or loss to followup, incomplete records, no permission to access data. None of the women recalled for analysis met these criteria and no recalls were excluded from analysis.

Ethical approval by our local Institutional Review Board was not required for this prospective observational follow-up study, according to the Dutch Central Committee on Research involving Human Subjects (CCMO).

\section{Screening procedure and recall}

Details of our breast cancer screening programme have been described previously. ${ }^{14}$ In brief, the mammography screening programme in The Netherlands is a nationwide programme that provides free biennial screening mammography for women aged 5075 years. Women are personally invited for screening and the attendance rate is more than $80 \%$. Before each screening examination, the woman completes a short questionnaire with questions about previous recalls and any previous breast surgery or breast malignancy. 
All digital mammograms were obtained with a Lord Selenia FFDM system (Hologic, Danbury, CT, USA), with a $70-\mu \mathrm{m}$ pixel size and a $232 \times 286-\mathrm{mm}$ field of view. The examinations were obtained by specialised screening mammography radiographers and all screening mammograms were double-read in a blinded fashion by a team of 12 certified screening radiologists. Each radiologist evaluated at least 3,000 mammograms yearly.

The screening radiologists classified abnormal mammographic findings into one of the following categories: suspicious mass, suspicious calcifications, suspicious mass in combination with calcifications, architectural distortion, asymmetry or other. Each screen was then classified according to the BIRADS lexicon. ${ }^{15}$ Women with a BI-RADS 1 or 2 were not recalled and women with a BI-RADS 0,4 or 5 were referred to a dedicated breast unit of a hospital for further analysis of their mammographic finding. The BI-RADS category 3 is not applied as short-term follow-up is not available in the Dutch screening programme.

\section{Diagnostic work-up after recall}

Although a total of 20 hospitals were involved in the diagnostic work-up of recalled women, the diagnostic work-up in the majority of women $(97.2 \%, 3,883 / 3,995)$ was performed in seven regional hospitals. All recalled women underwent physical examination by a surgical oncologist or dedicated breast nurse and received additional evaluation at the radiology department. A radiologist first reassessed the screening mammogram of both breasts, which was routinely available and stored in the Picture Archiving and Communication System (PACS) of the hospital. Additional imaging was obtained at the discretion of the radiologist after this review. Full-field digital mammography was available in each of the seven regional hospitals. Breast tomosynthesis was present in two hospitals from the beginning of the inclusion period and became available in three others in 2015. Breast ultrasonography was used for the further characterisation of mammographic abnormalities and palpable breast lesions, for biopsy guidance and for target or second look purposes following breast MRI. Whole-breast ultrasonography was not encouraged, in accordance with the Dutch guidelines. $^{16}$ Breast MRI was also available in each of the seven hospitals and performed if indicated, as defined by the guidelines of the European Society of Breast Imaging $^{17}$ and the Dutch guidelines. Fine-needle aspiration biopsy (FNAB), core-needle biopsy (CNB) and stereotactic biopsy were performed in each of the seven hospitals, whereas MRI guided biopsy procedures were concentrated in the larger hospitals. All recalls were discussed by multidisciplinary teams that consisted of surgical oncologists, radiologists, medical oncologists, radiation oncologists, plastic surgeons, breast nurses and breast radiographers.

During 1-year follow-up, clinical data and data from diagnostic breast imaging, biopsy specimen and surgical procedures were collected of all recalled women. Information on breast density, hormonal replacement therapy and family history of breast cancer were also extracted from the screening records and clinical data. Breast 
cancers were categorised into ductal carcinoma in situ (DCIS) and invasive cancers; lobular carcinoma in situ was considered a non-malignant lesion. The TNM (tumour, nodes and metastases) classification was used for malignant lesions. ${ }^{18}$ For all cancers treated by neoadjuvant therapy (either chemotherapy or anti-hormonal therapy), tumour size was derived from breast imaging (usually MRI) prior to the start of this therapy.

\section{Detection and assessment of contralateral breast lesions}

The methods of detection and subsequent assessment of contralateral breast lesions were derived from the clinical records and clinical radiology reports. Similar to the work-up of screen-detected mammographic abnormalities, biopsy data and surgical reports of contralateral breast lesions were obtained.

Two screening radiologists reviewed the latest screening mammogram of each woman with a cancer diagnosed in the contralateral breast. They classified the cancer as missed, minimal sign or occult at the previous screen according to the European guidelines. $^{19,20}$

\section{Statistical analysis, missing data and bias}

Descriptive statistics were performed using Statistical Package for Social Science 23.0 (SPSS IBM, Chicago, IL, USA). The chi-squared test was used to test for differences between women without and with additional contralateral breast lesions detected following recall. A P value of less than 0.05 was considered to indicate a statistically significant difference. The $P$ values were two sided.

There was no loss to follow-up. In a small number of cases, data were missing (e.g. oestrogen or progesterone receptor status missing due to an insufficient tissue sample). Statistical correction was not performed for the very small numbers of missing data, and data missing was considered to be at random.

Bias was not expected in recall of women who attended screening. In the diagnostic setting, several types of bias may occur, especially observer bias and detection bias, but statistical correction for this type of bias is not feasible in this study. Selection bias was considered highly unlikely as all women analysed in the diagnostic setting were included for statistical analysis.

\section{Results}

\section{Overall screening results}

The mean age of the 130,338 consecutively screened women was 59.6 years $(95 \% \mathrm{Cl}$, 59.4-59.8 years) and $8.2 \%$ reported to have had previous breast surgery. A total of $3,995(3.1 \%)$ were recalled for further assessment. Breast cancer was diagnosed in 905 
recalled women [including $163(18.0 \%)$ ductal carcinoma in situ], resulting in an overall cancer detection rate of 6.9 per 1,000 screens [initial screens, $8.6(118 / 13,762)$; subsequent screens, $6.8(787 / 116,576)]$ and an overall positive predictive value (PPV) of recall of $22.7 \%$ [initial screens, $11.4 \%$ (118/1,037); subsequent screens, $26.6 \%$ $(787 / 2,958)]$. A patient flow chart is provided in Figure 3.2.1.

Figure 3.2.1 Flow chart of study population

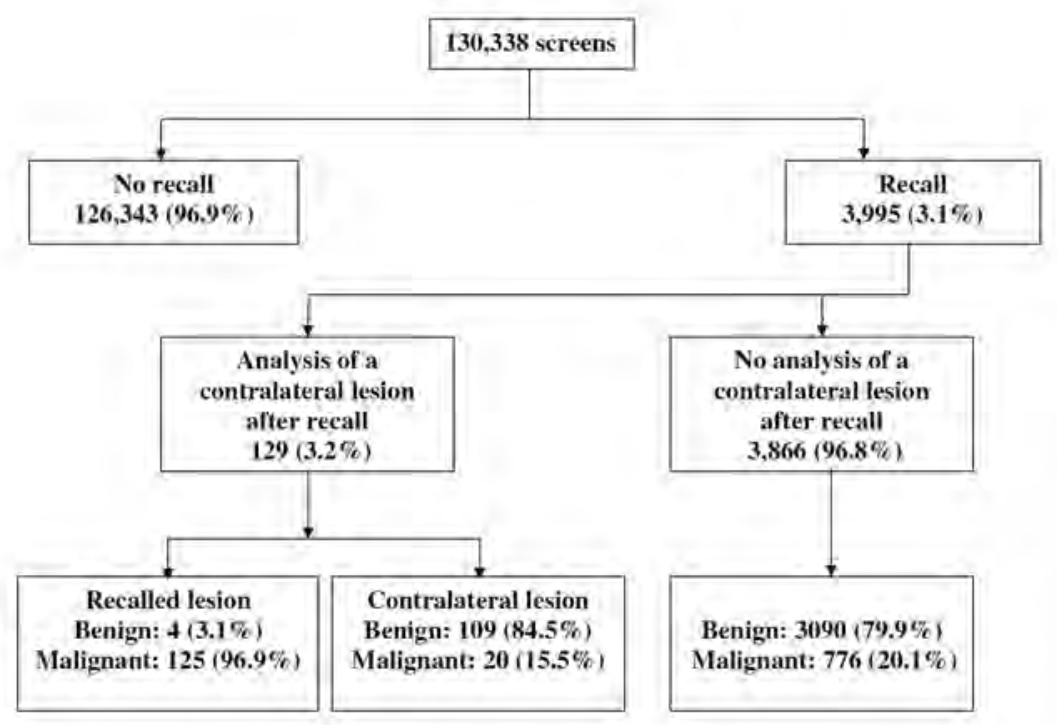

\section{Detection of contralateral lesions}

A total of 129 women, $3.2 \%$ of all recalls, underwent assessment of a contralateral breast abnormality that was detected after recall. Baseline characteristics of recalled women, with or without analysis of a contralateral non-recalled lesion, are shown in Table 3.2.1. These characteristics were similar for both groups except for a higher breast density (III + IV) in women assessed for a contralateral breast lesion when compared to a recalled breast lesion $(38.8 \%$ and $23.8 \%$ respectively, $\mathrm{P}<0.001)$. The contralateral abnormality was detected at clinical mammography and/or breast tomosynthesis in 101 women and at breast MRI in 23 women. In the remaining five women, the contralateral breast was evaluated due to the presence of a suspicious finding at clinical breast examination by the surgical oncologist or breast nurse (palpable breast lesion, four cases; Paget disease of the nipple, one case).

The mammographic characteristics of the contralateral lesions detected at clinical mammography (with/without tomosynthesis) were as follows: suspicious mass, 90; suspicious calcifications, 8; suspicious mass with calcifications, 1; architectural distortion, 2 . The indications for breast MRI in the 23 women with a contralateral lesion detected at MRI had been as follows: problem solving of the recalled lesion, 9 women; 
determination of tumour size and/or multifocality/multicentricity of a screen detected malignancy, 10 women; invasive lobular cancer, 4 women. Breast MRI showed a suspicious mass or non-mass enhancement in 19 women and 4 women, respectively.

Table 3.2.1 Baseline characteristics of recalled women

\begin{tabular}{|c|c|c|c|}
\hline & $\begin{array}{c}\text { No contralateral } \\
\text { lesions } \\
\mathrm{N}=3,866\end{array}$ & $\begin{array}{l}\text { Contralateral Lesions } \\
\qquad \mathrm{N}=129\end{array}$ & P-value \\
\hline Mean age, years $(95 \% \mathrm{Cl})$ & $59.1(58.8-59.4)$ & $58.4(57.1-59.8)$ & 0.35 \\
\hline Screening round, No (\%) & & & 0.13 \\
\hline Initial & $996(25.8)$ & $41(31.8)$ & \\
\hline Subsequent & $2870(74.2)$ & $88(68.2)$ & \\
\hline Breast density, No (\%) & & & $<0.001$ \\
\hline$|+| I(\leq 50 \%)$ & $2946(76.2)$ & $79(61.2)$ & \\
\hline III+IV (>50\%) & $920(23.8)$ & $50(38.8)$ & \\
\hline Previous breast surgery, No (\%) & & & 0.69 \\
\hline Yes & $322(8.3)$ & $12(9.3)$ & \\
\hline No & $3544(91.7)$ & $117(90.7)$ & \\
\hline Hormone replacement therapy, No (\%) & & & 0.11 \\
\hline Yes & $159(4.1)$ & $9(7.0)$ & \\
\hline No & 3707 (95.9) & $120(93.0)$ & \\
\hline Family history of breast cancer, No (\%) & & & 0.61 \\
\hline Yes & $509(13.2)$ & 19 (14.7) & \\
\hline No & $3357(86.8)$ & $110(85.3)$ & \\
\hline
\end{tabular}

\section{Work-up of lesions detected in the contralateral breast}

The majority of women with an abnormality detected in the contralateral breast underwent only breast imaging for the further evaluation of these lesions (Table 3.2.2). A total of 74 women (57.4\%) received breast ultrasonography and the remaining 55 women (42.6\%) underwent one or several percutaneous and/or excisional biopsy procedures to establish a final pathological diagnosis.

Table 3.2.2 Workup of lesions detected in the contralateral breast during recall

$\begin{array}{lc}\text { Breast ultrasonography, No (\%) } & 74(57.4) \\ \text { Breast ultrasonography plus biopsy, No (\%) } & 1(0.8) \\ \text { FNAC } & 36(27.9) \\ \text { CNB } & 10(7.8) \\ \text { SCNB } & 1(0.8) \\ \text { FNAC+CNB } & 2(1.6) \\ \text { CNB+SCNB } & 4(3.1) \\ \text { Percutaneous biopsy + excisional biopsy } & 1(0.8) \\ \text { Excisional biopsy } & \end{array}$

FNAC = fine needle aspiration cytology; CNB = core needle biopsy; SCNB = stereotactic core needle biopsy 


\section{Outcome of lesions detected in the contralateral breast}

Of the 129 lesions detected in the contralateral breast, 20 (15.5\%) proved to be malignant (Table 3.2.3). The majority of the malignancies presented themselves as a suspicious mass at clinical mammography (eight cases, $47.1 \%$ ) or breast MRI (seven cases, $41.2 \%)$. Of the nine contralateral breast cancers detected at mammography, two were visible only at breast tomosynthesis and not at the full-field digital mammogram. Of the seven cancers visible at the latest screening mammogram in retrospect, respectively four were considered to be missed and three showed a minimal sign. As mentioned previously, the remaining three contralateral cancers presented as palpable breast lesions, not primarily detected at breast imaging. In 16 of the 20 women with a breast cancer diagnosed in the contralateral breast, the mammographic abnormality at screening turned out to be malignant as well, resulting in 16 bilateral cancer cases. In the four remaining cases, the contralateral lesion turned out to be malignant, and the mammographic abnormality at screening turned out to be benign. One of these cases is presented in Figure 3.2.2. The majority of benign lesions detected in the contralateral breast comprised cysts $(52.3 \%, 57 / 109)$ and fibroadenomas $(13.8 \%, 15 / 109)$.

Table 3.2.3 Characteristics and outcome of lesions in the contralateral breast, detected at clinical breast imaging following recall

\begin{tabular}{lcc} 
& \multicolumn{2}{c}{ Final outcome } \\
Detection method and radiological abnormality, No (\%) & Benign & Malignant \\
\hline Mammography & & $6(35.3)$ \\
$\quad$ Suspicious mass & $81(65.2)$ & $1(5.9)$ \\
$\quad$ Suspicious calcifications & $8(6.5)$ & 0 \\
$\quad$ Suspicious mass with calcifications & $1(0.8)$ & 0 \\
$\quad$ Architectural distortion & $2(1.6)$ & $2(11.8)$ \\
Tomosynthesis-only & $9(7.3)$ & $7(41.2)$ \\
$\quad$ Suspicious mass & $19(15.3)$ & 1 \\
Breast MRI & $4(5.9)$ \\
$\quad$ Suspicious mass & &
\end{tabular}

\section{Comparison of unilateral, screen-detected abnormalities with those detected in the contralateral, non-recalled breast}

Of the recalled lesions and contralateral, non-recalled lesions, respectively $22.6 \%$ and $15.5 \%$ proved to be malignant ( $P=0.06$; Table 3.2.4). The type of assessment after recall (clinical breast imaging versus biopsy in addition to clinical breast imaging) was similar for both groups. The positive predictive value of biopsy, however, was higher for recalled lesions $(53.1 \%$ vs $36.4 \%, \mathrm{P}=0.01)$. The tumour characteristics and final surgical treatment of unilateral, screen-detected cancers were similar with those of cancers diagnosed in the contralateral, non-recalled breast (Table 3.2.5). 
Figure 3.2.2 A 64-year-old woman was recalled for a BI-RADS 4 mass in the left breast. Percutaneous core biopsy showed invasive ductal carcinoma and MRI was performed to determine the extent of the disease. MRI demonstrated a BIRADS 4 mass in the right breast, which was occult at subsequent target ultrasound. MRI guided vacuum assisted biopsy revealed invasive lobular carcinoma. Breast conserving surgery yielded and invasive ductal carcinoma of $8 \mathrm{~mm}$ in the left breast (sentinel node negative, B\&R II, ER+, PR+, Her2-) and an invasive lobular carcinoma of $6 \mathrm{~mm}$ in the right breast (sentinel node negative, B\&R I, ER+, PR-, Her2-)
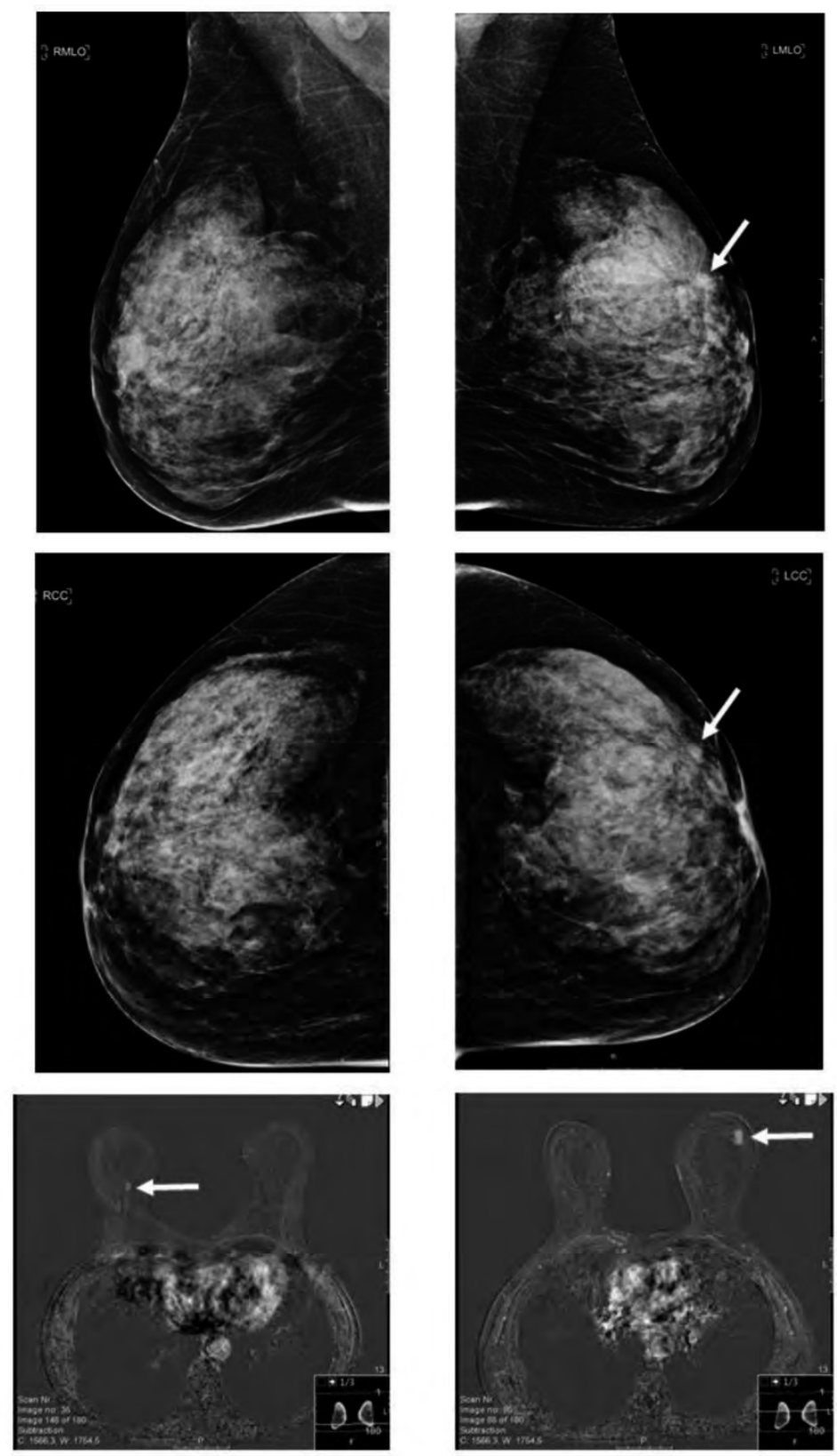
Table 3.2.4 Overall screening outcome of recalled lesions versus lesions analyzed in the contralateral, non-recalled breast

\begin{tabular}{|c|c|c|c|}
\hline & $\begin{array}{l}\text { Recalled } \\
\text { lesions }^{ \pm} \\
\mathrm{N}=3,995\end{array}$ & $\begin{array}{l}\text { Lesions assessed in the } \\
\text { contralateral, non-recalled breast } \\
\qquad N=129\end{array}$ & P-value \\
\hline Screening outcome, No (\%) & & & 0.06 \\
\hline False positive & $3094(77.4)$ & $109(84.5)$ & \\
\hline True positive & $901(22.6)$ & $20(15.5)$ & \\
\hline Type of assessment after recall, No (\%) & & & 0.98 \\
\hline Clinical breast imaging & $2297(57.5)$ & $74(57.4)$ & \\
\hline Clinical breast imaging + biopsy & $1698(42.5)$ & $55(42.6)$ & \\
\hline Positive predictive value of biopsy, $\%$ & 53.1 & 36.4 & 0.01 \\
\hline
\end{tabular}

${ }^{ \pm}$Dominant mammographic abnormality in case of multiple recalled lesions.

Table 3.2.5 Tumour characteristics of unilateral, screen-detected cancers versus cancers diagnosed in the contralateral, non-recalled breast

\begin{tabular}{|c|c|c|c|}
\hline & $\begin{array}{l}\text { Unilateral SDCs } \\
\qquad(n=901)\end{array}$ & $\begin{array}{l}\text { Contralateral cancers } \\
\qquad(n=20)\end{array}$ & P-value \\
\hline Type of cancer, No (\%) & & & 0.4 \\
\hline DCIS & $162(18.0)$ & $2(10.0)$ & \\
\hline Invasive & 739 (82.0) & $18(90.0)$ & \\
\hline Histology of invasive cancers, No (\%) & & & 0.2 \\
\hline Ductal & $581(78.6)$ & $12(66.7)$ & \\
\hline Lobular & $91(12.3)$ & $5(27.8)$ & \\
\hline Ductolobular & $23(3.1)$ & 0 & \\
\hline Other & $44(6.0)$ & $1(5.6)$ & \\
\hline Tumour stage of invasive cancers, No (\%) & & & 0.97 \\
\hline $\mathrm{T} 1$ & $569(77.0)$ & $14(77.8)$ & \\
\hline $\mathrm{T} 2+$ & $169(22.9)$ & $4(22.2)$ & \\
\hline Unknown & $1(0.1)$ & 0 & \\
\hline Lymph node status of invasive cancers, No (\%) & & & 0.7 \\
\hline $\mathrm{N}+$ & $164(22.2)$ & $5(27.8)$ & \\
\hline $\mathrm{N}-$ & $561(76.0)$ & $13(72.2)$ & \\
\hline Unknown & 14 (1.9) & 0 & \\
\hline Bloom \& Richardson grade, No (\%) & & & 0.8 \\
\hline 1 & $329(44.5)$ & $8(44.4)$ & \\
\hline II & $318(43.0)$ & $9(50.0)$ & \\
\hline III & $87(11.8)$ & $1(5.6)$ & \\
\hline Unknown & $5(0.7)$ & 0 & \\
\hline Estrogen receptor status, No (\%) & & & 0.4 \\
\hline Positive & $667(90.3)$ & $18(100)$ & \\
\hline Negative & $69(9.3)$ & 0 & \\
\hline Unknown & $3(0.4)$ & 0 & \\
\hline Progesteron receptor status, No (\%) & & & 0.5 \\
\hline Positive & $520(70.4)$ & $15(83.3)$ & \\
\hline Negative & $216(29.2)$ & $3(16.7)$ & \\
\hline Unknown & $3(0.4)$ & 0 & \\
\hline Her $2 /$ Neu receptor status, No (\%) & & & 0.8 \\
\hline Positive & 72 (9.7) & $1(5.6)$ & \\
\hline Negative & $663(89.7)$ & $17(94.4)$ & \\
\hline Unknown & $4(0.5)$ & 0 & \\
\hline Final surgical treatment, No (\%) & & & 0.9 \\
\hline Breast conserving surgery & $726(80.6)$ & $17(85.0)$ & \\
\hline Mastectomy & $163(18.1)$ & $3(15.0)$ & \\
\hline No surgery & $11(1.2)$ & 0 & \\
\hline Unknown & $1(0.1)$ & 0 & \\
\hline
\end{tabular}

DCIS = Ductal carcinoma in-situ 


\section{Discussion}

In the current study, we found that one out of 30 recalled women underwent analysis of a contralateral, non-recalled breast lesion and about one out of seven of these latter lesions proved to be malignant. The positive predictive value of biopsy of contralateral abnormalities, detected following recall, was lower than that of screen-detected lesions. Contralateral cancers and screen-detected cancers showed similar histological tumour characteristics, tumour stage and surgical treatment.

In retrospect, four out of 20 contralateral malignancies in our series were considered to be missed at the latest screening examination. Setz-Pels et al. ${ }^{6}$ found that the sensitivity of screening mammography for the detection of bilateral breast cancer is less than $20 \%$. The authors concluded that both screening radiologists and clinical radiologists should pay vigorous attention to the contralateral breast in order to detect bilateral malignancies without diagnostic delay. However, they do not provide information on the overall presence and work-up of contralateral, non-recalled breast abnormalities. We found that $3.2 \%$ of recalled women underwent assessment of a contralateral, non-recalled breast abnormality. The majority of these lesions were detected at clinical mammography and/or breast tomosynthesis. Tomosynthesis is increasingly used, both at screening mammography and in a diagnostic setting. The addition of tomosynthesis to digital screening mammography may increase the cancer detection rate. A recent US study reported a decreased recall rate 3 years after the introduction of breast tomosynthesis (from 10.4 to $9.0 \%, \mathrm{P}<0.001$ ), as well as an increased positive predictive value of recall (from 4.4 to $6.7 \%, \mathrm{P}=0.02$ ) and a decreased interval cancer rate. A UK study found an increased specificity when adding tomosynthesis to digital screening mammography (70\% versus $57 \%, \mathrm{P}<0.001)$ and an increased sensitivity for cancer detection in dense breasts ( $93 \%$ versus $86 \%, P=0.03$ ).

Tomosynthesis is not yet implemented in the Dutch screening mammography setting. An increasing number of hospitals have this modality at their disposal. In our series, two of the contralateral breast cancers were visible only at breast tomosynthesis and not at the full-field digital mammogram. It is likely that the intensified use of tomosynthesis in the work-up of recalled women will increase the number of lesions detected in contralateral, non-recalled breasts. ${ }^{7,8}$ A substantial number of contralateral lesions in our study were detected at breast MRI. Again, it can be expected that a further increase in the use of MRI, as well as the introduction of new and promising imaging modalities such as contrast-enhanced spectral mammography ${ }^{22,23}$, will increase the number of breast lesions detected in the contralateral breast of recalled women.

Additional percutaneous biopsy was performed in $43 \%$ of these lesions, with a lower positive predictive value of biopsy (36.4\%) than the one observed for recalled lesions (53.1\%, $\mathrm{P}<0.01)$. Excision biopsy, all with benign final pathology, was performed in five women. In some rare cases, excision biopsy may be necessary to establish a final diagnosis. Also, some women may desire excision of a benign lesion. Nevertheless, one should aim to minimise excision biopsy for diagnostic purposes as it has been shown 
that the sensitivity of screening mammography is lower in women after benign breast surgery. ${ }^{24}$

We found no statistically significant differences in the proportions of malignancies among recalled lesions and contralateral, non-recalled malignant lesions (22.6\% versus $15.5 \%)$. This study could be statistically underpowered to detect a clinically relevant difference due to small patient numbers. The observed trend of a lower cancer risk for contralateral lesions may be due to the fact that screening radiologists have no other tool than the screening mammogram and they have to keep recall percentages within acceptable limits. On the other hand, clinical radiologists are likely to have a lower threshold to exclude malignancy in mammographic lesions for which a woman has not been recalled.

Diagnosis of bilateral breast cancer was established in 16 of 20 women with a contralateralmalignant lesions in the non-recalled breast, and four unilateral cancers were diagnosed in a breast for which a woman had not been recalled. A synchronous diagnosis of bilateral breast cancer may have an impact on the choice of final surgical therapy as these women are more inclined to opt for mastectomy over breastconserving surgery. ${ }^{25}$ The survival of patients with bilateral disease is likely to be worse than that of patients with unilateral disease. ${ }^{26,27}$

Studies have demonstrated an improved cancer detection when MRI or wholebreast ultrasound is added to mammography..$^{12,28,29}$ The increased sensitivity, however, is accompanied by an increase in false-positive findings. Moreover, enhanced use of MRI is correlated with an increase in mastectomy procedures. ${ }^{30-32}$ Therefore, the guidelines of the European Society of Breast Imaging and the Dutch guidelines do not promote the standard use of MRI or whole-breast ultrasound in recalled women or in women with pathologically proven breast cancer. ${ }^{16,17}$ Breast ultrasonography should be used mainly as an evaluation tool of lesions detected at mammography or MRI (target ultrasonography or second look) and for the assessment of palpable breast lesions that are occult at mammography. Indications for breast MRI are screening of high risk women, screening of women with dense breasts, detection of additional ipsilateral and contralateral malignancies in invasive lobular cancer, determination of tumour size in dense breasts and in select cases for problem solving of lesions detected at mammography and/or breast ultrasonography.

Recalled women with or without assessment of a non-recalled, contralateral abnormality showed similar baseline characteristics except of a higher mammographic breast parenchyma density in the first group $(P<0.001)$. This may be explained by the fact that additional imaging modalities used in the clinical setting, as mentioned above, have a higher sensitivity for lesion detection compared to mammography, especially in dense breasts. ${ }^{10,12,29,30,33,34}$

It seems remarkable that three out of 20 detected contralateral malignancies were diagnosed by physical examination only. Contrary to a common perception that imaging obviates the need for physical examination, it remains a mainstay of diagnosis and an integral part of breast awareness and (self-)screening. ${ }^{35}$ 
Tumour characteristics of cancers diagnosed in the contralateral, non-recalled breast were similar to those of unilateral, screen-detected cancers. A majority of cancers in both groups were of the invasive ductal type, stage T1, lymph node negative and grade I or II. A Dutch study found that contralateral breast cancers detected by screening comprised more lobular cancers and showed less nodal involvement than index cancers or unilateral cancers. ${ }^{6}$

Our study has certain strengths and limitations. To our knowledge, we are the first to describe the frequency and characteristics of contralateral breast lesions following recall. The study population is large and recalled women were evaluated in multiple hospitals. Our results, however, may not be representative for other regional or nationwide screening mammography programmes as these programmes may show variations in screening interval (1-3 years), reading strategy (single reading versus double reading), percentage of recalled women and availability of higher-end radiological equipment (e.g. tomosynthesis, stereotactic core-needle biopsy, 3-TMRI) at departments of radiology. Furthermore, as mentioned previously, the number of lesions detected in the contralateral breast may increase in the future as new techniques are increasingly implemented in the setting of clinical breast imaging. Ultimately, a majority of the women with contralateral breast lesions only underwent clinical breast imaging, without additional biopsy. BI-RADS 1 and BI-RADS 2 findings did not receive any radiological follow-up, whereas BI-RADS 3 lesions were either biopsied or received their first radiological follow-up at 6 months. As the follow-up period of all recalled women was 1 year, we cannot rule out that a contralateral lesion with benign follow-up may eventually turn out to be malignant.

In summary, reassessment of the complete screening mammogram, including the contralateral breast after recall, is important as contralateral cancers may be detected. We do not advocate a routine evaluation of the contralateral breast with additional imaging procedures following this reassessment, as this strategy will like not be costeffective. A timely diagnosis of the contralateral breast may be of influence on the choice of surgical therapy of a screen-detected cancer and survival. 


\section{References}

1. Sankatsing VDV, van Ravesteyn NT, Heijnsdijk EAM, et al. The effect of population-based mammography screening in Dutch municipalities on breast cancer mortality: 20 years of follow-up. Int J Cancer 2017;141:671-7.

2. Otto SJ, Fracheboud J, Looman CW, et al. Initiation of population-basedmammography screening in Dutch municipalities and effect on breast-cancer mortality: a systematic review. Lancet 2003;361: 1411-7.

3. Welch HG, Prorok PC, O'Malley AJ, Kramer BS. Breastcancer tumor size, overdiagnosis, and mammography screening effectiveness. N Engl J Med 2016;375:1438-47.

4. Pisano ED, Gatsonis C, Hendrick E, et al. Diagnostic performance of digital versus film mammography for breast-cancer screening. N Engl J Med 2005;353:1773-83.

5. Bernardi D, Macaskill P, Pellegrini M, et al. Breast cancer screening with tomosynthesis (3D mammography) with acquired or synthetic 2D mammography compared with 2D mammography alone (STORM-2): a population-based prospective study. Lancet Oncol 2016;17:1105-13.

6. Setz-Pels W, Duijm LE, Groenewoud JH, et al. Detection of bilateral breast cancer at biennial screening mammography in the Netherlands: a population-based study. Radiology 2011;260:357-63.

7. Waldherr C, Cerny P, Altermatt HJ, et al. Value of one-view breast tomosynthesis versus two-view mammography in diagnostic workup of women with clinical signs and symptoms and in women recalled from screening. AJR Am J Roentgenol 2013;200:226-31.

8. Lei J, Yang P, Zhang L, Wang Y, Yang K. Diagnostic accuracy of digital breast tomosynthesis versus digital mammography for benign and malignant lesions in breasts: a meta-analysis. Eur Radiol 2014;24: 595-602.

9. Gilbert FJ, Tucker L, Gillan MG et al. The TOMMY trial: a comparison of TOMosynthesis with digital MammographY in the UK NHS Breast Screening Programme-a multicentre retrospective reading study comparing the diagnostic performance of digital breast tomosynthesis and digital mammography with digital mammography alone. Health Technol Assess 2015;19:i-xxv 1-136.

10. Lang K, Andersson I, Zackrisson S. Breast cancer detection in digital breast tomosynthesis and digital mammography-a sideby- side review of discrepant cases. Br J Radiol 2014;87:20140080.

11. El Sharouni MA, Postma EL, Menezes GL, et al. High prevalence ofMRI-detected contralateral and ipsilateral malignant findings in patients with invasive ductolobular breast cancer: impact on surgical management. Clin Breast Cancer 2016;16:269-75.

12. Brennan ME, Houssami N, Lord S, et al. Magnetic resonance imaging screening of the contralateral breast in women with newly diagnosed breast cancer: systematic review and meta-analysis of incremental cancer detection and impact on surgical management. J Clin Oncol 2009;27:5640-9.

13. Wang SY, Long JB, Killelea BK, et al. Preoperative breast magnetic resonance imaging and contralateral breast cancer occurrence among older women with breast cancer. J Clin Oncol 2016;34:321-8.

14. Duijm LE, Groenewoud JH, Jansen FH, Fracheboud J, van Beek M, de Koning HJ. Mammography screening in the Netherlands: delay in the diagnosis of breast cancer after breast cancer screening. $\mathrm{Br} \mathrm{J}$ Cancer 2004;91:1795-9.

15. Sickles EA, D’Orsi CJ, Bassett LW, et al. ACR BI-RADS ${ }^{\circledR}$ Mammography. In: ACR BI-RADS ${ }^{\circledR}$ Atlas, Breast Imaging Reporting and Data System. American College of Radiology, Reston 2013.

16. NABON (2012) Richtlijn Mammacarcinoom. Available via http://www.oncoline.nl/mammacarcinoom. Accessed 11 July 2017

17. Mann RM, Balleyguier C, Baltzer PA, et al. Breast MRI: EUSOBI recommendations for women's information. Eur Radiol 2015;25:3669-78.

18. Sobin LH, Gospodarowicz MK, Wittekind C (eds). TNM classification of malignant tumours, 7th edn. Wiley, Chichester 2009.

19. Maes RM, Dronkers DJ, Hendriks JH, Thijssen MA, Nab HW. Do non-specific minimal signs in a biennial mammographic breast cancer screening programme need further diagnostic assessment? $\mathrm{Br} \mathrm{J}$ Radiol 1997;70:34-8. 
20. Perry N, BroedersM, deWolf C, Tornberg S, Holland R, von Karsa L. European guidelines for quality assurance in breast cancer screening and diagnosis. Fourth edition-summary document. Ann Oncol 2008;19:614-22.

21. McDonald ES, Oustimov A, Weinstein SP, Synnestvedt MB, Schnall M, Conant EF. Effectiveness of digital breast tomosynthesis compared with digital mammography: outcomes analysis from 3 years of breast cancer screening. JAMA Oncol 2016;2:737-43.

22. Lobbes MB, Lalji U, Houwers J, et al. Contrast-enhanced spectral mammography in patients referred from the breast cancer screening programme. Eur Radiol 2014;24:1668-76.

23. Lalji UC, Houben IP, Prevos R, et al. Contrast-enhanced spectral mammography in recalls from the Dutch breast cancer screening program: validation of results in a large multireader, multicase study. Eur Radiol 2016;26:4371-9.

24. van Breest Smallenburg V, Duijm LE, Voogd AC, et al. Lower sensitivity of screening mammography after previous benign breast surgery. Int J Cancer 2012;130:122-8.

25. O'Brien JA, Ho A, Wright GP, et al. Breast-conserving surgery in bilateral breast cancer. Ann Surg Oncol 2015;22:3389-96.

26. Heron DE, Komarnicky LT, Hyslop T, Schwartz GF,Mansfield CM. Bilateral breast carcinoma: risk factors and outcomes for patients with synchronous and metachronous disease. Cancer 2000;88:2739-50.

27. Schaapveld M, Visser O, Louwman WJ, et al. The impact of adjuvant therapy on contralateral breast cancer risk and the prognostic significance of contralateral breast cancer: a population based study in the Netherlands. Breast Cancer Res Treat 2008;110:189-97.

28. Iacconi C, Galman L, Zheng J, et al. Multicentric cancer detected at breastMR imaging and not at mammography: important or not? Radiology 2016;279:378-84.

29. Melnikow J, Fenton JJ, Whitlock EP, et al. Supplemental screening for breast cancer in women with dense breasts: a systematic review for the U.S. Preventive Services Task Force. Ann Intern Med 2016;164:268-78.

30. Houssami N, Abraham LA, Onega T, et al. Accuracy of screening mammography in women with a history of lobular carcinoma in situ or atypical hyperplasia of the breast. Breast Cancer Res Treat 2014;145: 765-73.

31. Chandwani S, George PA, Azu M, et al. Role of preoperative magnetic resonance imaging in the surgical management of earlystage breast cancer. Ann Surg Oncol 2014;21:3473-80.

32. Vriens $\mathrm{IJH}$, Keymeulen $\mathrm{K}$, Lobbes $\mathrm{MBI}$, et al. Breast magnetic resonance imaging use in patients undergoing neoadjuvant chemotherapy is associated with less mastectomies in large ductal cancers but not in lobular cancers. Eur J Cancer 2017;81:74-80.

33. Sprague BL, Stout NK, Schechter C, et al. Benefits, harms, and cost-effectiveness of supplemental ultrasonography screening for women with dense breasts. Ann Intern Med 2015;162:157-66.

34. Lee $\mathrm{Cl}$, Cevik M, Alagoz O, et al. Comparative effectiveness of combined digital mammography and tomosynthesis screening for women with dense breasts. Radiology 2015;274:772-80.

35. Provencher L, Hogue JC, Desbiens C, et al. Is clinical breast examination important for breast cancer detection? Curr Oncol 2016;23:e332-9. 


\section{Chapter 4}

Delayed diagnosis 


\section{Chapter 4.1}

Trends in delayed breast cancer diagnosis after recall at screening mammography

Lameijer JRC, Voogd AC, Broeders MJM, Pijnappel RM, Setz-Pels W, Strobbe LJ, Jansen FH, Tjan-Heijnen VCG, Duijm LEM

Submitted to the European Journal of Radiology (September 2020) 


\section{Abstract}

\section{Objectives}

To determine the extent and characteristics of delay in breast cancer diagnosis in women recalled at screening mammography.

Methods

We included a consecutive series of 817,656 screens of women who received biennial screening mammography in a Dutch breast cancer screening region between 1997 and 2016. During at least three-year follow-up, radiological reports and biopsy reports were collected of all recalled women. The inclusion period was divided into four cohorts of four years each. We determined the number of screen-detected cancers and their characteristics, and assessed the proportion of recalled women who experienced a diagnostic delay of at least 4 months in breast cancer confirmation.

\section{Results}

The proportion of recalled women who experienced diagnostic delay decreased from $7.5 \%$ in $1997-2001(47 / 623)$ to $3.0 \%$ in $2012-2016(67 / 2223, P<0.001)$. The proportion of women with a delay of at least two years increased from $27.7 \%$ (13/47) in 1997-2001 to $75.7 \%(53 / 70)$ in 2012$2016(P<0.001)$.

Cancers with a diagnostic delay $>2$ years were more frequently invasive $(P=0.009)$ than cancers with a diagnostic delay of 4-24 months. The most frequent cause of diagnostic delays was incorrect radiological classifications by clinical radiologists ( $55.2 \%$ overall) after recall.

\section{Conclusions}

The proportion of recalled women with a delayed breast cancer diagnosis has more than halved during two decades of screening mammography. Delays in breast cancer diagnosis are characterized by longer delay intervals, although the proportion of these delays among all screen-detected cancers has not increased. Preventing longer delays in breast cancer confirmation may help improve breast cancer survival. 


\section{Introduction}

In many countries breast cancer is one of the most commonly diagnosed malignancies in women. ${ }^{1}$ Screening mammography programmes have been established with the aim to reduce breast cancer morbidity and mortality through early detection and treatment of the disease. In combination with improved therapy, this early detection has resulted in a significant reduction of breast cancer mortality over the past decades. ${ }^{2,3}$ After recall for a suspicious abnormality at screening mammography, a timely confirmation of a breast malignancy is of utmost importance in order to prevent a treatment delay. A diagnostic delay after recall may cause the tumour to be diagnosed in a more advanced stage, which could have a negative impact on breast cancer survival. ${ }^{4}$

Several studies have shown that up to $5 \%$ of recalled women experience a delay in the confirmation of their breast cancer. ${ }^{5,6}$ Most of these studies have been performed in the era of screen-film mammography (SFM). Currently, full-field digital mammography (FFDM) has replaced screen-film mammography in both the screening setting and in the setting of clinical mammography in most countries. Also, the management of breast disease has changed considerably over the years, with the introduction of new diagnostic modalities (digital breast tomosynthesis, 3D ultrasonography, spectral mammography, advanced magnetic resonance techniques), replacement of fine needle aspiration cytology by core biopsy, implementation of multidisciplinary meetings, and a further specialization of health care professionals in breast diseases. $^{6}$ For these reasons, one may assume that the proportion of women who face a delay in their breast cancer diagnosis after recall at screening mammography has decreased over time. At the same time, a reduction in length of delay is expected due to increased diagnostic accuracy preventing false positive recall and repeated recall, while also reducing the need for radiological follow-up in cases of equivocal findings at mammography or ultrasound. We therefore determined trends in the frequency of delayed breast cancer confirmation and lengths of delays in women recalled at screening mammography. We also assessed the causes of these delays and investigated tumour characteristics of these breast cancers with short and longer delay intervals in an observational follow-up study spanning two decades of screening mammography conducted in the south of the Netherlands.

\section{Materials and methods}

\section{Study population and screening procedure}

We included a consecutive series of 817,656 screens (SFM: 49,318 initial screens and 32,8637 subsequent screens; FFDM: 48,223 initial screens and 39,1478 subsequent screens) of women aged 50-75 years who received biennial screening mammography in a southern region of the Netherlands between January 1, 1997 and December 31, 2016 
(Table 1). Women participating in the screening programme can indicate that they do not give permission to use their data for quality assessment and scientific purposes. Three recalled women did not give this permission and they were excluded from analysis. Ethical approval was waived by the Dutch Central Committee on Research involving Human Subjects (CCMO).

All screening mammograms were obtained by certified radiographers at one of four dedicated screening units (one fixed unit and three mobile units). Screen-film mammography was replaced by full-field digital mammography in $2009 / 2010$. The examinations were routinely and independently double read by a team of 17 certified screening radiologists. The radiologists classified the mammographic abnormality in case of recall (suspicious mass, suspicious calcifications, suspicious mass in combination with calcifications, asymmetry, architectural distortion or other suspicious abnormality). Recalled women were referred by their general practitioner to a hospital breast unit for further analysis of the mammographic abnormality. In case of a false positive recall (i.e., no breast cancer at workup) women were encouraged to return to the screening programme.

\section{Workup of recalled women and follow-up}

A total of 36 hospitals were involved in the workup of recalled women, of which the majority (99.4\%, 18476/18592) was analyzed in eight hospitals centrally located in our screening region. Recalled women first underwent physical examination by a surgical oncologist or dedicated breast nurse at the surgical department. The type of diagnostic workup was at the discretion of the clinical radiologist and could include additional mammographic views, breast tomosynthesis, breast ultrasonography (including 3D ultrasonography) and/or magnetic resonance imaging of the breasts. Clinical breast imaging was followed by percutaneous breast biopsy if indicated, and included fine needle aspiration biopsy (FNAB), ultrasound guided core needle biopsy (CNB, 14-18 Gauge) and/or vacuum assisted core needle biopsy (9-11 Gauge, either stereotactic guided or MRI guided). The use of surgical biopsy for diagnostic purposes sharply declined over the years and is currently reserved for those cases where malignancy has not been ruled out by percutaneous biopsy. ${ }^{7}$ Recalled women were discussed at multidisciplinary meetings that were gradually implemented in the hospitals.

During a minimum of three-year follow-up (until January 1, 2020), one of the screening radiologists (LD) and several radiology residents collected clinical data and data from diagnostic breast imaging, biopsy procedures and surgical interventions of all recalled women. The radiologist entered these data in a database which had been constructed for quality assurance of the regional screening programme. Breast cancers were categorized into ductal carcinoma in-situ (DCIS) and invasive cancers. Lobular carcinoma in-situ was considered a non-malignant lesion. The TNM classification $\left(6^{\text {th }}\right.$ and $7^{\text {th }}$ edition) was used for malignant lesions. ${ }^{8,9}$ For women with a bilateral malignancy, the cancer with the highest TNM was retained and multiple foci of cancer in one breast were counted as one cancer. 


\section{Delayed breast cancer diagnosis}

In the current study, we defined an interval of at least four months between the recall at screening mammography and the confirmation of breast cancer as a diagnostic delay. The 20-year inclusion period was divided into four cohorts of five years each: 1997-2001, 2002-2006, 2007-2011 and 2012-2016. For each cohort, we determined the number of and characteristics of detected cancers at recall, and assessed the proportion of recalled women who experienced a diagnostic delay of at least 4 months in breast cancer confirmation. The database for quality assurance was used to determine the interval between recall and time of diagnosis of breast cancer to determine whether an interval of at least four months between recall and diagnosis had occurred. The database for quality assurance was also used to identify women who had been recalled twice for the same mammographic abnormality between January 1997 and January 2017. A team of three radiologists (WS, FJ, LD) then determined whether the second recall concerned the same mammographic abnormality for which a woman had been recalled previously. Each case was independently assessed by two radiologists and discrepant observations between them were solved by consensus.

To determine whether an incorrect radiological assessment after recall had resulted in a diagnostic delay, the radiologists also independently and retrospectively reviewed the screening mammograms and diagnostic breast imaging and intervention reports of all women with a diagnostic delay. Each reviewer classified the lesions using the Breast Imaging Reporting and Data System (BI-RADS). ${ }^{10,11}$

Finally, the radiologists reviewed the clinical data (including biopsy reports, discharge records, outcome of multi-disciplinary team meetings) to identify other causes than a false negative radiological assessment for a delayed breast cancer diagnosis, including false-negative biopsy results or patient related delays.

Outcome parameters were calculated for women with a delay of respectively 4-24 months or a delay of at least 24 months between recall and breast cancer diagnosis.

\section{Statistical analysis}

Descriptive statistics were performed using Statistical Package for Social Science 23.0 (SPSS Inc., IBM, Chicago, IL). The chi-square test was used to test for differences between women with a diagnostic delay of 4-24 months and women with a diagnostic delay of at least 24 months with respect to tumour characteristics i.e. histology, stage, nodal status, receptor status, and type of final surgical treatment. The proportions of women with diagnostic delays (4-24 months versus $\geq 24$ months) in the four time periods (1997-2001, 2002-2006, 2007-2011, and 2012-2016) were tested using the chisquare test. Each delay was categorized according to causes of delayed diagnosis over the time periods as mentioned above, and differences in proportions were tested using the chi-square test. 
Her2/Neu-receptor status was routinely determined from 2008 onward and thus not available for the earlier inclusion periods. Missing data were excluded in the Chisquare test analyses when comparing tumour characteristics for the two delay cohorts.

A P-value of less than 0.05 was considered to indicate a statistically significant difference. P-values were two-sided.

\section{Results}

\section{Overall screening outcome}

A total of 18,592 women were recalled at screening mammography (recall rate: $2.3 \%$ $(18592 / 817656)$ ), of whom4932 proved to have breast cancer at workup (6.0 cancers detected per 1000 screens (4760/817656), positive predictive value of recall: $25.6 \%$ (4760/18592)). The 4932 screen detected cancers comprised 947 DCIS (19.2\%) and 3985 invasive cancers (80.8\%).

\section{Women with a delayed diagnosis of breast cancer}

A delay in breast cancer diagnosis of at least four months was present in $4.8 \%$ of recalled women with breast cancer at workup (239/4932). This percentage gradually decreased from $7.5 \%$ in $1997-2001(47 / 623)$ to $3.1 \%$ in $2012-2016(70 / 2223, P<0.001$, Table 4.1.1).

Table 4.1.1 Proportions of women with a diagnostic delay in breast cancer diagnosis after recall at screening mammography

\begin{tabular}{lccccc} 
& \multicolumn{4}{c}{ Year of screening } & Total \\
& $1997-2001$ & $2002-2006$ & $2007-2011$ & $2012-2016$ & \\
Screens, $N$ & 128081 & 155398 & 209523 & 324654 & 817616 \\
Recalls, $N$ & 1324 & 2123 & 4972 & 10173 & 18592 \\
Screen detected cancers, $N$ & 623 & 798 & 1288 & 2223 & 4932 \\
Cancers with a diagnostic delay, $N(\%)$ & $47(7.5)$ & $53(6.6)$ & $69(5.4)$ & $70(3.1)$ & 239 \\
$\quad$ Delay 4-24 months & $34(72.3)$ & $34(64.2)$ & $21(30.4)$ & $17(24.3)$ & $106(44.4)$ \\
$\quad$ Delay $\geq 24$ months & $13(27.7)$ & $19(35.8)$ & $48(69.6)$ & $53(75.7)$ & $133(55.6)$
\end{tabular}

Among all delays, the proportion of women with a delay of at least 24 months increased from $27.7 \%(13 / 47)$ in $1997-2001$ to $75.7 \%(53 / 70)$ in $2012-2016(P<0.001)$. Figure 4.1.1 shows the number of delayed cancer diagnosis per 1000 screen-detected cancers. A decline in the rate of cancers with a 4-24 months diagnostic delay is seen over the years, whereas the rate of cancers confirmed at least 24 months after recall remained stable (except for the cohort screened 2007-2011). 
Figure 4.4.1 Time trend in number of delays per 1000 screen detected cancers
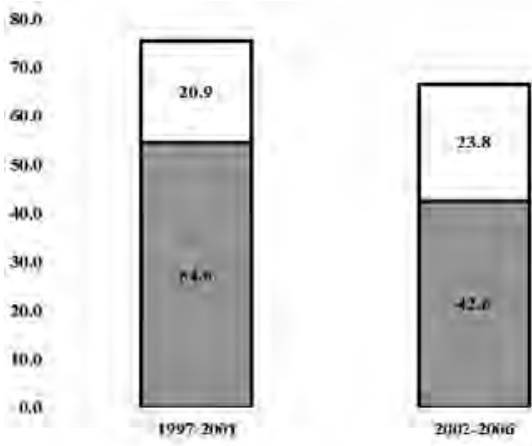

aDelisy +24 maethe DDelay $\geq 24$ manths
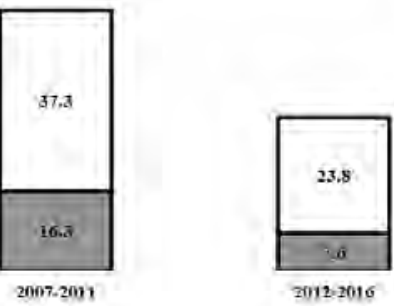

Year of screening

In 93.2\% (124/133) of the women with a delay of at least 24 months, the breast cancer was finally confirmed after a second recall for the same lesion for which she had been recalled previously. This second recall took place at the subsequent screen, two years after the initial recall, in $59.7 \%$ of the women (74/124) and at a later subsequent screening round in $40.3 \%$ (50/124). Six women, who preferred opportunistic screening rather than returning to the screening programme, proved to have breast cancer at one of the subsequent opportunistic screening mammograms. Two women with a palpable breast lump consulted a surgical oncologist more than two years after their false positive recall, with breast cancer confirmed at the site of the previous abnormality at screening mammography. One diagnostic delay was due to a patient's refusal to undergo biopsy. Cancers with a diagnostic delay of at least 2 years were more frequently invasive $(P=0.009)$, but showed a similar Bloom \& Richardson grading $(P=0.16)$ compared to cancers with a diagnostic delay of 4-24 months (Table 4.1.2). Tumour size and lymph node status were comparable for both groups, as well as the type of surgical treatment (breast conserving surgery versus mastectomy).

\section{Causes of diagnostic delays}

In all 4 cohorts an incorrect radiological classification given by the clinical radiologists after recall was the most frequently encountered cause of a diagnostic delay (Table 4.1.3). These women received a BI-RADS 1 (no abnormalities) or BI-RADS 2 (benign) classification at workup, without additional biopsy. The reviewing study radiologists (LD, WS, FJ), however, considered the lesions suspicious or malignant in retrospect, with the necessity of subsequent biopsy. Examples of erroneous BI-RADS classifications are shown in Figure 4.1.2 and Figure 4.1.3. 
Table 4.1.2 Tumour characteristics and surgical therapy of breast cancers with a diagnostic delay of 4-24 months versus a diagnostic delay of at least 2 years

\begin{tabular}{|c|c|c|c|}
\hline & $\begin{array}{c}\text { Delay in breast } \\
\text { cancer diagnosis } \\
\text { 4-24 months }(N=106)\end{array}$ & $\begin{array}{c}\text { Delay in breast } \\
\text { cancer diagnosis } \\
\geq 2 \text { years }(N=133)\end{array}$ & $P$ \\
\hline Type of cancer, $\underline{N}(\%)$ & & & 0.007 \\
\hline DCIS & $26(24.5)$ & $15(11.5)$ & \\
\hline Invasive & $80(75.5)$ & $118(88.5)$ & \\
\hline Histology of invasive cancers, $N(\%)$ & & & 0.92 \\
\hline Ductal & $58(72.5)$ & $88(74.6)$ & \\
\hline Lobular & $11(13.8)$ & $14(11.8)$ & \\
\hline Ductolobular & $1(1.3)$ & $1(0.8)$ & \\
\hline Other & $8(10.0)$ & $15(12.8)$ & \\
\hline Unknown & $2(2.5)$ & 0 & \\
\hline Tumour stage of invasive cancers, $N(\%)$ & & & 0.40 \\
\hline $\mathrm{T} 1 \mathrm{a}+\mathrm{b}$ & $33(41.3)$ & $39(33.1)$ & \\
\hline T1c & $33(41.3)$ & $56(47.5)$ & \\
\hline $\mathrm{T} 2+$ & $12(15.0)$ & $23(19.4)$ & \\
\hline Unknown & $2(2.5)$ & 0 & \\
\hline Lymph node status of invasive cancers, $N(\%)$ & & & 0.08 \\
\hline $\mathrm{N}+$ & $20(25.0)$ & $18(15.3)$ & \\
\hline $\mathrm{N}-$ & $57(71.3)$ & $97(82.2)$ & \\
\hline Unknown & $3(3.8)$ & $3(2.5)$ & \\
\hline Bloom \& Richardson grade, $N(\%)$ & & & 0.16 \\
\hline 1 & $31(38.8)$ & $45(38.1)$ & \\
\hline II & $22(27.6)$ & $56(47.5)$ & \\
\hline III & $12(15.0)$ & $15(12.8)$ & \\
\hline Unknown & $15(18.8)$ & $2(1.6)$ & \\
\hline Estrogen receptor status, No (\%) & & & 0.90 \\
\hline Positive & $66(82.5)$ & $105(88.9)$ & \\
\hline Negative & $8(10.0)$ & $12(10.3)$ & \\
\hline Unknown & $6(7.5)$ & $1(0.8)$ & \\
\hline Progesterone receptor status, No (\%) & & & 0.08 \\
\hline Positive & $58(72.5)$ & $77(65.3)$ & \\
\hline Negative & $16(20.0)$ & $39(33.1)$ & \\
\hline Unknown & $6(7.5)$ & $2(1.6)$ & \\
\hline Her2/Neu receptor status, No (\%) & & & $0.020^{*}$ \\
\hline Positive & $9(11.3)$ & $9(7.6)$ & \\
\hline Negative & $31(38.8)$ & $98(83.1)$ & \\
\hline Unknown & $40(50.0)$ & $11(9.3)$ & \\
\hline Final surgical treatment, No (\%) & & & 0.13 \\
\hline Breast conserving surgery & $74(69.8)$ & $106(79.7)$ & \\
\hline Mastectomy & $27(25.5)$ & $25(18.6)$ & \\
\hline No surgery & $5(4.7)$ & $2(1.5)$ & \\
\hline
\end{tabular}

DCIS = Ductal carcinoma in-situ. *In earlier cohorts (until 2008), Her2/Neu receptor status was not routinely reported, yielding a large number of missing data. Missing numbers were not incorporated in the Chi-square test. 
Figure 4.1.2 Patient example of a 12-month delay due to erroneous BI-RADS classification by the clinical radiologist. Two-view screening mammograms ( $A$ and $C$, cranio-caudal $(C C)$ view, and $B$ and $D$, medio-lateral oblique (MLO) view) of the right breast at recall in 2013. Images A and B show a lesion in the retroareolar region of the breast (white arrows), classified as BI-RADS 4 by the screening radiologists. Digital breast tomosynthesis and ultrasound were performed, and the lesion was classified as BI-RADS 2 (benign lesion). No biopsy was performed. Twelve months later the patient reported to the surgical department with a growing lump in the right breast. Images C and D in 2014 show increased density of the retroareolar lesion in the right breast (white arrows), with possible satellite lesions (white arrowheads). Targeted ultrasound showed an irregular, hypoechogenic lesion with satellite lesions, which was classified as BI-RADS 5. Ultrasound guided true-cut biopsy was performed which revealed an invasive ductal carcinoma with axillary metastases (TNM: T3N2M0). The patient was treated with neo-adjuvant chemotherapy, mastectomy, radiotherapy, and hormonal therapy.

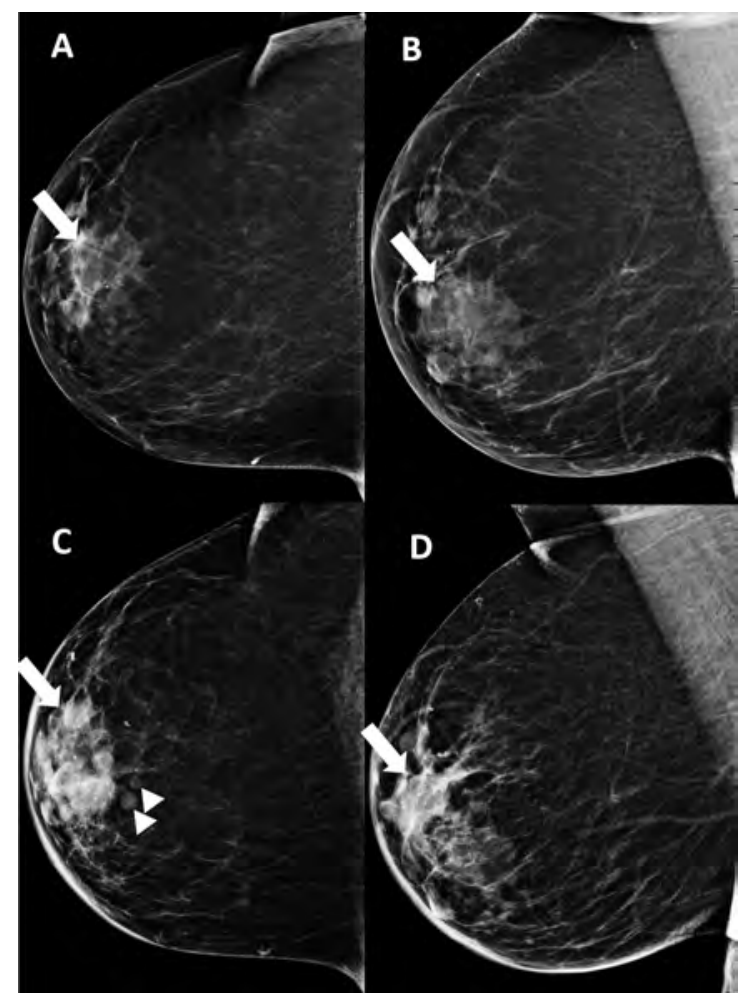

Among all delays, the proportion of women with an erroneous radiological classification increased from $42.6 \%$ in $1997 / 2001$ (20/47) to $72.9 \%$ in $2012-2016$ (51/70, $\mathrm{P}=0.001$ ) and this increase was most prominent in women with diagnostic delays of at least 24 months (Figure 4.1.4). False negative percutaneous biopsy was another major cause of a diagnostic delay and comprised $15.7 \%$ (2012-2016) to 30.2\% (2002-2006) of all delays in the screened cohorts. The proportion of women who experienced a delayed breast cancer confirmation as a result of radiological surveillance of a probably benign lesion at radiology significantly decreased over the years, from $21.3 \%$ (10/47) in 1997 2001 to $5.7 \%(4 / 70)$ in 2012-2016 ( $P=0.01)$. 
Figure 4.1.3 Patient example of a 24-month delay due to erroneous BI-RADS classification by the clinical radiologist. Two-view screening mammograms ( $A$ and $C$, cranio-caudal $(C C)$ view, and $B$ and $D$, medio-lateral oblique (MLO) view) of the right breast at recall in 2015 show a lesion in the upper lateral quadrant of the right breast. Images A and B show the lesion in 2015 (white arrows), classified as BI-RADS 4 by the screening radiologists. Digital breast tomosynthesis and ultrasound were performed, and the lesion was classified as BI-RADS 2 (benign lesion). No biopsy was performed. At repeated recall in 2017 for the same lesion (again characterized as BIRADS 4 by the screening radiologists), increased density of the lesion was seen, with an increase in size (images $C$ and D). Targeted ultrasound showed a spiculated, irregular and hypoechogenic lesion, which was classified as BI-RADS 5 . Ultrasound guided true-cut biopsy was performed which revealed an invasive ductal carcinoma. There were no axillary metastases (TNM: T1bNO). The patient was treated with breast conserving surgery and adjuvant radiotherapy.

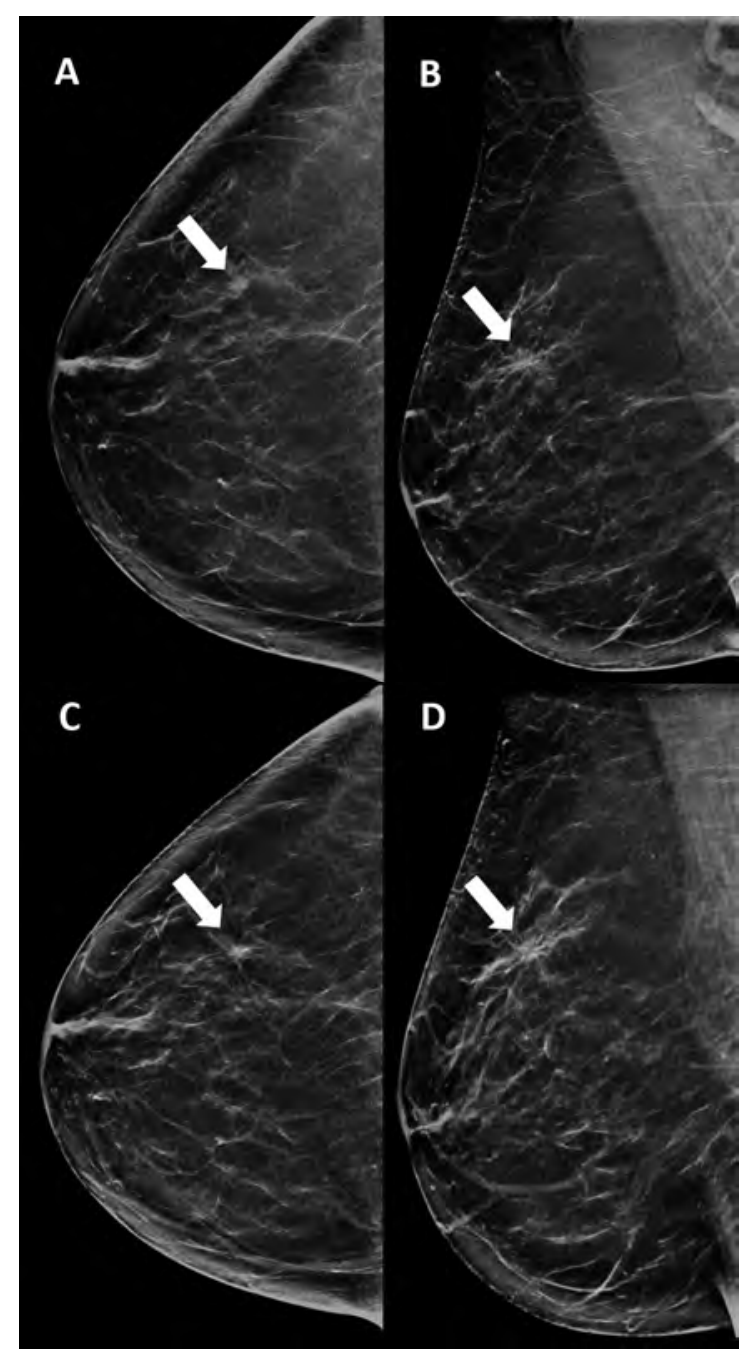


Figure 4.1.4 Trends in causes of delayed breast cancer diagnosis per 1000 screen detected cancers

0

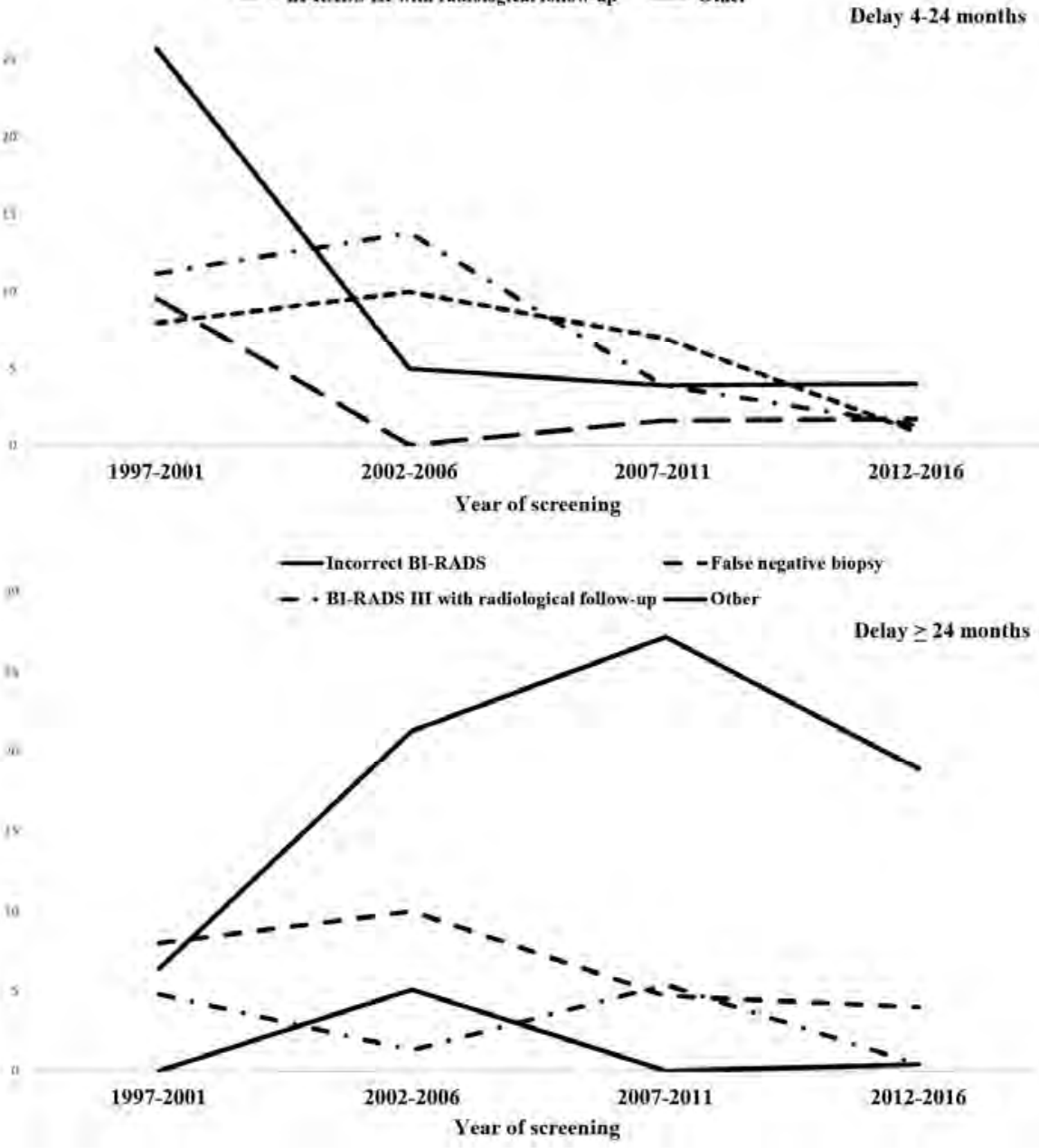


Table 4.1.3 Causes of diagnostic delay in breast cancer diagnosis following recall at screening mammography

\begin{tabular}{|c|c|c|c|c|c|}
\hline \multirow[t]{2}{*}{ Cause of diagnostic delay, $N(\%)$} & \multicolumn{4}{|c|}{ Year of screening } & \multirow[t]{2}{*}{ Total } \\
\hline & 1997-2001 & $2002-2006$ & 2007-2011 & $2012-2016$ & \\
\hline Incorrect radiological classification & $20(42.6)$ & $21(39.6)$ & $40(58.0)$ & $51(72.9)$ & $132(55.2)$ \\
\hline False negative percutaneous biopsy & $10(21.3)$ & $16(30.2)$ & $15(21.7)$ & $11(15.7)$ & $52(21.8)$ \\
\hline $\begin{array}{l}\text { Probably benign lesion at radiology (BI-RADS 3) } \\
\text { followed by radiological surveillance }\end{array}$ & $10(21.3)$ & $12(22.6)$ & $12(17.4)$ & $4(5.7)$ & 38 (15.9) \\
\hline $\begin{array}{l}\text { False negative surgical (excision) biopsy } \\
\text { Other: }\end{array}$ & $4(8.5)$ & 1 (1.9) & $0(0)$ & $2(2.9)$ & $7(2.9)$ \\
\hline $\begin{array}{l}\text { Surgical oncologist does not follow radiologist's } \\
\text { advice of (repeated) lesion biopsy }\end{array}$ & $1(2.1)$ & $1(1.9)$ & $1(1.4)$ & $0(0)$ & $3(1.3)$ \\
\hline $\begin{array}{l}\text { Surgical oncologist does not follow pathologist's } \\
\text { advice of lesion excision }\end{array}$ & $1(2.1)$ & $1(1.9)$ & $0(0)$ & $0(0)$ & $2(0.8)$ \\
\hline $\begin{array}{l}\text { Surveillance of a radiologically suspicious lesion } \\
\text { which is inaccessible to percutaneous biopsy }\end{array}$ & $0(0)$ & $0(0)$ & $1(1.4)$ & $1(1.4)$ & $2(0.8)$ \\
\hline Patient refuses biopsy & $1(2.1)$ & $1(1.9)$ & $0(0)$ & $1(1.4)$ & $3(1.3)$ \\
\hline Total & 47 & 53 & 69 & 70 & 239 \\
\hline
\end{tabular}

\section{Discussion}

In the current study we found that the proportion of recalled women with a delay of at least four months in their confirmation of breast cancer more than halved during two decades of screening mammography. This reduction was mainly due to the sharp decline in the number of women with a delay of 4-24 months in their breast cancer diagnosis. At the same time, the number of women who experienced a delay of at least 24 months in their breast cancer diagnosis, per 1000 screen-detected cancers, has remained stable over the years. Tumours that were diagnosed after a delay of at least 24 months were more often invasive and less frequently Her2/Neu positive compared to breast cancers that were confirmed after a delay of 4-24 months, but other tumour histology characteristics, tumour size and nodal status were comparable for both groups. Frequent causes of delay included incorrect radiological classification at recall and false negative percutaneous biopsy.

Several studies have shown that longer diagnostic and therapeutic intervals may have a detrimental effect on breast cancer survival. ${ }^{12-14}$ Therefore, a timely diagnosis of breast cancer not only requires the recognition of suspicious mammographic findings at screening, but it also necessitates a prompt confirmation of the malignancy after recall. Over the years, we observed a significantly reduced probability of a delayed breast cancer confirmation after recall. The last decade has seen substantial changes in the diagnostic management of (a)symptomatic breast disease, with the introduction of multi-disciplinary meetings and new imaging modalities (e.g., digital breast tomosynthesis), an intensified use of advanced imaging modalities (breast MRI), a further replacement of fine needle biopsy by (vacuum assisted) large core biopsy, and an increased sub-specialization of physicians in breast care. ${ }^{6,15,16}$ These developments 
have likely resulted in the decline of women facing a delayed breast cancer confirmation. However, this improvement was mainly present for diagnostic delays of less than 24 months but not for longer delays. All Dutch screening radiologists are trained and certified by the Dutch Expert Centre for Screening (LRCB). This centre increasingly emphasizes a timely confirmation of the benign or malignant nature of a recalled mammographic abnormality. ${ }^{17,18}$ The LRCB therefore discourages abnormalities to be classified as probably benign at workup, if possible, as these lesions require follow-up for 6-24 months. Although this policy shortens the period of uncertainty among recalled women and helps to reduce short delays after recall, it may at the same time result in longer diagnostic delays, i.e. when radiological re-evaluation of a probably benign breast lesion at follow-up would have resulted in additional biopsy rather than a second recall for the same mammographic abnormality at a later screening round. The shift from shorter to longer diagnostic delays is related to the finding that the most frequent cause of a diagnostic delay in this study was an incorrect radiological classification at workup, with a proportional increase of these delays over the years. At the same time, the probability to experience a delayed breast cancer confirmation as a result of radiological surveillance of a probably benign lesion decreased. Diagnostic improvements at screening mammography result in an increased lesion detection, reflected by increased recall rates and cancer detection as shown previously. ${ }^{19-22}$ Subtle lesions may have a larger potential to receive an incorrect workup after recall and may also lead to equivocal findings necessitating additional follow-up. It is subject of debate whether a delayed diagnosis of small lesions significantly influences prognosis and further studies are needed to address this topic. $^{4,16}$

The breast cancers in the two groups of diagnostic delays showed comparable tumour characteristics except of fewer DCIS and more Her2/Neu negative invasive cancers among women with a longer delay. DCIS is usually detected through the presence of calcifications at mammography. The availability of stereotactic core needle biopsy as an alternative to surgical biopsy has gradually resulted in a routine biopsy of BI-RADS 3 calcifications rather than follow-up, which may explain the low proportion of DCIS among women experiencing a long delay in their breast cancer confirmation.

To improve the communication between screening radiologists and clinicians, the BI-RADS classification for mammographic abnormalities was implemented in the Dutch screening mammography programme in 2009 , along with the replacement of screenfilm by digital screening mammography. ${ }^{18,23}$ The BI-RADS classification system increases inter-observer agreement between breast radiologists and helps to guide the diagnostic pathways at recall. A further reduction in the number of women with a delayed breast cancer confirmation may be obtained by restricting the workup to dedicated breast radiologists in accredited hospitals. The Dutch screening programme differs from those in several other European countries and the USA as screening and recall are not integrated. Hospitals handling recalled women are separated from the screening units and quality control of the workup is not mandatory. ${ }^{18,24}$ The Dutch screening 
programme, however, is subject to quality assurance, consistent with recommendations of the European Society of Breast Imaging (EUSOBI) and International Agency for Research on Cancer (IARC). ${ }^{24-27}$ The introduction of quality assurance and assessment sessions may prove beneficial for hospitals handling recall, reducing the number of recalled women facing a delayed cancer diagnosis.

Our study has several strengths and limitations. To our knowledge, this is the first study focusing on time trends in delayed breast cancer confirmation after recall for a screen detected mammographic abnormality. A large series of consecutive screening mammograms with almost complete follow-up was analyzed during two decades of screening mammography. On the other hand, the relatively short follow-up period of at least three years may not have enabled us to identify all cases with a longer delay in the most recently screened cohort.

Also, screening mammography programmes are continuously subject to changes and the design of these programmes differs among countries. Assessment after recall may be performed in hospitals that are not linked to the screening programme, like in the Netherlands, or may be embedded in the screening procedure itself. Finally, missing data of the Her2/Neu-receptor status in patients with a 4-24 months of delay hampered statistical analysis.

We conclude that the proportion of recalled women with a delay in their confirmation of breast cancer has significantly decreased during two decades of screening mammography, but these delays are now characterized by longer delay intervals. Quality assurance should not only cover the screening mammography programmes, but it should also focus on the hospitals handling the workup of recalled women, in order to prevent a worse breast cancer survival due to a delayed breast cancer confirmation. 


\section{References}

1 Global Cancer Observatory 2019. International Agency for Research on Cancer. Available via http://gco.iarc.fr. Accessed 15th of November 2019.

2 Myers ER, Moorman P, Gierisch JM, et al. Benefits and Harms of Breast Cancer Screening: A Systematic Review. JAMA 2015;314:1615-34.

3 Sankatsing VDV, van Ravesteyn NT, Heijnsdijk EAM, et al. The effect of population-based mammography screening in Dutch municipalities on breast cancer mortality: 20 years of follow-up. Int J Cancer 2017;141:671-7.

4 Broeders MJ, Onland-Moret NC, Rijken HJ, Hendriks JH, Verbeek AL, Holland R. Use of previous screening mammograms to identify features indicating cases that would have a possible gain in prognosis following earlier detection. Eur J Cancer 2003;39:1770-5.

5 Ciatto S, Houssami N, Ambrogetti D, Bonardi R, Collini G, Del Turco MR. Minority report - false negative breast assessment in women recalled for suspicious screening mammography: imaging and pathological features, and associated delay in diagnosis. Breast Cancer Res Treat 2007;105:37-43.

6 Duijm LE, Groenewoud JH, de Koning HJ, et al. Delayed diagnosis of breast cancer in women recalled for suspicious screening mammography. Eur J Cancer 2009;45:774-81.

7 Luiten JD, Voogd AC, Tjan-Heijnen VCG, Wesseling J, Luiten EJT, Duijm LEM. Utility of diagnostic breast excision biopsies during two decades of screening mammography. Breast 2019;46:157-62.

8 Sobin $\mathrm{LH}$, Wittekind C, International Union against Cancer. TNM classification of malignant tumours, 6th edn. Wiley-Liss, New York, 2002.

9 Sobin LH, Gospodarowicz MK, Wittekind C, International Union against Cancer., ebrary Inc. TNM classification of malignant tumours, 7th. Wiley-Blackwell,, Chichester, West Sussex, UK ; Hoboken, NJ, 2009 pp xx, 310 p.

10 American College of Radiology. BI-RADS Committee. ACR BI-RADS atlas: Breast Imaging Reporting and Data System, 4th edn. American College of Radiology, Reston, VA, 2003.

11 American College of Radiology. BI-RADS Committee. (2013) ACR BI-RADS atlas: Breast Imaging Reporting and Data System, 5th edn. American College of Radiology, Reston, VA, 2013.

12 Torring ML, Frydenberg M, Hansen RP, Olesen F, Vedsted P. Evidence of increasing mortality with longer diagnostic intervals for five common cancers: a cohort study in primary care. Eur J Cancer 2013;49: 2187-98

13 Neal RD, Tharmanathan P, France B, et al. Is increased time to diagnosis and treatment in symptomatic cancer associated with poorer outcomes? Systematic review. Br J Cancer 2015;112 Suppl 1:S92-107.

14 Eriksson L, Bergh J, Humphreys K, Warnberg F, Tornberg S, Czene K. Time from breast cancer diagnosis to therapeutic surgery and breast cancer prognosis: A population-based cohort study. Int J Cancer 2018;143:1093-104.

15 Duijm LE, Groenewoud JH, Roumen RM, de Koning HJ, Plaisier ML, Fracheboud J. A decade of breast cancer screening in The Netherlands: trends in the preoperative diagnosis of breast cancer. Breast Cancer Res Treat 2007;106:113-9.

16 Lameijer JRC, Voogd AC, Pijnappel RM, et al. Delayed breast cancer diagnosis after repeated recall at biennial screening mammography: an observational follow-up study from the Netherlands. Br J Cancer. 2020;10.1038/s41416-020-0870-2.

17 Lazarus E, Mainiero MB, Schepps B, Koelliker SL, Livingston LS. BI-RADS lexicon for US and mammography: interobserver variability and positive predictive value. Radiology 2006;239:385-91.

18 Timmers JM, van Doorne-Nagtegaal HJ, Zonderland HM, et al. The Breast Imaging Reporting and Data System (BI-RADS) in the Dutch breast cancer screening programme: its role as an assessment and stratification tool. Eur Radiol 2012;22:1717-23.

19 Nederend J, Duijm LE, Louwman MW, Groenewoud JH, Donkers-van Rossum AB, Voogd AC. Impact of transition from analog screening mammography to digital screening mammography on screening outcome in The Netherlands: a population-based study. Ann Oncol 2012;23:3098-103.

20 Glynn CG, Farria DM, Monsees BS, Salcman JT, Wiele KN, Hildebolt CF. Effect of transition to digital mammography on clinical outcomes. Radiology 2011;260:664-70. 
21 Hambly NM, McNicholas MM, Phelan N, Hargaden GC, O'Doherty A, Flanagan FL. Comparison of digital mammography and screen-film mammography in breast cancer screening: a review in the Irish breast screening program. AJR Am J Roentgenol 2009;193:1010-8.

22 Karssemeijer N, Bluekens AM, Beijerinck D, et al. Breast cancer screening results 5 years after introduction of digital mammography in a population-based screening program. Radiology 2009;253:353-8.

23 Richtlijn Mammacarcinoom 2012. Het Nationaal Borstkanker Overleg Nederland (NABON). Available via http://www.oncoline.nl/mammacarcinoom. Accessed 23rd of May 2020

24 Sardanelli F, Aase HS, Alvarez M, et al. Position paper on screening for breast cancer by the European Society of Breast Imaging (EUSOBI) and 30 national breast radiology bodies from Austria, Belgium, Bosnia and Herzegovina, Bulgaria, Croatia, Czech Republic, Denmark, Estonia, Finland, France, Germany, Greece, Hungary, Iceland, Ireland, Italy, Israel, Lithuania, Moldova, The Netherlands, Norway, Poland, Portugal, Romania, Serbia, Slovakia, Spain, Sweden, Switzerland and Turkey. Eur Radiol 2017;27: 2737-43.

25 Arbyn M, Anttila A, Jordan J, et al. European Guidelines for Quality Assurance in Cervical Cancer Screening. Second edition--summary document. Ann Oncol 2010;21:448-58.

26 Lauby-Secretan B, Scoccianti C, Loomis D, et al. Breast-cancer screening--viewpoint of the IARC Working Group. N Engl J Med 2015;372:2353-8.

27 Perry N, Broeders M, de Wolf C, Tornberg S, Holland R, von Karsa L. European guidelines for quality assurance in breast cancer screening and diagnosis. Fourth edition--summary document. Ann Oncol 2008;19:614-22. 


\section{Chapter 4.2}

Delayed breast cancer diagnosis after repeated recall at biennial screening mammography: an observational follow-up study from the Netherlands

Lameijer JRC, Voogd AC, Pijnappel RM, Setz-Pels W, Broeders MJ, Tjan-Heijnen VCG, Duijm LEM

British Journal of Cancer 2020;123(2):325-332 


\section{Abstract}

\section{Background}

Delay in detection of breast cancer may worsen tumour characteristics, with progression of tumour size and a higher risk of metastatic lymph nodes. The purpose of this study was to investigate delayed breast cancer diagnosis after repeated recall for the same mammographic abnormality at screening.

\section{Methods}

This was a retrospective study performed in two cohorts of women enrolled in a mammography screening programme in the Netherlands. All women aged 50-75 who underwent biennial screening mammography either between January 1, 1997 and December 31, 2006 (cohort 1) or between January 1, 2007 and December 31, 2016 (cohort 2) were included.

\section{Results}

The cohorts showed no difference in proportions of women with delayed breast cancer diagnosis of at least 2 years $(2.2 \%$ versus $2.8 \%, P=0.29)$. Most delays were caused by incorrect BI-RADS classifications after recall (74.2\%). An increase in mean tumour size was seen when comparing sizes at initial false-negative recall and at diagnosis of breast cancer $(P<0.001)$.

\section{Conclusions}

The proportion of women with a long delay in breast cancer confirmation following repeated recall at screening mammography has not decreased during 20 years of screening. These delays lead to larger tumour size at detection and may negatively influence prognosis. 


\section{Background}

The Dutch nationwide biennial screening mammography programme has been shown to be effective in the early detection of breast cancer and reduction in breast cancer mortality. ${ }^{1,2}$ Early detection of breast cancer does not solely involve detection of suspicious mammographic abnormalities at screening, as a swift confirmation of malignant lesions after recall is mandatory as well for the success of the screening programme.

Delay in the detection of breast cancer remains an important topic in health care, both for its frequency of occurrence and its possible negative effects on survival. ${ }^{3-8} \mathrm{~A}$ delay in breast cancer diagnosis may worsen tumour characteristics, with a progression of tumour size and a higher risk of metastatic lymph nodes. Previous studies have mostly focused on shorter diagnostic delays in symptomatic patients and very limited data are available on this subject in asymptomatic, screen-detected breast cancers. ${ }^{3,5,6,8}$ Ciatto et al. ${ }^{9}$ found that $1.4 \%$ of women experienced a delay of at least 2 years in their breast cancer confirmation after repeated recall for a screen-detected abnormality. Several causes for a delayed breast cancer diagnosis after recall at screening have been reported, including an improper classification of mammographic abnormalities at subsequent clinical breast imaging, communication errors between physicians, and sample errors at biopsy. $3,6,9$

The last decade is characterised by substantial changes in the diagnostic management of (a)symptomatic breast disease, including the introduction of multidisciplinary meetings and new imaging modalities (e.g., digital breast tomosynthesis), an intensified use of advanced imaging modalities (breast MRI), a further replacement of fine-needle biopsy by (vacuum-assisted) large core biopsy, and an increased sub-specialisation of physicians in breast care. ${ }^{6}$ However, the impact of these improvements on the proportion of women who experience a long delay in breast cancer diagnosis after recall at screening mammography is unknown. In the current study, we focused on women who experienced a delay of at least 2 years in their confirmation of breast cancer following a repeated recall for the same mammographic abnormality at biennial screening mammography in the period from 1997 to 2016. We investigated this delay over time, comparing two screening cohorts of 10 years each, and specified the radiological and tumour characteristics of the cancers with a diagnostic delay. Finally, we determined the causes of diagnostic delay and assessed whether the hospitals that handled recall varied in the number of women who experienced a delay in their breast cancer confirmation. 


\section{Methods}

\section{Study population and screening procedure}

This is a retrospective observational study, based on a prospective database of women aged 50-75 years attending the biennial breast cancer screening programme conducted in the south of the Netherlands. Characteristics of this programme have been reported previously. $^{10-12}$ In brief, women are personally invited by letter to attend the programme, with about $80 \%$ of the women accepting the invitation. Women who are being treated for breast cancer and those who still receive clinical oncologic follow-up after breast cancer treatment usually do not attend the screening programme.

A consecutive series of 283,479 screen-film mammography screens $(39,098$ initial screens and 244,381 subsequent screens) were included between January 1, 1997 and December 31, 2006 and this series is labelled cohort 1. A second consecutive series of 534,177 screen-film and full-field digital mammography (FFDM) screens (58,443 initial screens and 475,734 subsequent screens) were included between January 1, 2007 and December 31, 2016 and this series is labelled cohort 2.

Screen-film mammograms were obtained with commercially available units (Performa, Oldelft, Tuusula, Finland) and dedicated mammography screens were utilised (Mamoray MR-R; Agfa, Mortsel, Belgium). Dedicated film was used (Mamoray HDR; Agfa, Mortsel, Belgium) to process mammography screens and processing was done by extended-cycle dedicated processing. During 2009/2010, screen-film mammography in the southern screening region of the Netherlands was gradually replaced by FFDM. All digital mammograms were obtained with a Lord Selenia FFDM system (Hologic Inc, Danbury, CT), with a $70 \mu \mathrm{m}$ pixel size and a $232 \times 286 \mathrm{~mm}$ field of view.

The examinations were obtained by specialised screening mammography radiographers. Since the start of FFDM screening in 2009/2010, two-view mammography (medio-lateral-oblique (MLO) and cranio-caudal (CC) view) of each breast was performed in first as well as subsequent screens. In the era of screen-film screening, all women who attended the programme for the first time received twoview mammography, whereas subsequent screens comprised a routine MLO view of each breast and additional CC views if indicated. All screening mammograms were then independently double read by certified breast cancer screening radiologists. Since the start of our screening programme in 1995, all previous screens were always available for comparison at the time of assessment of a new screening examination. Screening radiologists categorised abnormal mammographic findings into one of the following categories: suspicious mass, suspicious calcifications, suspicious mass combined with calcifications, asymmetry, architectural distortion, or other abnormalities not otherwise categorised. In the FFDM screening period only, each recall was also classified according to the Breast Imaging Reporting and Data System (BIRADS) lexicon and the radiologists annotated each recalled mammographic abnormality on a drawing which was part of the recall report. ${ }^{13,14}$ Women with a BI-RADS 1 (normal findings) or 
2 (benign findings) were not recalled. Women with a BI-RADS 0,4 or 5 finding were referred to a dedicated breast unit of a hospital for further analysis. BI-RADS category 3 (probably benign findings) is not used in the Dutch screening programme, as short-term follow-up is not available in the screening setting.

\section{Diagnostic workup after recall}

The diagnostic workup in the vast majority of recalled women (98\%) was performed in six regional hospitals in the south of the Netherlands, whereas the remainder underwent additional examinations at various other hospitals. After physical examination by a surgical oncologist or dedicated breast nurse, additional breast imaging (when needed) was performed at the radiology department. The screening mammogram was first reassessed by a radiologist and the screening mammograms were routinely available. Additional mammographic projections were obtained at the discretion of the radiologist. Breast ultrasonography was used for the additional characterisation of mammographic abnormalities and palpable breast lesions, as guidance for biopsy and for target or second look purposes following breast MRI. Breast MRI gradually became available in the hospitals from 1998 while whole breast ultrasound was performed in only one of the six hospitals. Digital breast tomosynthesis was introduced in 2011 and available in all but one of the hospitals in the later years of inclusion. Fine-needle aspiration biopsy (FNAB) and percutaneous core needle biopsy (CNB) were available in each hospital from the beginning of our study and FNAB was gradually replaced by CNB in the 1990s. Vacuum-assisted stereotactic core needle biopsy (SCNB) was introduced in 2000 and was available in each hospital from 2004. Multidisciplinary meetings for the discussion of recalled women were gradually implemented in the hospitals.

During a minimum of 2-year follow-up, clinical data and data from diagnostic breast imaging, biopsy specimen and surgical procedures were collected of all recalled women by one of the screening radiologists (L.E.M.D.) and several radiology residents. The radiologist then entered these data in a database that had been constructed for quality assurance of the screening programme in the south of the Netherlands. Breast cancers were categorised into ductal carcinoma in situ (DCIS) and invasive cancers. Lobular carcinoma in situ was considered a non-malignant lesion. The TNM classification (6th and 7th edition) was used for malignant lesions. ${ }^{15,16}$ For all cancers treated by neoadjuvant therapy (either chemotherapy or endocrine therapy), the initial tumour size was derived from breast imaging (usually MRI) prior to the start of this therapy.

\section{Delay}

In this study, we focused on women diagnosed with breast cancer after a second recall for a mammographic abnormality, which had been considered benign at workup after the first (initial) recall. Therefore, the delay in breast cancer diagnosis in these women was at least 2 years. We limited our study to these delays because this allowed us to 
review the initial and the subsequent screening mammograms to measure tumour size and calculate progression. As we had only access to the radiology reports and the screening mammograms and not to the mammographic images obtained after recall, we could not determine tumour sizes at the clinical mammograms of women with a diagnostic delay of less than 2 years following recall.

The database for quality assurance was used to identify women who had been recalled twice between January 1997 and January 2017 and two radiologists (L.E.M.D., W.S.-P.) then determined independently whether or not the second recall concerned the same lesion for which a woman had been recalled previously. Discrepant observations between the two radiologists were solved by consensus. For all cases in which both recalls concerned the same mammographic abnormality and the second recall resulted in confirmation of invasive breast cancer, the two radiologists measured the diameter of the suspicious abnormality both at the initial, false-negative recall, and at the second, true-positive recall. These measurements were also done in an independent fashion, followed by consensus reading. Both reviewers knew they reassessed cases characterised by a delay in breast cancer diagnosis. We restricted the reassessment of tumour sizes on the screening mammograms to cohort 2 as, contrary to cohort 1, almost all screening examinations of cohort 2 consisted of two-view mammography which better enabled the radiologists to determine lesion size. Like the screening radiologists, the two radiologists had the availability of all previous screening rounds at the time they reviewed women with a possible delay in cancer diagnosis. To explore the causes of the diagnostic delays, the radiologists reviewed the clinical data (including radiological findings and biopsy reports, discharge records, outcome of multidisciplinary team meetings) and assessed whether a delay was due to an erroneous BI-RADS classification assignment at workup, a false-negative biopsy result, a patient related delay, or other causes.

\section{Ethical approval and informed consent}

Ethical approval by our local Institutional Review Board was not required for this observational follow-up study, according to the Dutch Central Committee on Research involving Human Subjects (CCMO). Prior to their participation in the programme, women were asked for permission to use their data for the evaluation of the screening programme and scientific purposes.

\section{Statistical analysis}

Descriptive statistics were performed using Statistical Package for Social Science 23.0 (SPSS Inc., IBM, Chicago, IL). The chi-square test was used to test for differences between cohorts with respect to categorical data and for differences between hospitals with respect to delayed breast cancer diagnoses in cohort 2 . A P value $<0.05$ was considered to indicate a statistically significant difference. $P$ values were two-sided. Whenever applicable (due to small sample sizes), the Fisher's exact test was used. 
The dependent samples $T$ test was used to compare the mean tumour size of invasive cancers in cohort 2 at the false-negative assessment after initial recall with the mean tumour size at subsequent (second) recall when breast cancer was finally confirmed. To test for differences in median delay between the two cohorts, the Mann-Whitney $U$ test was used. Similarity in distributions of both cohorts with respect to delays was tested and comparable distributions were found. Data in cohort 2 were missing in $<0.5 \%$ of the patients, which in most cases involved the lack of oestrogen or progesterone receptor status due to an insufficient tissue sample. In the analysis of the categorical data, we treated the missing numbers as a separate category to allow a complete case analysis.

\section{Results}

\section{Cohort characteristics}

The recall rate was significantly higher in cohort $2(2.8 \%(15,145 / 534,177)$ versus $1.2 \%$ $(3447 / 283,479), P<0.001$, Table 4.2.1). Compared to the first cohort, this higher recall rate in cohort 2 came along with a higher cancer detection rate (6.6 versus 5.0 per 1000 screens, $\mathrm{P}<0.001)$ and a lower positive predictive value (PPV) of recall $(23.2 \%$ versus $41.2 \%)$.

Table 4.2.1 Overall screening outcome of women screened between 1997-2006 versus 2007-2016

\begin{tabular}{lccc} 
Screening years & $1997-2006$ & $2007-2016$ & P-value \\
\hline Screens, No & 283479 & 534177 & \\
First screens, No (\%) & $39098(13.8)$ & $58443(10.9)$ & $<0.001$ \\
Subsequent screens, No (\%) & $244381(86.2)$ & $475734(89.1)$ & $<0.001$ \\
Recall, No (\%) & $3447(1.2)$ & $15145(2.8)$ & $<0.001$ \\
Screen detected cancers, No & 1421 & 3511 & $<0.001$ \\
Cancer detection rate* & 5.0 & 6.6 & 0.29 \\
PPV of recall, \% & 41.2 & 23.2 & 0.001 \\
Delayed breast cancer & $32(2.2)$ & $98(2.8)$ & 0.001 \\
diagnosis, No (\%^) & & & $33.8(21-97)$ \\
Delay in months (range) & $45.0(24-97)$ & $\wedge .01$
\end{tabular}

* Per 1000 screens. PPV = positive predictive value. ^ Proportion as the number of diagnostic delays among all screen detected breast cancers

\section{Frequency of delayed breast cancer confirmation and tumour characteristics of invasive cancers with a diagnostic delay}

Focusing on a delay in breast cancer diagnosis of at least 2 years after the first recall, $2.2 \%$ (32/1421 women) who were diagnosed with breast cancer in cohort 1 experienced this delay, compared to $2.8 \%(98 / 3,511)$ in cohort $2(P=0.29)$. The median delay in cohort 1 was 26.0 months (range 24-97 months), whereas the median delay in cohort 2 was 25.0 months (range 24-97 months). The difference in median delay of the two cohorts was not statistically significant $(P=0.12)$. In cohort 1,12 out of the 
32 women (37.5\%) with a diagnostic delay had their breast cancer confirmed at the next biennial screen, 2 years after their first, false negative recall. In the remaining 20 women, breast cancer was finally confirmed after a second recall that took place at least 4 years after the first recall. In cohort 2, 66.3\% of women (65/98) with a diagnostic delay had their breast cancer confirmed at the next biennial screen $(37.5 \%$ versus $66.3 \%, \mathrm{P}=0.003)$.

Sufficient data in cohort 2 were available to compare the tumour characteristics of breast cancers with or without a diagnostic delay. A smaller proportion of DCIS was found among breast cancers with a delayed diagnosis $(9.2 \%$ (9/98) versus $20.8 \%$ (710/3414), $\mathrm{P}=0.005$, Table 4.2.2). Tumour histology of invasive cancers also differed between the two groups, with a lower proportion for invasive ductal cancers and more invasive cancers of "other" type (e.g., tubular cancers, mucinous cancers) among the cases with a diagnostic delay $(P=0.006)$.

Tumour size of invasive cancers was comparable for both groups, with a majority of cancers sized between 10 and $20 \mathrm{~mm}$ (45.5\% of invasive cancers with a delayed diagnosis versus $44.2 \%$ of properly diagnosed invasive cancers, $P=0.33$ ). Invasive cancers also showed a similar histological grade distribution in both groups, with a majority of them classified Bloom \& Richardson grade I or II (87.6\% (78/89) versus $87.2 \%(2358 / 2703), P=0.19)$. The majority of invasive breast cancers were lymph node negative in both groups, although there was a slightly larger number of lymph-nodenegative cancers in case of a delayed diagnosis $(84.3 \%$ (75/89) versus $74.9 \%$ (2023/2703), P=0.14). We observed no significant differences in oestrogen-receptor, progesterone receptor and Her2/Neu receptor status, as well as triple-negative receptor status, between the two groups. Finally, the type of surgical therapy (breast conserving surgery or mastectomy) was also similar for both groups ( $P=0.74)$.

\section{Causes of delay in breast cancer confirmation}

In cohort 1, a false-negative biopsy (13 cases, 40.6\%) was the most frequent cause of a diagnostic delay after the first recall, followed by an erroneous BI-RADS classification given by the clinical radiologists after the first recall (10 cases, 31.3\%). The latter women received a BI-RADS 1 (no abnormalities) or BI-RADS 2 (benign) classification without additional biopsy. Another seven lesions (21.9\%) were classified as BI-RADS 3 at initial assessment and follow-up consisted of imaging only. These seven lesions proved to be malignant after the second recall of these lesions at a subsequent screening round. In one case the surgeon did not follow the radiologists' advice for additional biopsy and one woman refused biopsy of a suspicious mass. In cohort 2, a majority of the diagnostic delays (73 cases, $74.5 \%$ ) was attributed to an erroneous BI-RADS classification after the first recall. A false negative biopsy after the first recall was observed in 18 cancers (18.4\%) with a delayed diagnosis. In 17 of these women (17/18, $94.4 \%)$, the false-negative biopsy was due to a sample error as repeated biopsy at subsequent recall 2 years later yielded proof of malignancy. In one case, the patient refused a repeated biopsy of a lesion that had grown at follow-up. Another six lesions 
(6.1\%) were classified as BI-RADS 3 at initial assessment and one patient (1.0\%) underwent excision of a lesion other than the recalled one and the latter lesion proved malignant after the second recall. An example of delayed breast cancer diagnosis due to previous false negative recall is shown in Figure 4.2.1.

Table 4.2.2 Tumour characteristics of breast cancers with or without a diagnostic delay following recall in Cohort 2

\begin{tabular}{|c|c|c|c|}
\hline & $\begin{array}{c}\text { Delay in breast } \\
\text { cancer diagnosis } \\
(n=98)^{*}\end{array}$ & $\begin{array}{l}\text { No delay in breast } \\
\text { cancer diagnosis } \\
\quad(n=3413)\end{array}$ & P-value \\
\hline Type of cancer, No (\%) & & & 0.005 \\
\hline DCIS & $9(9.2)$ & $710(20.8)$ & \\
\hline Invasive & $89(90.8)$ & $2703(79.2)$ & \\
\hline \multicolumn{4}{|l|}{ Histology of invasive cancers, No (\%) } \\
\hline Ductal & 64 (71.9) & $2137(79.0)$ & 0.006 \\
\hline Lobular & $11(12.4)$ & $322(11.9)$ & \\
\hline Ductolobular & $1(1.1)$ & $101(3.7)$ & \\
\hline Other & $13(14.6)$ & $143(5.3)$ & \\
\hline \multicolumn{4}{|c|}{ Tumour stage of invasive cancers, No (\%) } \\
\hline $\mathrm{T} 1 \mathrm{a}+\mathrm{b}$ & $32(35.9)$ & $945(35.0)$ & 0.32 \\
\hline $\mathrm{T} 1 \mathrm{c}$ & 40 (44.9) & $1196(44.2)$ & \\
\hline $\mathrm{T} 2+$ & $17(19.2)$ & $558(20.6)$ & \\
\hline Unknown & 0 & $4(0.1)$ & \\
\hline \multicolumn{4}{|c|}{ Lymph node status of invasive cancers, No (\%) } \\
\hline $\mathrm{N}+$ & $13(14.6)$ & $614(22.7)$ & 0.14 \\
\hline $\mathrm{N}-$ & $75(84.3)$ & $2023(74.9)$ & \\
\hline Unknown & $1(1.1)$ & $66(2.4)$ & \\
\hline \multicolumn{4}{|l|}{ Bloom \& Richardson grade, No (\%) } \\
\hline 1 & $38(42.7)$ & $1213(44.9)$ & 0.19 \\
\hline II & $39(43.8)$ & $1145(42.4)$ & \\
\hline III & $11(12.4)$ & $308(11.4)$ & \\
\hline Unknown & $1(1.1)$ & $37(1.4)$ & \\
\hline \multicolumn{4}{|l|}{ Estrogen receptor status, No (\%) } \\
\hline Positive & $82(92.1)$ & 2429 (89.9) & 0.80 \\
\hline Negative & $7(7.9)$ & 259 (9.6) & \\
\hline Unknown & 0 & $15(0.6)$ & \\
\hline \multicolumn{4}{|l|}{ Progesterone receptor status, No (\%) } \\
\hline Positive & $57(64.0)$ & 1943 (71.9) & 0.16 \\
\hline Negative & $32(36.0)$ & $737(27.3)$ & \\
\hline Unknown & 0 & $23(0.9)$ & \\
\hline Her2/Neu receptor status, No (\%) & & & 0.81 \\
\hline Positive & $6(6.7)$ & 262 (9.7) & \\
\hline Negative & $83(93.3)$ & 2415 (89.3) & \\
\hline Unknown & 0 & $26(1.0)$ & \\
\hline \multicolumn{4}{|c|}{ Triple negative receptor status, No (\%) } \\
\hline Yes & $5(5.6)$ & $173(6.4)$ & 0.99 \\
\hline No & $84(94.4)$ & $2515(93.0)$ & \\
\hline Unknown & 0 & $15(0.6)$ & \\
\hline \multicolumn{4}{|l|}{ Final surgical treatment, No (\%) } \\
\hline Breast conserving surgery & $78(79.5)$ & $2756(80.8)$ & 0.74 \\
\hline Mastectomy & $18(18.4)$ & $616(18.0)$ & \\
\hline No surgery & $2(2.1)$ & $41(1.2)$ & \\
\hline
\end{tabular}

$D C I S=$ Ductal carcinoma in-situ. *Diagnostic delay was defined as confirmation of breast cancer $\geq 24$ months following initial recall 
Figure 4.2.1 Patient example, repeated recall after previous false negative recall. Two-view screening mammograms (a and c, mediolateral oblique (MLO) view, and b and d, cranio-caudal (CC) view) of the left breast in 2014 ( $a$ and b) and in 2016 (c and d). In 2014, it shows a lesion in the medial upper quadrant of the breast (arrows), initially classified as BI-RADS 0 (additional analysis needed) by the screening radiologist. At recall (2014), additional digital breast tomosynthesis (DBT) and ultrasound were performed, and the lesion was classified as BIRADS 2 (benign lesion). No biopsy was performed. Two years later (2016), the patient was recalled for the same lesion now classified as BI-RADS 5 (due to spiculae). Ultrasound-guided true-cut biopsy was performed, which revealed an invasive lobular carcinoma without axillary metastases. The patient was treated with breast conserving surgery and adjuvant radiotherapy.

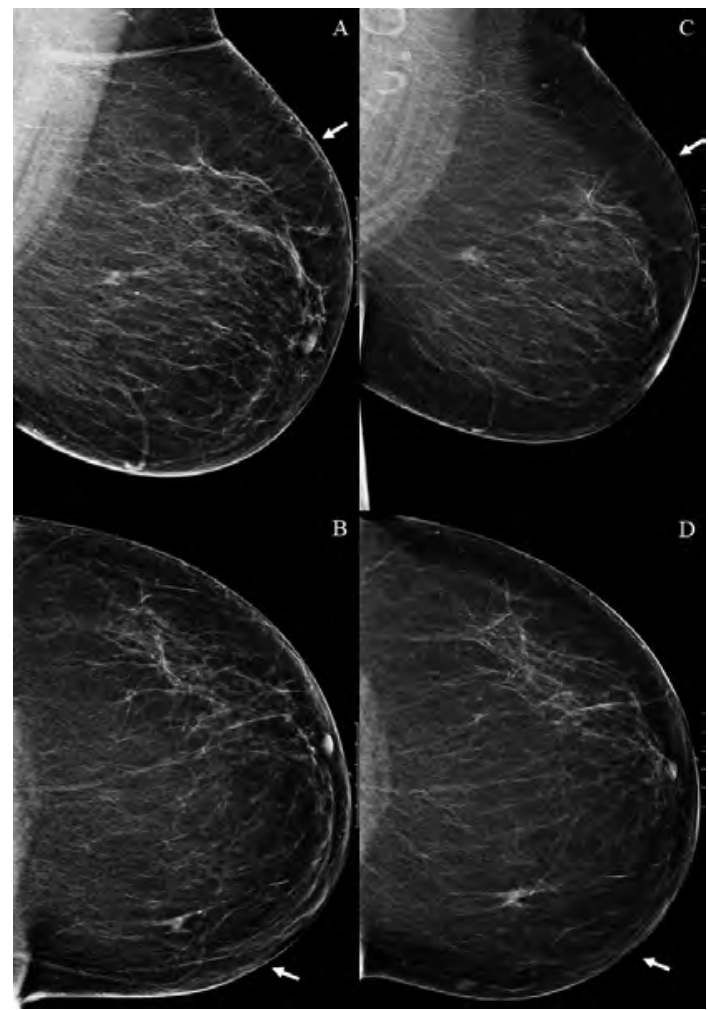

\section{Tumour size at screening mammography of cancers with a diagnostic delay}

The tumour size in patients with a delayed diagnosis of invasive breast cancer was measured, both at the screening mammogram that initiated the first, false-negative recall and at the screening mammogram that resulted in a repeated recall for the same lesion and the confirmation of breast cancer. The average tumour size was $10.2 \mathrm{~mm}$ (range, 3-53 mm) at the first recall, compared to $17.3 \mathrm{~mm}$ (range, 4-88 $\mathrm{mm}$ ) at the second recall $(P<0.001$, Table 4.2.3). 
A majority of invasive cancers, namely $71.9 \%$ (64/89), was sized $\leq 10 \mathrm{~mm}$ at the first recall, compared to only $25 \%(22 / 89)$ of the cancers at the second recall $(P<0.001)$.

Table 4.2.3 Invasive cancers with a diagnostic delay following recall in Cohort 2: tumour size measured at screening mammography

$\begin{array}{lccc} & \begin{array}{c}\text { Measured at the screening } \\ \text { mammogram with a false } \\ \text { negative assessment after } \\ 1^{\text {st }} \text { recall } \\ (\mathrm{n}=89)\end{array} & \begin{array}{c}\text { Measured at a subsequent } \\ \text { screening mammogram with } \\ \text { breast cancer confirmation } \\ \text { after } 2^{\text {nd }} \text { recall } \\ (\mathrm{n}=89)\end{array} & \begin{array}{c}\text { P-value } \\ \text { Mean tumour size, mm (range) }\end{array} \\ \begin{array}{l}\text { Absolute tumour size, mm } \\ \leq 5 \mathrm{~mm}\end{array} & 14(3-53) & 17.3(4-88) & <0.001 \\ 6-10 \mathrm{~mm} & 49(55.7) & 1(1.1) & <0.001 \\ 11-20 \mathrm{~mm} & 20(22.7) & 21(23.9) & \\ >20 \mathrm{~mm} & 5(5.7) & 24(47.7) & 27.3)\end{array}$

\section{Variations among hospitals in delayed breast cancer confirmation after recall in cohort 2}

The majority of the assessments after recall was performed in six regional hospitals located in our screening region. The proportion of women who experienced a more than 2-year diagnostic delay in their breast cancer confirmation varied from 0 to $4.8 \%$ among the hospitals ( $P=0.027$, Table 4.2.4). Hospitals II, III, IV and V are teaching hospitals that employ radiology residents, fellows and senior radiologists. The departments of radiology of hospitals I and VI are staffed by senior radiologists only.

Table 4.2.4 Delayed breast cancer confirmation after recall at screening mammography: variations among hospitals*

\begin{tabular}{lccc} 
Hospital & \multicolumn{2}{c}{ Delayed breast cancer confirmation, No (\%) } & Total, No \\
Yes & No & 371 \\
I & $0(0)$ & $371(100)$ & 917 \\
II & $26(2.8)$ & $891(97.2)$ & 834 \\
III & $25(3.0)$ & $809(97.0)$ & 907 \\
IV & $29(3.2)$ & $878(96.8)$ & 306 \\
V & $12(3.9)$ & $294(96.1)$ & 105 \\
VI & $5(4.8)$ & $100(95.2)$ & 71 \\
VII & $1(1.4)$ & $70(98.6)$ & 3,511 \\
Total & $98(2.8)$ & $3413(97.2)$ &
\end{tabular}

* Diagnostic delay was defined as confirmation of breast cancer $\geq 24$ months following initial. recall.

${ }^{ \pm}$Remaining hospitals 


\section{Discussion}

This study describes the frequency of a delay in breast cancer diagnosis after repeated recall at screening mammography, as well as the tumour characteristics of these cancers, the causes of diagnostic delay and the frequency of this delay among hospitals. Cohort 2 was characterised by a higher recall rate and cancer detection rate than cohort 1 . Cohort 1 consisted of screen-film screens only, whereas the majority of women in cohort 2 was screened by digital mammography. In the Dutch screening programme, the transition from screen-film to digital screening significantly increased the recall rate and cancer detection rate, at the expense of a lower PPV of recall and biopsy. ${ }^{17,18}$ During two decades of screening mammography, we did not find a decrease in the proportion of recalled women who experienced a delay in breast cancer confirmation of at least 2 years. Most delays were caused by incorrect BI-RADS classifications at clinical assessment after recall. The tumour characteristics of breast cancers with a diagnostic delay were comparable to cancers without this delay, with the exception of the proportions of DCIS and tumour histology. The delayed confirmation of breast cancer significantly increased the mean tumour size and hospitals, where assessment of recalled lesions took place, showed significant variations in the proportion of women who experienced a diagnostic delay in the confirmation of their breast cancer.

We were surprised to find a comparable proportion in the two cohorts of women who faced a long delay in their breast cancer diagnosis, despite improvements in diagnostic imaging, biopsy procedures and patient management over the years. We previously found that most of the improvements in diagnostics and patient management after recall (e.g., breast MRI, SCNB, multidisciplinary meetings) were widely implemented after 2005 (cohort 2). ${ }^{6}$ We expected that the proportion of diagnostic delays among recalled women would be lower in the second decade because of these technical developments and continuously improving standards of care. Unfortunately, this was not the case. We did not use the transition from screen-film to digital screening mammography or the availability of two-view mammography at screening to define the cohorts as we feel that the reasons for delays in breast cancer confirmation after recall are primarily hospital related and not related to the screening procedure itself. Unfortunately, the limited number of delays did not allow us to perform a sophisticated time trend analysis using cohorts of, for example, 2 years each.

A few studies have previously reported on delayed breast cancer confirmation after recall at screening mammography, with $4.1-6.5 \%$ of women experiencing a diagnostic delay. $^{3,6,9}$ These three studies, however, used different definitions for diagnostic delay. A majority of women had a diagnostic delay of 3-12 months, with only 4, 9 and 10 women respectively with a delay of at least 2 years. We found median delays of 26 and 25 months in the two study cohorts. Our lower proportion of $2.2-2.8 \%$ of diagnostic delays on average can be explained by the fact that we merely focused on delays of at least 2 years (until the next screening round) as these delays will probably have a more 
significant impact on survival and thus being more clinically relevant than shorter delays. Inclusion of shorter delay intervals would obviously increase and probably more than double our number of women with a delay in their breast cancer confirmation, but these delays were outside of the scope of the current study.

Most delays in cohort 2, which mainly comprised digital screening mammograms, were due to an incorrect interpretation of radiological findings after the first falsenegative recall.

The exact impact of a delay in breast cancer confirmation on patient survival is a controversial topic, with studies yielding heterogeneous outcomes. Little is known on the natural history of breast cancer and researchers have raised the possibility of spontaneous breast cancer regression. ${ }^{19,20}$ This type of cancer may result in an infinite diagnostic delay as it may lead to recall and be overlooked, only to have vanished at a later screening and therefore go undetected. On the other hand, these cancers may be difficult to diagnose and may be the ones that are subject to delayed diagnosis. Overdiagnosis and subsequent over-treatment of cancers detected at screening mammography is another issue to be taken into account when dealing with diagnostic delays. Over-diagnosed breast cancers are cancers that would never have become clinical when not detected at screening and would never lead to death. While an infinite delay for these cancers is desirable, they may actually be difficult to diagnose and thus be included as cancers with a delay in diagnosis-and from a healthcare system view, we might well think that such delay should be avoided. Finally, we did not include interval cancers that were missed at the latest screen in this study as having a delayed diagnosis, since they do not participate in the next screening round. All in all, it is difficult to assess whether estimates from this study are likely to under- or overestimate the actual occurrence of delay in diagnosis. ${ }^{21-23}$

Most studies focus on delayed diagnosis of symptomatic breast cancer and breast cancer in younger women, which differs from the asymptomatic breast cancers found at screening mammography in women aged over $50 ., 5,8,24$ We found a decrease in mean delay from 45 months to 33.8 months between the two cohorts and the majority of delays in cohort 2 were diagnosed at the next biennial screen, 2 years after the first, false-negative recall. However, it is likely that the delay of 33.8 months is somewhat flattered as cohort 2 had a shorter overall follow-up period.

The differences in tumour histology between cancers with or without a diagnostic delay in our study may have a multi-factorial explanation. Only a few diagnostic delay cases comprised DCIS. Improvement in biopsy techniques have made biopsy of calcifications faster, easier, and provides considerable amounts of tissue for pathological analysis. ${ }^{25}$ Moreover, the high interobserver variation for the classification of microcalcifications at mammography may also encourage radiologists to rather biopsy than follow-up these lesions. ${ }^{26,27}$

We observed a shift in the distribution of mean tumour size among cancers with a long diagnostic delay. This phenomenon emphasises the need of a swift confirmation of breast cancer in order to prevent a further progression of the disease, as is stressed in 
other studies as well. ${ }^{28-30}$ Over the past two decades, screening mammography and clinical breast imaging have been subject to many changes, with the aim to improve the accuracy and efficiency of breast radiology. Despite the availability and proven benefit of state-of-the-art imaging, specialised outpatient clinics for breast care, specialised breast nurses and multidisciplinary team meetings and the continuous improvement of biopsy techniques, a delayed confirmation of breast cancer following recall at screening mammography continues to be a point of concern in the Netherlands and probably in other countries as well. An Italian biennial screen-film breast screening programme, conducted from 1992 to 2001, also reported a diagnostic delay in breast cancer diagnosis of more than 2 years in $2.1 \%$ of confirmed breast cancers, comparable to the $2.2 \%$ we observed in the era of screen-film screening.

Similar to screening mammography, screening programmes for other diseases have also shown benefit in terms of a reduction in cancer-related morbidity and mortality. ${ }^{31-35}$ In contrast to the screening mammography programme, the Dutch nationwide screening programmes for cervical cancer and large bowel cancer have embedded a quality assurance protocol with respect to structured assessment after recall. Quality assurance is partially based on accreditation, e.g., only accredited endoscopists are allowed to perform diagnostic colonoscopy after a positive screening result. Also, cervical smears are assessed in only a handful of accredited laboratories. Screening radiologists who are involved in the Dutch breast cancer screening programme have to obtain an accreditation by a national training programme prior to their employment as screening radiologists; they have to attend breast radiology courses at regular intervals and screening radiologists receive feedback on their performance continuously. These kinds of quality assurance measures are not mandatory at all for radiologists who perform the radiological assessment after recall. We found a worrisome variation in the proportions of delayed breast cancer cases among the hospitals handling the recalls in our screening region. Differences among hospitals may not be explained by the type of hospital (teaching versus nonteaching hospital) or case load, but probably by the experience of the clinical breast radiologists, as the lowest proportion of breast cancer delays was observed in a smaller nonteaching hospital. Moreover, there are similar diagnostic pathways due to national guidelines and no notable differences in diagnostic imaging capabilities. To our knowledge, no (recent) data are available on differences in diagnostic delay of breast cancer diagnosis in teaching versus non-teaching hospitals. Earlier studies on difference in breast cancer survival between teaching and nonteaching hospitals showed no statistically significant differences, although these results have to be interpreted with care as data on delayed diagnosis is not reported in these studies. ${ }^{36-39}$

To reduce the variations in diagnostic errors and delay an accreditation, similar to the one that is applied to screening radiologists, may be beneficial for radiology departments assessing recalled women and it could help to improve diagnostic accuracy, reduce diagnostic errors and prevent unnecessary delays. Perhaps, centralisation of breast care may also further improve the current standard of breast 
cancer diagnosis and treatment. Studies have shown that centralisation of complex and high-risk treatment in accredited hospitals may have a beneficial effect on the treatment outcome and survival. ${ }^{40-43}$ The use of breast assessment centres has also been studied and might be the first step towards centralisation of breast cancer care in the Netherlands. ${ }^{24}$ However, due to high patient volumes and concerns for the impact on demographics, centralisation of care in a limited number of hospitals in the whole country does not seem feasible. Nevertheless, cooperation between hospitals on a regional scale could prove beneficial, with implementation of adequate quality assurance, accreditation of radiologists handling referrals, and regular audits to continuously improve breast care in these hospitals. ${ }^{24,44-46}$

There are several strengths and limitations to this study. To our knowledge, this is the first study focusing on long delays in breast cancer confirmation after recall for a screen-detected mammographic abnormality. A large series of consecutive screening mammograms were included during two decades of screening mammography, with an almost complete follow-up of recalled women. On the other hand, certain outcome measures should be interpreted with care due to the relatively small sample size of patients with a delayed breast cancer diagnosis. Also, screening mammography programmes are constantly subject to changes and the design of the programmes and the assessment of recalled women differ between countries. These parameters influence diagnostic accuracy (both positively and negatively) and may limit extrapolation of our findings to other screening programmes.

We cannot rule out the rare occasion that a lesion with a delayed confirmation of malignancy was in fact precancerous rather than cancerous at the time of the initial assessment. However, the majority of delayed cases showed suspicious mammographic characteristics that should have been biopsied at initial workup. Moreover, in women with benign biopsy outcome at the initial workup, sampling errors will likely have caused the diagnostic delays as only benign pathological findings and no high-risk lesions, that are associated with an increased breast cancer risk in the future (e.g., flat epithelial atypia, atypical ductal hyperplasia or lobular carcinoma in situ), were reported at this workup.

In summary, we found that the proportion of women who experience a long delay in their breast cancer confirmation following recall at screening mammography did not decrease during 20 years of screening, despite improvements in diagnostic modalities, biopsy procedures and multidisciplinary approaches. These delays worsen the tumour size and may negatively influence prognosis of survival. Over-estimation of the negative impact on survival of a delayed breast cancer diagnosis may be due to over-diagnosed breast cancers and further study is needed on this subject. Further study is also necessary to determine whether accreditation of hospitals and/or centralisation of breast care may lower the number of diagnostic delays, especially in hospitals with larger proportions of women facing a diagnostic delay. We suggest that quality assurance not only covers the screening mammography programmes, but also the hospitals handling the workup of recalled women. 


\section{References}

1. Sankatsing VDV, van Ravesteyn NT, Heijnsdijk EAM, Looman CWN, van Luijt PA, Fracheboud J, et al. The effect of population-based mammography screening in Dutch municipalities on breast cancer mortality: 20 years of followup. Int J Cancer 2017;141:671-7.

2. Otto SJ, Fracheboud J, Verbeek AL, Boer R, Reijerink-Verheij JC, Otten JD, et al. Mammography screening and risk of breast cancer death: a population-based case-control study. Cancer Epidemiol Biomarkers Prev. 2012;21:66-73.

3. Duijm LE, Groenewoud JH, Jansen FH, Fracheboud J, van Beek M, de Koning HJ. Mammography screening in the Netherlands: delay in the diagnosis of breast cancer after breast cancer screening. $\mathrm{Br} \mathrm{J}$ Cancer 2004;91:1795-9.

4. Eriksson L, Bergh J, Humphreys K, Warnberg F, Tornberg S, Czene K. Time from breast cancer diagnosis to therapeutic surgery and breast cancer prognosis: a population-based cohort study. Int J Cancer 2018; 143:1093-104.

5. Richards MA, Smith P, Ramirez AJ, Fentiman IS, Rubens RD. The influence on survival of delay in the presentation and treatment of symptomatic breast cancer. Br J Cancer 1999;79:858-64.

6. Duijm LE, Groenewoud JH, de Koning HJ, Coebergh JW, van Beek M, Hooijen MJ, et al. Delayed diagnosis of breast cancer in women recalled for suspicious screening mammography. Eur J Cancer 2009;45:774-81.

7. Regev GS, Ser AM. Breast cancer medical malpractice litigation in New York: the past 10 years. Breast 2019;46:1-3.

8. Smith EC, Ziogas A, Anton-Culver H. Delay in surgical treatment and survival after breast cancer diagnosis in young women by race/ethnicity. JAMA Surg 2013;148:516-23.

9. Ciatto S, Houssami N, Ambrogetti D, Bonardi R, Collini G, Del Turco MR. Minority report-false negative breast assessment in women recalled for suspicious screening mammography: imaging and pathological features, and associated delay in diagnosis. Breast Cancer Res Treat 2007;105:37-43.

10. van Bommel RMG, Weber R, Voogd AC, Nederend J, Louwman MWJ, Venderink D, et al. Interval breast cancer characteristics before, during and after the transition from screen-film to full-field digital screening mammography. BMC Cancer 2017;17:315.

11. Setz-Pels W, Duijm LE, Groenewoud JH, Louwman MW, Jansen FH, van Beek M, et al. Patient and tumor characteristics of bilateral breast cancer at screening mammography in the Netherlands, a populationbased study. Breast Cancer Res Treat 2011;129:955-61.

12. Setz-Pels W, Duijm LE, Groenewoud JH, Voogd AC, Jansen FH, Hooijen MJ, et al. Detection of bilateral breast cancer at biennial screening mammography in the Netherlands: a population-based study. Radiology 2011;260:357-63.

13. American College of Radiology. BI-RADS Committee. ACR BI-RADS Atlas: Breast Imaging Reporting and Data System 4th edn (American College of Radiology, Reston, VA, 2003).

14. American College of Radiology. BI-RADS Committee. ACR BI-RADS Atlas: Breast Imaging Reporting and Data System 5th edn (American College of Radiology, Reston, VA, 2013).

15. Sobin LH, Wittekind C. International Union Against Cancer. TNM Classification of Malignant Tumours. 6th edn, xxiii, 239pp. (Wiley-Liss, New York, 2002).

16. Sobin LH, Gospodarowicz MK, Wittekind, C. International Union Against Cancer. TNM Classification of Malignant Tumours 7th edn, 310 pp. (Wiley-Blackwell, Chichester, West Sussex; Hoboken, NJ, 2010).

17. Nederend J, Duijm LE, Louwman MW, Groenewoud JH, Donkers-van Rossum AB, Voogd AC. Impact of transition from analog screening mammography to digital screening mammography on screening outcome in The Netherlands: a population-based study. Ann Oncol 2012;23:3098-103.

18. Bluekens AM, Holland R, Karssemeijer N, Broeders MJ, den Heeten GJ. Comparison of digital screening mammography and screen-film mammography in the early detection of clinically relevant cancers: a multicenter study. Radiology 2012;265:707-14.

19. Zahl PH, Gotzsche PC, Maehlen J. Natural history of breast cancers detected in the Swedish mammography screening programme: a cohort study. Lancet Oncol 2011;12:1118-24.

20. Zahl PH, Maehlen J, Welch HG. The natural history of invasive breast cancers detected by screening mammography. Arch Intern Med 2008;168:2311-6. 
21. Harding C, Pompei F, Burmistrov D, Wilson R. Use of mastectomy for overdiagnosed breast cancer in the United States: analysis of the SEER 9 Cancer Registries. J Cancer Epidemiol 2019;2019:5072506.

22. Marmot MG, Altman DG, Cameron DA, Dewar JA, Thompson SG, Wilcox M. The benefits and harms of breast cancer screening: an independent review. Br J Cancer 2013;108:2205-40.

23. Jorgensen KJ, Gotzsche PC. Overdiagnosis in publicly organised mammography screening programmes: systematic review of incidence trends. BMJ 2009;339:b2587.

24. Chiarelli AM, Muradali D, Blackmore KM, Smith CR, Mirea L, Majpruz V, et al. Evaluating wait times from screening to breast cancer diagnosis among women undergoing organised assessment vs usual care. Br J Cancer 2017;116:1254-63.

25. Park HL, Hong J. Vacuum-assisted breast biopsy for breast cancer. Gland Surg 2014;3:120-7.

26. Pijnappel RM, Peeters PH, Hendriks JH, Mali WP. Reproducibility of mammographic classifications for non-palpable suspect lesions with microcalcifications. Br J Radiol 2004;77:312-4.

27. Menezes GLG, Pijnappel RM, Meeuwis C, Bisschops R, Veltman J, Lavin PT, et al. Downgrading of breast masses suspicious for cancer by using optoacoustic breast imaging. Radiology 2018;288:355-65.

28. Olivotto IA, Gomi A, Bancej C, Brisson J, Tonita J, Kan L, et al. Influence of delay to diagnosis on prognostic indicators of screen-detected breast carcinoma. Cancer 2002;94:2143-50.

29. Caplan L. Delay in breast cancer: implications for stage at diagnosis and survival. Front. Public Health 2014;2:87.

30. Doubeni CA, Gabler NB, Wheeler CM, Mc Carthy AM, Castle PE, Halm EA, et al. Timely follow-up of positive cancer screening results: a systematic review and recommendations from the PROSPR Consortium. CA: Cancer J Clin 2018;68:199-216.

31. Vaccarella S, Franceschi S, Engholm G, Lonnberg S, Khan S, Bray F. 50 years of screening in the Nordic countries: quantifying the effects on cervical cancer incidence. Br J Cancer 2014;111:965-9.

32. Vaccarella S, Lortet-Tieulent J, Plummer M, Franceschi S, Bray F. Worldwide trends in cervical cancer incidence: impact of screening against changes in disease risk factors. Eur J Cancer 2013;49:3262-73.

33. Bronzwaer MES, Depla A, van Lelyveld N, Spanier BWM, Oosterhout YH, van Leerdam ME, et al. Quality assurance of colonoscopy within the Dutch national colorectal cancer screening program. Gastrointest Endosc 2019;89:1-13.

34. European Colorectal Cancer Screening Guidelines Working G, von Karsa L, Patnick J, Segnan N, Atkin W, Halloran S, et al. European guidelines for quality assurance in colorectal cancer screening and diagnosis: overview and introduction to the full supplement publication. Endoscopy 2013;45:51-9.

35. Arbyn M, Anttila A, Jordan J, Ronco G, Schenck U, Segnan N, et al. European Guidelines for Quality Assurance in Cervical Cancer Screening. Second edition-summary document. Ann Oncol 2010;21: 448-58.

36. Simunovic M, Rempel E, Theriault ME, Coates A, Whelan T, Holowaty $E$, et al. Influence of hospital characteristics on operative death and survival of patients after major cancer surgery in Ontario. Can J Surg 2006;49:251-8.

37. Hebert-Croteau N, Brisson J, Lemaire J, Latreille J, Pineault R. Investigating the correlation between hospital of primary treatment and the survival of women with breast cancer. Cancer 2005;104:1343-8.

38. Brucker SY, Schumacher C, Sohn C, Rezai M, Bamberg M, Wallwiener D, et al. Benchmarking the quality of breast cancer care in a nationwide voluntary system: the first five-year results (2003-2007) from Germany as a proof of concept. BMC Cancer 2008;8:358.

39. Chaudhry R, Goel V, Sawka C. Breast cancer survival by teaching status of the initial treating hospital. CMAJ 2011;164:183-8.

40. Williams SB, Ray-Zack MD, Hudgins HK, Oldenburg J, Trinh QD, Nguyen PL, et al. Impact of centralizing care for genitourinary malignancies to highvolume providers: a systematic review. Eur Urol Oncol 2019;2:265-73.

41. Markar SR, Mackenzie H, Wiggins T, Askari A, Karthikesalingam A, Faiz O, et al. Influence of national centralization of oesophagogastric cancer on management and clinical outcome from emergency upper gastrointestinal conditions. Br J Surg 2018;105:113-20.

42. Vonlanthen R, Lodge P, Barkun JS, Farges O, Rogiers X, Soreide K, et al. Toward a consensus on centralization in surgery. Ann Surg 2018;268:712-24.

43. van Putten M, Nelen SD, Lemmens V, Stoot J, Hartgrink HH, Gisbertz SS, et al. Overall survival before and after centralization of gastric cancer surgery in the Netherlands. Br J Surg 2018;105:1807-15. 
44. Kalager M, Haldorsen T, Bretthauer M, Hoff G, Thoresen SO, Adami HO. Improved breast cancer survival following introduction of an organized mammography screening program among both screened and unscreened women: a population-based cohort study. Breast Cancer Res 2009;11:R44.

45. Blackmore KM, Weerasinghe A, Holloway CMB, Majpruz V, Mirea L, O'Malley FP, et al. Comparison of wait times across the breast cancer treatment pathway among screened women undergoing organized breast assessment versus usual care. Can J Public Health 2019;110:595-605.

46. Smith CR, Chiarelli AM, Holloway CM, Mirea L, O'Malley FP, Blackmore KM, et al. The impact of organized breast assessment on survival by stage for screened women diagnosed with invasive breast cancer. Breast 2018;41:25-33. 


\section{Chapter 5}

Summary 


\section{Summary}

Breast cancer continues to be a major concern in health care worldwide, mainly due to its frequent occurrence; overall, one in every seven women is confronted with a diagnosis of breast cancer in her lifetime. Several improvements in breast cancer care in the past decades have led to a significant reduction in breast cancer mortality, and this mortality continues to decline with further improvements in breast cancer care.

The implementation of breast cancer screening programmes has resulted in a significant reduction in breast mortality worldwide. Nowadays, screening programmes have been implemented in almost all countries with modern health care systems. The Dutch breast cancer screening programme was introduced between 1989 and 1995. Women aged 50 to 75 years old are invited to participate in this biennial screening programme, and the attendance rate has been very high ( $\approx 80 \%)$ since the start.

Improvements in screening such as enhanced reading strategies and advancements in imaging modalities (i.e., conversion from screen-film to digital mammography) have led to an increase in programme efficiency. However, continuous improvements in the various aspects of the screening programme as outlined in the aims of this thesis are paramount to improve overall programme efficiency.

In chapter 1, a general introduction to this thesis is given.

The main aims of this thesis were:

- to evaluate varying aspects of the breast cancer screening programme in the southern region of the Netherlands. These studies may contribute to an overview for screening and diagnostic radiologists and other personnel involved in the screening mammography programme on the outcome of various types of recall as well as additional findings found at recall.

- to improve our understanding of causes of delayed diagnosis of breast cancer after screening mammography, and hopefully providing means to further reduce these delayed diagnoses to improve the diagnostic accuracy and efficacy of this biennial screening mammography programme in the southern region of the Netherlands.

In chapter 2, we looked at bilateral recall and bilateral interval cancers. As a standard screening procedure, a two view mammogram is obtained of both breasts. These are then assessed by two screening radiologists and both breasts are classified according to the BI-RADS classification system. Usually, women are recalled for one breast, but sometimes women experience a bilateral recall. In our study, we found that $2.7 \%(\mathrm{~N}=271)$ of all recalled women had a bilateral recall, which mostly occurred in the first screening round. This is probably caused by increased vigilance of the screening radiologist and a lack of earlier mammographic studies available for comparison. In most cases, the contralateral lesion turned out to be benign and, fortunately, bilateral breast cancer occurs infrequently. Only $7.4 \%$ of women with a bilateral recall were diagnosed with bilateral breast cancer $(\mathrm{N}=20)$, compared to $0.4 \%$ in women with a unilateral recall $(\mathrm{N}=34)$ and $0.5 \%$ of all recalls $(\mathrm{N}=54)$. Despite its rare occurrence, studies suggest a worse survival for women with bilateral breast cancer compared to 
those with unilateral disease. Vigilance is therefore required when studying both breasts for abnormalities.

When a cancer is missed or radiologically occult, women may present with an interval cancer. These cancers account for $25 \%$ of the breast malignancies diagnosed in the screened population. Interval cancers are generally larger, more aggressive, and have a worse prognosis than screen-detected cancers. Like screen-detected cancers, interval cancers may also simultaneously occur in both breasts. However, such events are rare; in a cohort of 468,720 women screened between January 2005 to January 2015, 753 developed an interval cancer and 24 of these were bilateral. Bilateral interval cancers were larger compared to bilateral screen-detected cancers, a finding which is also seen in unilateral breast cancer (unilateral interval cancers versus unilateral screen-detected cancers). Also, bilateral interval cancers showed a higher proportion of lobular histology and a more favourable histological grade.

In chapter 3, we studied additionally detected lesions at clinical breast imaging after recall for a specific screen-detected abnormality. These additional lesions are common and can be found in the breast harbouring the recalled lesion (1 out of recalled 16 women) as well as in the contralateral breast (1 out of 30 women). These additionally detected lesions are generally benign ( 4 out of 5 lesions in the recalled breast, 6 out of 7 in the non-recalled breast) and predominantly consist of cysts and fibroadenomas, but in some cases they may prove to be malignant. This cancer can either be a part of a multicentric or multifocal breast malignancy, it may be a cancer diagnosed in the contralateral, non-recalled breast in a woman with bilateral breast cancer or the recalled lesion may be benign whilst the additionally detected lesion is malignant. The lesions are usually found at additional imaging as part of the diagnostic work-up, such as ultrasound, digital breast tomosynthesis and, in selected cases, by breast MRI. Both screening radiologists and clinical radiologists should pay attention to both breasts as multiple malignant lesions may be present which can influence treatment strategy and prognosis.

In chapter 4, we studied the frequency and causes of delayed breast cancer diagnosis after recall at screening mammography. A delayed diagnosis of cancer, not just breast cancer, continues to pose a problem for physicians involved in breast cancer care. It may carry a psychological burden it can have a negative effect on the prognosis and it may be a reason for malpractice claims. Limited data are available on the impact of delayed cancer diagnosis on breast cancer survival, which can be largely attributed to the heterogeneity between studies with respect to tumour types, definition of delay and screening programme characteristics, as well as difficulties in study design to study the subject. The largely unknown natural history of breast cancer also plays a role in accurately quantifying the impact of delayed breast cancer diagnosis. Some studies have suggested spontaneous regression of breast cancers and these tumours would benefit from an infinite diagnostic delay. The same may be true for low to intermediate grade tumours, which may never progress to clinically significant disease, especially in women with a limited life-expectancy due to co-morbidity. 
We hypothesized that, due to many improvements in breast cancer care, including the introduction of the BI-RADS classification in both screening and diagnostic setting, multi-disciplinary meetings, advances in imaging modalities and biopsy techniques, the occurrence of a delay in breast cancer diagnosis would have been significantly reduced over the years. We observed a reduction in diagnostic delays after recall of 4-24 months $(7.5 \%$ in $1997-2001$ to $3.1 \%$ in $2012-2016, P<0.001)$, but the proportion of women with a delay of more than 24 months was similar (2.2\% from 1997-2006 versus $2.8 \%$ in 2006-2016, $\mathrm{P}=0.29$ ). The most frequent causes of delay were incorrect BI-RADS classification and false-negative biopsies. Although the impact of a diagnostic delay is not fully understood, it is important to reduce its occurrence. We found that the frequency of delays differs between non-teaching and teaching hospitals in our region (ranging from $0.0 \%$ in non-teaching hospitals to $4.8 \%$ in teaching hospitals, $\mathrm{P}=0.027$ ). Because of similar diagnostic pathways and imaging capabilities in all hospitals, we think this difference is more likely related to experience of clinical radiologists handling recall instead of type of hospital (teaching versus non-teaching) or case load. We suggest that mandatory quality assurance of hospitals handling recall may prove beneficial. 


\section{Chapter 6}

General discussion and future perspectives 


\section{General discussion}

Detecting breast cancer at an early stage involves several challenges. One of the main challenges of a successful screening programme is to keep the number of false-positive referrals within acceptable limits. The number of false positive referrals is an important indicator of the performance of a breast screening programme. The introduction of improved screening techniques has resulted in the detection of increasingly smaller lesions, which may be difficult to characterize and which may cause an increase in the number of false-positive referrals. Such an increase has been shown in earlier studies conducted after the transition from screen-film to digital mammography in the Netherlands. ${ }^{1-4}$ False-positive referrals should be avoided as much as possible, as these can cause substantial psychological distress, decreased screening re-attendance, unnecessary biopsies, and possibly overtreatment in women participating in breast screening programmes. ${ }^{5-8}$

Newer imaging modalities used at screening mammography and in hospitals handling recalled women such as the introduction of breast MRI, digital breast tomosynthesis and digital mammography, have resulted in an increase of the image quality. This allows a better depiction of lesions in both breasts and may increase the probability of recall for a lesion in the contralateral breast as well. Unfortunately, little is known about the frequency and outcome of bilateral recall in women participating in a breast cancer screening programme. The same is true for the impact of additionally detected lesions at recall such as ipsilateral or contralateral findings. In this thesis, we aimed to evaluate the frequency of bilateral recall and analysis of additional lesions after recall.

As mentioned previously, the importance of a timely diagnosis of breast cancer has been demonstrated in earlier studies, and a delayed breast cancer diagnosis may lead to a decreased survival rate. Despite improvements in breast cancer detection, delayed diagnoses in screened women still occur. ${ }^{9-17}$ In this thesis we tried to identify the causes for these delays and we discuss options that could lead to a reduction in the proportions of delayed breast cancer diagnosis in women attending a screening programme.

\section{Bilateral recall and bilateral cancers}

Bilateral recall at screening mammography is not a frequent event. ${ }^{18,19}$ We found that $2.7 \%$ of recalled women were recalled for a suspicious lesion in both breasts, a percentage comparable to the proportion of bilateral recalls reported earlier. ${ }^{18,19}$ Most bilateral recalls occurred in the first round of screening, a finding that can be explained by an increased vigilance of the screening radiologists and a larger degree of uncertainty due to the absence of earlier mammograms for comparison. We found a higher percentage of bilateral recalls in women with a true positive recall at initial screening compared to subsequent screening rounds, which may be related to the increased vigilance of the screening radiologist as well. 
The uncertainty among screening radiologists when bilateral lesions are found in women attending the screening programme for the first time, also appears to have its impact on the clinical radiologists, who are involved in the diagnostic work-up in the hospital. This seems to be reflected by a larger proportion of women who are biopsied after bilateral recall than after unilateral recall. However, to our knowledge no studies have been performed yet that investigate the influence of the screening radiologists' opinion on the opinion of the clinical radiologist. The clinical radiologists may also be more inclined to perform a biopsy in the case of equivocal findings, resulting in a lower positive predictive value (PPV) of biopsy and potential psychological and physical harm for the patients. Studies have found that the psychological effect of recall is transient, but it can be present for more than a year after recall and it may have adverse psychological consequences at the time of subsequent screening in women who have undergone biopsy at a previous recall. ${ }^{20,21}$ Better characterization of lesions might improve the PPV, as has been reported in a study from the United Kingdom, in which a reduction of $33 \%$ in the number of benign biopsies was observed following the additional use of digital breast tomosynthesis (DBT) after full field digital mammography (FFDM) screening. A reduction of biopsies for bilateral lesions by the use of DBT has yet to be proven, preferably in a study with a similar design, but we expect that such a study will also show a decrease in unnecessary biopsies in lesions in the contralateral breast. ${ }^{22}$ The UK-study mentioned above shows the importance of using additional diagnostic modalities by the clinical radiologists to prevent unnecessary biopsies.

We showed that mammographic abnormalities at recall differ between bilateral and unilateral recall. Index lesions at bilateral recall were more often characterized as suspicious calcifications compared to index lesions at unilateral recall, which were more often characterized as masses. Alertness among screening radiologists may be higher for calcifications than for other, more subtle lesions. However, detecting these more subtle abnormalities is equally important. Studies have reported that especially invasive lobular carcinomas can be difficult to detect at screening mammography, as they frequently present as small architectural distortions, focal asymmetries or may not present with mammographic abnormalities at all. The detection of these lesions requires increased vigilance by the screening radiologists. It also necessitates a second look by the clinical radiologist in case of referral to determine if additional imaging at recall is warranted after carefully assessing the remaining breast tissue outside the abnormality for which the woman was recalled. ${ }^{18,19,23}$

The difficulty of detecting specific abnormalities on screening mammograms is reflected by the increased proportion of invasive lobular carcinomas found among interval cancers. ${ }^{23,24}$ Interval cancers are cancers that are found between two screening rounds. In our biennial screening programme, $25 \%$ of breast cancers detected in women participating in this programme were interval cancers. This percentage is comparable to the figures observed in other population-based screening programmes applying biennial mammography. ${ }^{4,25,26}$ Bilateral interval breast cancer was seen in $3.2 \%$ 
of all women with interval cancers, with a slightly higher proportion of invasive lobular carcinoma in interval index cancers compared to screen-detected index cancers, although this difference was not statistically significant $(P=0.09)$. Index lesions in interval cancer were defined as the largest lesion at pathology in the case of bilateral interval cancer. $^{24}$

We found that women with a bilateral recall had a larger index tumour than those with a unilateral recall, and there was a tendency for their index tumours to have a worse $B \& R$ grade and a higher risk of lymph node invasion, although the observed differences were not statistically significant. We do not have a clear explanation for these findings. The cancers in our study showed comparable histological distributions after unilateral and bilateral recall. Tumours in synchronous bilateral breast cancers (tumours diagnosed within 3 months of each other) may be considered as two biologically separate malignancies, but this does also not provide an explanation for the increased size of tumours after bilateral recall. ${ }^{27}$

Our data showed that mastectomy was more frequently performed after bilateral recall than after unilateral recall. This can partially be explained by the larger tumour size, and by the larger proportion of histologically confirmed bilateral breast cancers after bilateral recall compared to unilateral recall $(7.4 \%$ versus $0.4 \%, \mathrm{P}<0.001)$. The difference may also be explained by a preference of the women to undergo bilateral mastectomy when they are recalled for both breasts, even when one of the lesions is proven to be benign. In more recent years, studies in the USA have shown an increase in the rate of contralateral prophylactic mastectomy. ${ }^{28,29}$ This trend was not seen in Europe, although only a limited number of studies are available on this subject. ${ }^{30,31}$ According to some studies, the primary reason for choosing contralateral prophylactic mastectomy is reported to be fear of developing contralateral breast cancer after a woman has already suffered from breast cancer in one breast, ${ }^{32,33}$ One study reported that most women interviewed demanded?/required that their risk of contralateral breast cancer should be more than halved after prophylactic mastectomy to justify the procedure. ${ }^{34}$ Therefore, results from our study need to be interpreted with care as we did not take patients' preferences into account when comparing mastectomy and breast conserving surgery.

Fortunately, bilateral recall occurs infrequently at screening (2.8\% of all recalls). In $7.4 \%$ of bilateral recalls, breast cancer is found in both breasts. Increased vigilance remains required for both screening and clinical radiologists to detect both the index cancer and the contralateral breast cancer to prevent the occurrence of contralateral interval cancers. ${ }^{35-42}$ Although data is sparse, bilateral interval cancers in women enrolled in a biennial screening programme occur infrequently (3.2\%). ${ }^{24}$ In the future, further improvements in imaging modalities used at screening, such as digital breast tomosynthesis, may increase the bilateral recall rate, which may help to reduce the risk of bilateral interval cancers, although this could come at the expense of an increased false-positive recall rate. ${ }^{43,44}$ However, it is likely that the higher recall rates and higher 
false positive rates will decrease again when more experience is obtained with the use of DBT in screening mammography. ${ }^{43,45,46}$

\section{Additional findings}

In our studies, we found that in roughly one out of 16 recalled women an additional non-recalled lesion in the ipsilateral breast was found by the clinical radiologist which warranted further analysis. Furthermore, in one out of 30 recalled women a contralateral suspicious, non-recalled lesion was found. No other studies are available on additional ipsilateral and contralateral findings after recall at screening mammography. The majority of lesions in the ipsilateral and contralateral breast were benign, with the majority being cysts and fibro-adenomas. This largely corresponds with results from earlier studies on additional findings in contrast-enhanced mammography, ultrasound and MRI, although these studies were not performed in recalled women. ${ }^{47-49}$ One out of five additionally detected ipsilateral lesions proved to be malignant. The majority of the lesions were part of multifocal or multicentric disease, and most of the lesions were invasive ductal carcinomas. Multi-focal and multicentric carcinomas may have a significant impact on 5-year survival rates, and their detection may lead to significant changes in therapy. ${ }^{50}$ In our study on contralateral additional findings, we found that one out of seven contralateral non-recalled lesions were malignant. In the majority of cases, women proved to have synchronous bilateral breast cancer. As mentioned before, synchronous bilateral breast cancer may have a negative impact on survival.

In our region, the screening mammograms of recalled women are viewed again by the clinical radiologist, and a new mammogram is routinely performed (with or without DBT and with or without contrast enhancement). Subsequently, in accordance with Dutch and European guidelines, breast ultrasonography is routinely performed of the quadrant where a suspicious mammographic lesion is found. In our study, $26 \%$ of additional ipsilateral malignancies in our study were initially found using ultrasound. ${ }^{51,52}$

Just like ultrasound, the use of breast MRI may also increase the chance of finding additional lesions, and in our studies around $26 \%$ of ipsilateral and $41 \%$ of contralateral non-recalled malignancies were found with breast MRI. According to Dutch guidelines, indications for breast MRI include the evaluation of multicentric, multifocal or contralateral disease in case of invasive lobular carcinoma, as well as the determination of tumour size in dense breasts. ${ }^{51}$ In selected cases, its use is recommended as a problem solving-tool for indeterminate lesions at mammography and/or ultrasonography. Routine use of breast MRI is not recommended in the Dutch and European guidelines. ${ }^{51,52}$

Although most of the additionally detected lesions in both the recalled and nonrecalled breast are benign (i.e., cysts and fibroadenomas), both the screening radiologist and clinical radiologist should pay attention to both breasts as additional malignant lesions may be present which could be part of a multifocal or multicentric malignancy or may present as synchronous contralateral breast cancer in addition to 
malignant index lesions. These additional lesions may require a shift in the surgical planning from breast conserving surgery to mastectomy, or the addition of radiotherapy or (neo-)adjuvant chemotherapy to the treatment regimen. Suboptimal treatment of these lesions may have a significant impact on disease-free and overall survival.

\section{Delayed diagnosis}

Delayed diagnosis of cancer, not just breast cancer, continues to pose a problem for physicians involved in cancer care. Not only do these delays carry a psychological burden for the patients, they may also have a negative impact on their prognosis and are often a reason for malpractice claims. ${ }^{17,53,54}$ Little is known on the prognostic implications of a delay in the diagnosis of breast cancer in screened women. However, due to the recent emergence of the novel 2019 Corona-virus (COVID-19), authors of a recent UK-based study calculated that the delay in cancer diagnosis due to limited access to cancer screening may eventually cause a substantial increase in cancer related deaths of $7.9 \%$ to $9.6 \%$ up to year 5 after diagnosis. ${ }^{55,56}$ Another study from the UK concluded that the delay in surgery in cancer patients in general may have a significant negative impact on life-years gained, with a possible reduction of 2.19 lifeyears gained per patient for a delay up to 6 months. Although no subgroup analysis was performed for breast cancer patients, it is expected that the delay in breast cancer diagnosis due to the COVID-19 epidemic will have an impact on breast cancer survival, although studies are needed to assess whether this is a significant impact. Earlier studies before the COVID-19 pandemic have also looked at delayed diagnosis of breast cancer and its prognostic implications, but there is a large heterogeneity in tumour types, definitions of delay and screening programme characteristics among studies, which make an adequate analysis difficult. At the same time, a study design to adequately determine the effect of delayed diagnosis in breast cancer is very difficult and is limited to observational studies due to ethical concerns.

In a recent study in our population, covering a screening period of 11 years, a survival analysis was performed comparing interval cancers that were considered missed at prior screening versus tumours considered occult on prior screening. No differences were found in the overall survival between the groups. These results were not compared with survival after diagnosis of screen-detected cancers, but do show that despite missing the tumour at screening, survival would still be comparable to true interval carcinomas. ${ }^{57}$ Recently, a study by Irvin et al. looked at disease specific mortality among patients with screen-detected and interval breast cancer and reported a higher disease specific mortality for patients with interval cancers detected within one year of a negative mammogram at screening. However, the authors note that this difference may not be entirely accounted for by the delay in diagnosis but is more likely to have been caused by a biologically more aggressive behaviour of the interval cancers, compared to the screen-detected cancers. They also reported that breast cancers found one until 2.5 years after a negative screening mammogram were more 
likely to be early stage tumours compared to tumours found within one year after screening, which was also attributed to their more aggressive behaviour. A limitation of the study is that differentiation between true interval carcinomas and missed carcinomas could not be made on data available. Also, the results from this US-based study need to be interpreted and extrapolated to our population with care because of the differences between the screening programmes in the Netherlands and the United States with respect to screening intervals. Further studies in our population with longer follow-up are needed to provide more convincing results on possible survival differences between screen-detected cancers, true interval carcinomas and interval carcinomas considered missed at prior screening. ${ }^{58}$

The impact of a diagnostic delay is difficult to quantify in detail because of the largely unknown natural history of asymptomatic breast cancer. Some authors have even suggested the possibility of spontaneous breast cancer regression. ${ }^{59-62}$ These cancers would never have a significant impact on patient survival and therefore would theoretically benefit from an infinite delay in diagnosis. Also, part of the lesions with a low to intermediate malignant potential could benefit from infinite diagnostic delay, as there is a chance that these lesions might never develop into a clinically relevant breast cancer. This is especially the case in elderly women and others with limited life expectancy due to comorbid conditions. Measuring overdiagnosis and overtreatment is difficult, and estimates of the amount of overdiagnosis are generally based on the modelling of observational data. A recent study concluded that a reasonable estimate of the overdiagnosis rate at screening mammography appears to be between one and $10 \% .{ }^{63}$ Until we are able to discriminate with a high degree of confidence between lesions that will require treatment and those lesions that will not, this percentage of overdiagnosis is likely to persist. One of the important topics of debate is the treatment and diagnosis of ductal carcinoma in situ (DCIS). Tumour characteristics are being investigated that play a role in predicting behaviour of DCIS, and several studies have been started in an attempt to assess management of low and intermediate grade DCIS, i.e., the Low-Risk DCIS (LORD) study from the Netherlands and the European Organisation for Research and Treatment of Cancer (EORTC), and the Low-Risk DCIS (LORIS) study from the United Kingdom. ${ }^{64,65}$ Lack of accurate estimates of overdiagnosis and overtreatment impede an adequate analysis of the influence of delayed breast cancer diagnosis on the survival of patients.

In this thesis, we hypothesized that, due to improvements in the past decades such as multi-disciplinary meetings, advancement in imaging modalities and biopsy techniques, and specialization of health care professionals in breast diseases, the risk and length of delay in breast cancer diagnosis after screening mammography would be significantly reduced. We observed a reduction in the overall percentage of recalled women with a diagnostic delay of at least 4 months $(7.5 \%$ in $1997-2001$ to $3.1 \%$ in 2012-2016, $\mathrm{P}<0.001)$. However, after more than two decades of screening mammography, a similar proportion of women is still faced with a diagnostic delay of breast cancer of at least 24 months compared to 20 years ago (2.2\% from 1997-2006 
versus $2.8 \%$ in 2006-2016, $\mathrm{P}=0.29) .{ }^{9,15,16}$ Unfortunately, we and others do not have detailed information on histology and other tumour characteristics from the oldest cohort. This impedes analysis of changes in tumour histology in delayed breast cancer diagnosis. Therefore, the influence on tumour histology on the occurrence of delay cannot be adequately determined. Future studies into this influence could shed light on the shift from shorter to longer delays in breast cancer diagnosis among screened women.

The BI-RADS system was introduced in the Dutch screening setting in 2009 , along with the replacement of screen-film by digital screening mammography. ${ }^{51,66,67}$ Its use has increased inter-observer agreement between breast radiologists and has the ability to help guide diagnostic pathways. The organization of the screening mammography programme in the Netherlands differs from other countries as screening and workup after recall are not integrated. Instead, there are separate pathways. Screening mammography for most women is taking place in mobile units, whereas the diagnostic work-up is performed in the hospitals in the screening region, to which the women are referred by their general practitioner.

The Dutch screening programme is subject to quality assurance, in accordance with EUSOBI and IARC guidelines. ${ }^{52,68}$ In contrast to the screening units and screening radiologists, the hospitals handling recalls are not subject to quality control, and the departments handling the recalls are not always staffed by dedicated breast radiologists. We found a difference in the proportion of long (>24 months) diagnostic delays in teaching hospitals versus smaller hospitals $(P=0.027)$, with the proportion of delay varying from $0 \%$ in one of the non-teaching hospitals to $4.8 \%$ (highest proportion) in one of the teaching hospitals. Diagnostic pathways in the hospitals in our region are similar due to national guidelines, and there are no notable differences in diagnostic imaging facilities between hospitals. Therefore, we believe that it is more likely that the differences in proportions of delay are rather caused by differences in experience of radiologists (performance of dedicated breast radiologists versus non-dedicated radiologists) handling recall than by the type of hospital (non-teaching versus teaching) or case load.

We think that mandatory quality assurance programmes in hospitals handling recall may prove beneficial. Positive effects of such programmes have been proven in other screening programmes in the Netherlands, such as the cervical cancer and large bowel cancer screening programmes, which have embedded quality assurance with respect to structured assessment after recall. In cervical cancer screening for example, there is both internal and external quality assurance for laboratories, primary care facilities, and other departments involved in the screening process. Also, there are special programmes for continuing education, not only for laboratories and personnel handling diagnostic material, but also for pathologists interpreting diagnostic specimens, medical microbiologists, and other disciplines involved in screening. ${ }^{69}$ In the Dutch screening programme for colorectal cancer, endoscopists are only allowed to perform the screening related endoscopies after they are accredited by following a special 
programme, and continuous monitoring of performance and continuing education are mandatory to keep the accreditation. ${ }^{70}$ In the Dutch breast cancer screening programme, as mentioned previously, a mandatory accreditation is necessary for screening radiologists to be able to participate in the screening programme. However, there are no forms of accreditation for clinical radiologists performing the diagnostic work-up in the women referred to their hospital. We believe that an accreditation for clinical radiologists, similar to accreditations for screening radiologists, screening endoscopists in the bowel cancer screening and professionals involved in cervical cancer screening is required and that this will substantially benefit the quality of the Dutch screening mammography programme ${ }^{16,70-72}$, including a further reduction in diagnostic delays.

Centralization of care could further improve breast care in the Netherlands, and this issue has both opponents and advocates. The centralization of complex treatments has been shown to improve treatment outcome and survival for several types of cancer. Convincing results have been published regarding the centralization of care for gastric and pancreatic cancer in the Netherlands and for breast cancer in Canada. ${ }^{11,73-76}$ However, due to differences in demographics and patient volumes the positive effects of centralization of care, as seen in countries such as Canada and the United States, may not applicable to a country such as the Netherlands, where breast cancer is already a high-volume disease in most hospitals. Further centralization of breast cancer care in a select number of hospitals might seem feasible, but utmost care must be taken to guarantee continuity of care and to prevent delay in the diagnosis and treatment. In the Netherlands, several regional networks were created to improve collaboration between hospitals in different regions and these initiatives have been successful. One good example is the Oncologisch Netwerk Zuidoost-Nederland (OncoZON). Such regional networks could also serve as a platform for the swift implementation of quality assurance programmes as suggested above, and for performing regular audits in hospitals involved in breast cancer care in different regions in the Netherlands.

As mentioned before, limited knowledge is available on the impact of delayed diagnosis on the survival of asymptomatic breast cancer. This is mainly caused by heterogeneity of studies performed and data that can only be obtained from observational studies. However, despites decades of improvements, delayed diagnosis persists, and better understanding of its causes and impact on prognosis might result in additional improvements of the Dutch screening programme. The recent COVID-19 pandemic has introduced an (although unwanted) opportunity to study the effects of a delay in breast cancer diagnosis due to limited access to screening programmes and breast cancer care programmes during a period of five months. This might shed some light and could help us to better understand the impact of a diagnostic delay on the prognosis of breast cancer patients. To further reduce delays and to optimize the screening programme, we think that the quality assurance programme that is currently used for screening radiologists should also be applied to the clinical radiologists 
responsible for the diagnostic work-up in recalled women, similar to the screening programmes for colorectal and cervical cancer. Centralization of selected cases of breast cancer care, such as those with triple-negative disease, and a more active role for the available regional networks might contribute to the continuing improvement of the quality and effectiveness of the Dutch breast cancer screening programme. Although a lot of progress has been made in the past decades, there is still a lot of work to be done.

\section{Future perspectives}

Continuous monitoring and improvements in the Dutch breast cancer screening programme are important to optimize programme efficacy. Despite many advancements in breast cancer screening and breast cancer care in the past decades, a delayed diagnosis of breast cancer after recall as well as the presence of interval cancers and false positive recalls continue to occur and continue to hamper programme efficiency.

Improvements are possible on several aspects of the screening programme as well as in the clinical setting for women who have been recalled. Improving image quality at screening may allow for a better depiction of lesions, especially the smaller lesions which would otherwise be considered as equivocal. This may help the screening radiologist in assigning an adequate BI-RADS classification, which in turn would improve the diagnostic work-up in the clinical setting. Several studies have been performed to evaluate the use of newer imaging modalities such as DBT and breast MRI in a screening setting, with promising results. ${ }^{45,46,77,78}$ They have shown increased cancer detection rates, with equal or lower referral rates. Future studies should focus on the feasibility of implementing these imaging modalities in daily practice, as screening requires a fast and efficient imaging modality with a low radiation dose. The influence on the false positive referral rate and interval cancer rate should be investigated in comparison to current screening standards to see if a significant change is to be expected when introducing these imaging modalities in screening programmes across the country. Also, the cost effectiveness of these modalities in screening are subject of debate and it needs to be determined if implementing new imaging modalities such as DBT and MRI in a screening setting are feasible and cost-effective. ${ }^{79}$ Improvements in screening such as DBT might also decrease the amount of additional lesions found at recall, which could help in the up-front differentiation of multicentric/multifocal or bilateral breast cancer, and may reduce the psychological burden when an additional lesion is found at recall which was not detected at screening.

Quality assurance is currently mandatory for radiologists involved in the screening mammography programme in the Netherlands. The radiologists need to obtain and maintain their accreditation to participate in the screening programme. This is done by continuing education, participating in workshops, and undergoing regular quality 
checks. Recently, a software system has been implemented in our screening region (ScreenIT), which allows the screening radiologist to obtain a quick and accurate feedback on his or her performance. A recent study has shown that feedback on screening results improves the performance. ${ }^{80}$ Thus, continuous feedback could help improve screening efficiency on an individual level, and ultimately on programme level. Currently, a software system is also being built which allows for feedback on diagnostic specifics including pathology outcome, results of multidisciplinary meetings, reports of other radiological examinations performed in the recall setting, and data on final treatment. This is expected to further improve performance of screening radiologists involved in the screening mammography programme in our region.

Currently, quality assurance is not mandatory in the clinical setting. The organization of the screening programme and recall rate in the Netherlands differ from other countries, probably because the screening setting is not integrated in the clinical setting. Each hospital in the Netherlands is allowed to perform the diagnostic work-up of recalled women. There are several teaching and several non-teaching hospitals in our screening region. Currently, the clinical radiologists in these hospitals who perform the diagnostic work-up are not subject to quality assurance programmes, contradictory to the screening radiologists. As mentioned before, we believe that providing quality assurance such as audits, feedback systems and regular education could improve the performance of the clinical radiologists involved in the diagnostic work-up of recall women, and that this will decrease the number of erroneous BI-RADS classifications, one of the most common causes of a delayed breast cancer diagnosis found in our region. Also, false-negative biopsy results may partially be caused by erroneous $\mathrm{BI}$ RADS classifications. This may also improve with a better performance of the radiologist handling recall. Regional cancer network groups have been implemented to further improve both breast cancer care and cancer care as a whole in the southern region of the Netherlands. These regional network groups could help to facilitate quality assurance programmes, in coordination with the Dutch Ministry of Health, Welfare and Sport and the National Institute for Public Health and Welfare (RIVM), to help improve efficiency and accuracy of the radiological work-up after recall. 


\section{References}

1. Bluekens AM, Broeders MJ, den Heeten GJ. Digital mammography in breast cancer screening: a step forward? Expert Rev Anticancer Ther 2013;13:505-7.

2. Bluekens AM, Holland R, Karssemeijer N, Broeders MJ, den Heeten GJ. Comparison of digital screening mammography and screen-film mammography in the early detection of clinically relevant cancers: a multicenter study. Radiology 2012;265:707-14.

3. Bluekens AM, Karssemeijer N, Beijerinck D, et al. Consequences of digital mammography in populationbased breast cancer screening: initial changes and long-term impact on referral rates. Eur Radiol 2010;20:2067-73.

4. Nederend J, Duijm LE, Louwman MW, Groenewoud JH, Donkers-van Rossum AB, Voogd AC. Impact of transition from analog screening mammography to digital screening mammography on screening outcome in The Netherlands: a population-based study. Ann Oncol 2012;23:3098-103.

5. Keyzer-Dekker CM, De Vries J, van Esch L, et al. Anxiety after an abnormal screening mammogram is a serious problem. Breast 2012;21:83-8.

6. Klompenhouwer EG, Duijm LE, Voogd AC, et al. Re-attendance at biennial screening mammography following a repeated false positive recall. Breast Cancer Res Treat 2014;145:429-37.

7. Setz-Pels W, Duijm LE, Coebergh JW, Rutten M, Nederend J, Voogd AC. Re-attendance after falsepositive screening mammography: a population-based study in the Netherlands. Br J Cancer 2013;109: 2044-50.

8. Shen $Y$, Winget $M$, Yuan $Y$. The impact of false positive breast cancer screening mammograms on screening retention: A retrospective population cohort study in Alberta, Canada. Can J Public Health 2018;108:e539-e45.

9. Duijm LE, Groenewoud JH, de Koning HJ, et al. Delayed diagnosis of breast cancer in women recalled for suspicious screening mammography. Eur J Cancer 2009;45:774-81.

10. Duijm LE, Groenewoud JH, Jansen FH, Fracheboud J, van Beek M, de Koning HJ. Mammography screening in the Netherlands: delay in the diagnosis of breast cancer after breast cancer screening. $\mathrm{Br} J$ Cancer 2004;91:1795-9.

11. Blackmore $\mathrm{KM}$, Weerasinghe $\mathrm{A}$, Holloway $\mathrm{CMB}$, et al. Comparison of wait times across the breast cancer treatment pathway among screened women undergoing organized breast assessment versus usual care. Can J Public Health 2019;110(5):595-605.

12. Olivotto IA, Gomi A, Bancej C, et al. Influence of delay to diagnosis on prognostic indicators of screendetected breast carcinoma. Cancer 2002;94:2143-50.

13. Ciatto S, Houssami N, Ambrogetti D, Bonardi R, Collini G, Del Turco MR. Minority report - false negative breast assessment in women recalled for suspicious screening mammography: imaging and pathological features, and associated delay in diagnosis. Breast Cancer Res Treat 2007;105:37-43.

14. Eriksson L, Bergh J, Humphreys K, Warnberg F, Tornberg S, Czene K. Time from breast cancer diagnosis to therapeutic surgery and breast cancer prognosis: A population-based cohort study. Int J Cancer 2018;143:1093-104.

15. Duijm LE, Groenewoud JH, Roumen RM, de Koning HJ, Plaisier ML, Fracheboud J. A decade of breast cancer screening in The Netherlands: trends in the preoperative diagnosis of breast cancer. Breast Cancer Res Treat 2007;106:113-9.

16. Lameijer JRC, Voogd AC, Pijnappel RM, et al. Delayed breast cancer diagnosis after repeated recall at biennial screening mammography: an observational follow-up study from the Netherlands. Br J Cancer 2020;123(2):325-32.

17. Torring ML, Frydenberg M, Hansen RP, Olesen F, Vedsted P. Evidence of increasing mortality with longer diagnostic intervals for five common cancers: a cohort study in primary care. Eur J Cancer 2013; 49:2187-98.

18. Setz-Pels W, Duijm LE, Groenewoud JH, et al. Patient and tumor characteristics of bilateral breast cancer at screening mammography in the Netherlands, a population-based study. Breast Cancer Res Treat 2011;129:955-61.

19. Setz-Pels W, Duijm LE, Groenewoud JH, et al. Detection of bilateral breast cancer at biennial screening mammography in the Netherlands: a population-based study. Radiology 2011;260:357-63.

20. Brett J, Bankhead C, Henderson B, Watson E, Austoker J. The psychological impact of mammographic screening. A systematic review. Psychooncology 2005;14:917-38. 
21. Brett J, Austoker J. Women who are recalled for further investigation for breast screening: psychological consequences 3 years after recall and factors affecting re-attendance. J Public Health Med 2001;23:292-300.

22. Sharma N, McMahon M, Haigh I, Chen Y, Dall BJG. The potential impact of digital breast tomosynthesis on the benign biopsy rate in women recalled within the uk breast screening programme. Radiology 2019;291:310-7.

23. van Bommel RMG, Voogd AC, Nederend J, et al. Incidence and tumour characteristics of bilateral and unilateral interval breast cancers at screening mammography. Breast 2018;38:101-6.

24. van Bommel R, Lameijer JRC, Voogd AC, et al. Tumour characteristics of bilateral screen-detected cancers and bilateral interval cancers in women participating at biennial screening mammography. Eur J Radiol 2018;108:215-21.

25. Houssami N, Hunter K. The epidemiology, radiology and biological characteristics of interval breast cancers in population mammography screening. NPJ Breast Cancer 2017;3:12.

26. Tornberg S, Kemetli L, Ascunce N, et al. A pooled analysis of interval cancer rates in six European countries. Eur J Cancer Prev 2010;19:87-93.

27. Fountzilas E, Kotoula V, Zagouri F, et al. Disease evolution and heterogeneity in bilateral breast cancer. Am J Cancer Res 2016;6:2611-30.

28. Yi M, Hunt KK, Arun BK, et al. Factors affecting the decision of breast cancer patients to undergo contralateral prophylactic mastectomy. Cancer Prev Res 2010;3:1026-34.

29. Kurian AW, Lichtensztajn DY, Keegan TH, Nelson DO, Clarke CA, Gomez SL. Use of and mortality after bilateral mastectomy compared with other surgical treatments for breast cancer in California, 19982011. JAMA 2014;312:902-14.

30. Fancellu A, Sanna V, Cottu P, et al. Mastectomy patterns, but not rates, are changing in the treatment of early breast cancer. Experience of a single European institution on 2315 consecutive patients. Breast 2018;39:1-7.

31. Guth U, Myrick ME, Viehl CT, Weber WP, Lardi AM, Schmid SM. Increasing rates of contralateral prophylactic mastectomy - a trend made in USA? Eur J Surg Oncol 2012;38:296-301.

32. Tracy MS, Rosenberg SM, Dominici L, Partridge AH. Contralateral prophylactic mastectomy in women with breast cancer: trends, predictors, and areas for future research. Breast Cancer Res Treat 2013;140: 447-52.

33. Srethbhakdi A, Brennan ME, Hamid G, Flitcroft K. Contralateral prophylactic mastectomy for unilateral breast cancer in women at average risk: Systematic review of patient reported outcomes. Psychooncology 2020;29:960-73.

34. Tesson S, Richards I, Porter D, et al. Women's preferences for contralateral prophylactic mastectomy following unilateral breast cancer: What risk-reduction makes it worthwhile? Breast 2017;31:233-40.

35. Beckmann KR, Buckingham J, Craft P, et al. Clinical characteristics and outcomes of bilateral breast cancer in an Australian cohort. Breast 2011;20:158-64.

36. Hartman $\mathrm{M}$, Czene $\mathrm{K}$, Reilly $\mathrm{M}$, et al. Incidence and prognosis of synchronous and metachronous bilateral breast cancer. J Clin Oncol 2007;25:4210-6.

37. Holm M, Tjonneland A, Balslev E, Kroman N. Prognosis of synchronous bilateral breast cancer: a review and meta-analysis of observational studies. Breast Cancer Res Treat 2014;146:461-75.

38. Jobsen JJ, van der Palen J, Ong F, Riemersma S, Struikmans H. Bilateral breast cancer, synchronous and metachronous; differences and outcome. Breast Cancer Res Treat 2015;153:277-83.

39. Kheirelseid EA, Jumustafa $\mathrm{H}$, Miller $\mathrm{N}$, et al. Bilateral breast cancer: analysis of incidence, outcome, survival and disease characteristics. Breast Cancer Res Treat 2011;126:131-40.

40. Kuo WH, Yen AM, Lee PH, et al. Cumulative survival in early-onset unilateral and bilateral breast cancer: an analysis of 1907 Taiwanese women. Br J Cancer 2009;100:563-70.

41. Mejdahl MK, Wohlfahrt J, Holm M, et al. Breast cancer mortality in synchronous bilateral breast cancer patients. Br J Cancer 2019;120:761-7.

42. Roder $\mathrm{D}$, de Silva $\mathrm{P}$, Zorbas $\mathrm{H}$, et al. Survival from synchronous bilateral breast cancer: the experience of surgeons participating in the breast audit of the Society of Breast Surgeons of Australia and New Zealand. Asian Pacific journal of cancer prevention: APJCP 2012;13:1413-8.

43. Bernardi D, Macaskill $P$, Pellegrini $M$, et al. Breast cancer screening with tomosynthesis (3D mammography) with acquired or synthetic 2D mammography compared with 2D mammography alone (STORM-2): a population-based prospective study. Lancet Oncol 2016;17:1105-13. 
44. Lang K, Andersson I, Zackrisson S. Breast cancer detection in digital breast tomosynthesis and digital mammography-a side-by-side review of discrepant cases. Br J Radiol 2014;87:20140080.

45. Ciatto S, Houssami N, Bernardi D, et al. Integration of 3D digital mammography with tomosynthesis for population breast-cancer screening (STORM): a prospective comparison study. Lancet Oncol 2013;14: 583-9.

46. Skaane $\mathrm{P}$, Bandos $\mathrm{Al}$, Gullien $\mathrm{R}$, et al. Comparison of digital mammography alone and digital mammography plus tomosynthesis in a population-based screening program. Radiology 2013;267:4756.

47. He H, Plaxco JS, Wei W, et al. Incremental cancer detection using breast ultrasonography versus breast magnetic resonance imaging in the evaluation of newly diagnosed breast cancer patients. Br J Radiol 2016;89:20160401.

48. Houben IPL, Van de Voorde P, Jeukens C, et al. Contrast-enhanced spectral mammography as work-up tool in patients recalled from breast cancer screening has low risks and might hold clinical benefits. Eur J Radiol 2017;94:31-7.

49. Lobbes MB, Lalji U, Houwers J, et al. Contrast-enhanced spectral mammography in patients referred from the breast cancer screening programme. Eur Radiol 2014;24:1668-76.

50. Houssami N, Ciatto $S$, Macaskill $P$, et al. Accuracy and surgical impact of magnetic resonance imaging in breast cancer staging: systematic review and meta-analysis in detection of multifocal and multicentric cancer. J Clin Oncol 2008;26:3248-58.

51. Richtlijn Mammacarcinoom 2012. Het Nationaal Borstkanker Overleg Nederland (NABON). (Accessed 23rd of May, 2020, at http://www.oncoline.nl/mammacarcinoom.)

52. Perry N, Broeders M, de Wolf C, Tornberg S, Holland R, von Karsa L. European guidelines for quality assurance in breast cancer screening and diagnosis. Fourth edition--summary document. Ann Oncol 2008;19:614-22.

53. Neal RD, Tharmanathan $P$, France $B$, et al. Is increased time to diagnosis and treatment in symptomatic cancer associated with poorer outcomes? Systematic review. Br J Cancer 2015;112 Suppl 1:S92-107.

54. Regev GS, Ser AM. Breast cancer medical malpractice litigation in New York: The past 10years. Breast 2019;46:1-3.

55. Maringe C, Spicer J, Morris M, et al. The impact of the COVID-19 pandemic on cancer deaths due to delays in diagnosis in England, UK: a national, population-based, modelling study. Lancet Oncol 2020; 21(8):1023-32

56. Sud A, Torr B, Jones ME, et al. Effect of delays in the 2-week-wait cancer referral pathway during the COVID-19 pandemic on cancer survival in the UK: a modelling study. Lancet Oncol 2020;21(8):1035-44.

57. Weber RJ, van Bommel RM, Louwman MW, et al. Characteristics and prognosis of interval cancers after biennial screen-film or full-field digital screening mammography. Breast Cancer Res Treat 2016;158: 471-83.

58. Irvin VL, Zhang Z, Simon MS, et al. Comparison of Mortality Among Participants of Women's Health Initiative Trials With Screening-Detected Breast Cancers vs Interval Breast Cancers. JAMA Netw Open 2020;3:e207227.

59. Zahl PH, Gotzsche PC, Maehlen J. Natural history of breast cancers detected in the Swedish mammography screening programme: a cohort study. Lancet Oncol 2011;12:1118-24.

60. Zahl PH, Maehlen J, Welch HG. The natural history of invasive breast cancers detected by screening mammography. Arch Intern Med 2008;168:2311-6.

61. Hellquist BN, Duffy SW, Abdsaleh S, et al. Effectiveness of population-based service screening with mammography for women ages 40 to 49 years: evaluation of the Swedish Mammography Screening in Young Women (SCRY) cohort. Cancer 2011;117:714-22.

62. Monticciolo DL, Helvie MA, Hendrick RE. Current Issues in the Overdiagnosis and Overtreatment of Breast Cancer. AJR Am J Roentgenol 2018;210:285-91.

63. Jorgensen KJ, Gotzsche PC. Overdiagnosis in publicly organised mammography screening programmes: systematic review of incidence trends. BMJ 2009;339:b2587.

64. Francis A, Fallowfield L, Rea D. The LORIS Trial: Addressing overtreatment of ductal carcinoma in situ. Clin Oncol 2015;27:6-8.

65. Elshof LE, Tryfonidis K, Slaets L, et al. Feasibility of a prospective, randomised, open-label, international multicentre, phase III, non-inferiority trial to assess the safety of active surveillance for low risk ductal carcinoma in situ - The LORD study. Eur J Cancer 2015;51:1497-510. 
66. Timmers JM, van Doorne-Nagtegaal HJ, Verbeek AL, den Heeten GJ, Broeders MJ. A dedicated BI-RADS training programme: effect on the inter-observer variation among screening radiologists. Eur J Radiol 2012;81:2184-8.

67. Timmers JM, van Doorne-Nagtegaal HJ, Zonderland HM, et al. The Breast Imaging Reporting and Data System (BI-RADS) in the Dutch breast cancer screening programme: its role as an assessment and stratification tool. Eur Radiol 2012;22:1717-23.

68. Global Cancer Observatory 2019. International Agency for Research on Cancer. (Accessed 15th of November, 2019, at http://gco.iarc.fr.)

69. Veen Nvd. Framework for the Execution of Cervical Cancer Population Screening Ministry of Health, Welfare and Sport; 2017.

70. Bronzwaer MES, Depla A, van Lelyveld N, et al. Quality assurance of colonoscopy within the Dutch national colorectal cancer screening program. Gastrointest Endosc 2019;89:1-13.

71. Arbyn M, Anttila A, Jordan J, et al. European Guidelines for Quality Assurance in Cervical Cancer Screening. Second edition--summary document. Ann Oncol 2010;21:448-58.

72. Vaccarella S, Franceschi S, Engholm G, Lonnberg S, Khan S, Bray F. 50 years of screening in the Nordic countries: quantifying the effects on cervical cancer incidence. Br J Cancer 2014;111:965-9.

73. Markar SR, Mackenzie H, Wiggins T, et al. Influence of national centralization of oesophagogastric cancer on management and clinical outcome from emergency upper gastrointestinal conditions. $\mathrm{Br} \mathrm{J}$ Surg 2018;105:113-20.

74. Chiarelli AM, Muradali D, Blackmore KM, et al. Evaluating wait times from screening to breast cancer diagnosis among women undergoing organised assessment vs usual care. Br J Cancer 2017;116: 1254-63.

75. Smith CR, Chiarelli AM, Holloway CM, et al. The impact of organized breast assessment on survival by stage for screened women diagnosed with invasive breast cancer. Breast 2018;41:25-33.

76. Gooiker GA, Lemmens VE, Besselink MG, et al. Impact of centralization of pancreatic cancer surgery on resection rates and survival. Br J Surg 2014;101:1000-5.

77. Bakker MF, de Lange SV, Pijnappel RM, et al. Supplemental MRI Screening for Women with Extremely Dense Breast Tissue. New Engl J Med 2019;381:2091-102.

78. Lang K, Nergarden M, Andersson I, Rosso A, Zackrisson S. False positives in breast cancer screening with one-view breast tomosynthesis: An analysis of findings leading to recall, work-up and biopsy rates in the Malmo Breast Tomosynthesis Screening Trial. Eur Radiol 2016;26:3899-907.

79. Sankatsing VDV, Juraniec K, Grimm SE, et al. Cost-effectiveness of Digital Breast Tomosynthesis in Population-based Breast Cancer Screening: A Probabilistic Sensitivity Analysis. Radiology 2020:192505.

80. Hofvind S, Bennett RL, Brisson J, et al. Audit feedback on reading performance of screening mammograms: An international comparison. J Med Screen 2016;23:150-9. 
Chapter 7

Impact 


\section{Impact}

The number of Dutch women confronted with a diagnosis of breast cancer each year is among the highest in Europe. To prevent death from breast cancer, a nationwide biennial screening programme has been implemented in the Netherlands between 1989 and 1996. The effectiveness of this programme is demonstrated by the substantial reduction of the breast cancer mortality rates over the past decades. Despite the success of the programme, there is still room for improvement.

The research described in this thesis was performed to look at several aspects of the screening programme, which might provide opportunities for improvement. These aspects include the detection of multiple lesions and delayed diagnosis in screened women. The studies that were done are probably of value for both screening and diagnostic radiologists, as well as for other personnel involved in breast cancer screening.

The studies in the first part of this thesis focused on the outcome of various types of recall (referral) to the hospital after breast cancer screening was performed, such as recall for both breasts at the same time. We found that synchronous bilateral breast cancer, which is breast cancer occurring in both breasts at the same time, did not occur frequently in referred women. However, it is important to evaluate both breasts in order to avoid missing a tumour in one of the breasts. Studies that have been performed over the years suggest a worse outcome for women with bilateral breast cancer, which is why it is important to reduce the delay in diagnosing bilateral breast malignancies and to start therapy as soon as possible.

The second part of this thesis focused on additional findings after recall. In the hospital, several diagnostic tests (e.g., mammography, ultrasonography and breast $\mathrm{MRI}$ ) are performed to analyse whether women truly have breast cancer. During these tests, the radiologist may encounter additional lesions in the same breast for which a woman has been recalled, or in some cases in the contralateral, non-recalled breast as well. We analysed these additional lesions, as they can have an impact on the choice of treatment. We found that these lesions were mainly benign, but a small proportion proved to be malignant. Although it is important to correctly analyse the lesion detected at screening, it remains equally important to carefully examine the other areas of both breasts to see if any tumours were missed (or invisible) at screening. Additional lesions found after recall may influence treatment strategy and survival, and a timely diagnosis of these lesions is important.

The third part of this thesis focused on delay in breast cancer diagnosis after recall. Despite improvements in the past decades, delayed diagnosis of breast cancer continues to pose a problem in screened women. It also carries a psychological burden, it can have a negative effect on survival and it may result in malpractice claims. We expected a more rapid decline of the number of women with a delayed diagnosis over the past two decades, but this was only true for recalled women who faced a diagnostic delay of less than 24 months. The proportion of longer delays (more than 24 months 
after recall) was stable over the years. Interestingly, we found a difference between teaching and non-teaching hospitals in the proportion of women experiencing a delay. Because guidelines and diagnostic facilities are similar for all hospitals in our region, we think that it is more likely that this difference is caused by experience of the radiologists. We feel that the number of diagnostic delays can be reduced by improving the quality of the assessments performed in recalled women by the hospitals. Currently, quality assurance is only mandatory for the screening programme. Screening radiologists have to obtain an accreditation by a national training programme, they have to attend breast radiology courses regularly and receive continuous feedback on their performance. In other Dutch screening programmes such as cervical cancer screening and large bowel cancer screening, quality assurance is mandatory in the hospitals and laboratories handling recalled patients. In our opinion, the introduction of quality assurance in the hospitals handling recall after breast screening will help to reduce delays in breast cancer diagnosis.

As mentioned before, we aimed to create an overview for health care providers involved in breast cancer screening. We believe that the results of our research are useful for both screening and diagnostic radiologists involved in breast cancer screening and recall. By presenting our research at international and national meetings, we hoped to inform radiologists about the specifics concerning bilateral recall, bilateral breast cancers, bilateral interval cancers and additional lesions found at recall. We also aimed to make them aware of the importance of carefully assessing both breasts, which could help prevent the so called "satisfaction of search". Satisfaction of search can occur when, for example, one focusses on one lesion and therefore misses a second tumour in the same or the other breast.

At the same time, making radiologists aware of the frequency of delayed cancer diagnosis and its causes is expected to lead to increased vigilance in the recall setting as well. Hopefully, this research will stimulate radiology departments to assess and improve their breast cancer care for screened women, for example by introducing quality assurance and regular feedback. This could lead to a reduction in delayed breast cancer diagnoses, ultimately improving the breast cancer screening programme as a whole.

As shown in the past decades, increasing effectiveness of the breast cancer screening programme has had a significant impact on mortality related to breast cancer.

Programme effectiveness can be increased even more by reducing the number of false positive findings. False positive recalls are women who are referred to the hospital for a lesion at breast cancer screening but do not have breast cancer. The rate of false positive recalls is an important quality indicator in screening programmes overall, not only in breast cancer screening. Although not studied in this thesis, we think a decrease in the number of false positive findings could also help to reduce psychological burden for women attending the programme, something which will ultimately benefit all those involved in screening. 
Another important indicator is programme sensitivity, which shows the ability of the screening programme to detect breast cancer. Improving programme sensitivity is beneficial for programme effectiveness. A higher programme sensitivity will also help to reduce the occurrence of interval cancer, another important indicator of screening programme quality.

When the burden of breast cancer can be reduced even more in the near future due to a higher programme effectiveness, this would not only benefit women on the individual level, but potentially on population level as well. It could lead to a further decrease in loss of life, and at the same time (through early detection) could help to decrease healthcare costs. Hopefully, boosting programme effectiveness will also lead to even higher screening programme attendance, due to an increased trust among eligible women in the effectiveness of the programme.

The screening programme has shown its effectiveness over the past decades. However, we do think that continuous evaluation and optimization of the quality indicators mentioned above will improve the programme even more in the future. 
Acknowledgements 


\section{Acknowledgements}

Mijn dank gaat uit naar de gehele beoordelingscommissie, te weten prof. Rutten, prof. De Bock, prof. Dinant, prof. De Ruysscher and last but most certainly not least, dr. Astrid Donkers-van Rossum. Ik kan jullie allen niet genoeg bedanken voor de tijd die jullie hebben willen investeren om deze thesis te lezen en te beoordelen. Daarnaast wil ik jullie bedanken dat jullie in deze moeilijke en veeleisende tijd bereid zijn om mij de kans te geven via een online platform deze thesis te verdedigen. Ik hoop daarnaast dat jullie besluiten om nog meer promoties bij te wonen als opponent omdat dit van onschatbare waarde is.

Lucien, maestro, je onvermoeibare enthousiasme en werklust hebben mij geïnspireerd. Altijd kon ik rekenen op je steun, je commentaar, ook op de meest rare tijdstippen. Ik kon me altijd wel vinden in je commentaar (behalve je commentaar op mijn gebruik van de Engelse taal..) en je hebt me geholpen mijn visie op screening en borstkanker te verbreden. Daarnaast heb je me ook geleerd kritisch te kijken en verbanden te ontdekken maar dan in de meer algemene zin, iets waar ik je niet genoeg voor kan bedanken. Ik kom graag nog een keer je collectie wagonnetjes en treinen bekijken. Als het goed is heb ik inmiddels mijn schuld aan je voldaan. Ik hoop dat mijn laatste toevoeging je ook kan bekoren: onze favoriete hobby's maar dan gecombineerd!

Adri, mijn dank is groot. Ik heb zoveel gehad aan je advies en hulp. Jij hebt me, net als Lucien, laten zien dat je kritisch moet blijven, ook al denk je er te zijn. Er is altijd nog wel het een en ander bij te schaven, maar je hebt me ook geleerd om te erkennen dat iets genoeg is. Ik ben ontzettend blij dat jij in mijn begeleidingsteam hebt gezeten en ik denk dat ik voor velen spreek als ik zeg dat je vooral door moet blijven gaan met het begeleiden van promovendi. Daarnaast vond ik het altijd leuk om met je te praten over de alledaagse dingen, over fietsen, en over vakanties (al dan niet in eigen land).

Vivianne, ook jou wil ik ontzettend graag bedanken. Ik weet nog dat we elkaar voor het eerst ontmoetten: je was kleiner dan ik dacht. Toch merkte ik al tijdens de virtuele ontmoetingen hoe vriendelijk en behulpzaam je was, en dat heb ik als zeer prettig ervaren. Ik mag van geluk spreken dat ik jou als promotor heb gehad. Je kritische blik heeft het onderzoek naar een hoger niveau getild en je hebt me (net als Adri en Lucien) geleerd kritisch te blijven denken en alles tegen elkaar af te wegen. Ik hoop dat er nog veel promovendi de kans krijgen om met je te werken.

Ik wil graag het secretariaat van het Bevolkingsonderzoek Zuid bedanken voor al hun ondersteuning en daarbij in het bijzonder Monique Bakker en Coby van Hintum. Zonder hen was deze thesis niet tot stand gekomen. 
Lieve papa en mama, ik kan jullie niet genoeg bedanken. Ik ben blij dat ik jullie mijn ouders mag noemen, ik kan me geen betere wensen. Het spijt me dat het geen officiële ceremonie is geworden, ik had dat het liefste voor jullie wel gedaan want zoveel promoties komen er nou ook weer niet voor. Ik hoop toch dat we het snel samen kunnen vieren, dat zou veel voor me betekenen.

Rob, je bent me gelukkig nog voor, en dat is je van harte gegund. Het maakt het voor mij ook allemaal iets makkelijker en ik weet waar ik me op moet voorbereiden. Je hebt een prachtig eindresultaat afgeleverd, gefeliciteerd. Bedankt dat ik je paranimf mag zijn, ook al heb ik er 0.0 ervaring mee!

Tiny, dank voor je editing van mijn thesis. Het is een prachtig geheel geworden en ik voelde mij stiekem een beetje trots toen ik de PDF met het eindresultaat zag. Ik wil je danken voor je snelle respons en behulpzaamheid en ik hoop dat je dit er toch als hobby bij blijft doen!

Patty, mijn dank is immens. Je hebt niet alleen een prachtige omslag voor me gemaakt, maar je hebt me ook op de moeilijke momenten geholpen met statistische discussie, afreageren en motiveren. Ik ben zo blij dat ook jij richting het einde van je PhD-traject gaat, het is je gegund.

Joost, waar moet ik beginnen.. Je was er vanaf het begin van mijn radiologische carrière, en hebt me bij zo ongeveer alles wel op een of andere manier geholpen. Zonder jou was dit niet mogelijk, en ik kan je er niet genoeg voor bedanken. Ook vind ik het fijn dat je me scherp houdt en me blijft uitdagen om beter te worden. Daarnaast hebben sommige mensen koffie nodig om hun dag te starten; ik heb vooral een goede mep van jou nodig. Ik hoop dat we elkaar ook na mijn vertrek nog blijven zien, omdat ik je na al die tijd niet meer alleen als collega zie maar ook als goede vriend.

Lonneke, ook al was je niet direct betrokken bij het tot stand komen van de artikelen of de thesis zelf, toch wil ik je bedanken. Je vertrouwen heeft er na een moeilijke periode voor gezorgd dat ik me toch bij elkaar kon rapen om weer verder te gaan. Dit is voor mij van onschatbare waarde geweest, ook al heb ik dat niet goed genoeg laten blijken. Daarnaast hoop ik dat je voor mijn vertrek over de plas de 2000 nog haalt, ik zou graag een keer met je mee willen rijden.

Frits, opnieuw heb je een grote hoeveelheid mammogrammen opnieuw beoordeeld in je eigen tijd. Zonder deze gigantische klus had dit proefschrift niet voltooid kunnen worden. Ik ben je zeer dankbaar. Daarnaast ben je een ontzettend fijne collega en lijkt het met jou altijd alsof het op maandag alweer vrijdag is. 
Wikke, je bent me al enige tijd geleden voorgegaan in het promoveren. Gelukkig ben je nog steeds betrokken bij het onderzoek en heb ook jij een heleboel mammogrammen opnieuw beoordeeld. Daarnaast ben ik je ook zeer dankbaar voor de hulp bij mijn artikelen en tijdens mijn opleiding. Ik hoop dat je hiermee door blijft gaan!

Jeannette, je was me gelukkig voor zodat ik bij je kon afkijken hoe het moest. Je hebt prachtig werk afgeleverd. Ik hoop dat je onderzoekcarrière hier niet stopt want je hebt een gezonde dosis eigenzinnigheid en kritisch denkvermogen, belangrijke trekjes van een goed onderzoeker. Succes!

Thiemo, bedankt dat je mijn opponent wil zijn bij de verdediging van mijn thesis. Voor ons allebei iets dat we voor de eerste keer gaan doen. Voor mij wordt het hopelijk de laatste keer, maar ik hoop dat er voor jou in deze rol nog vele keren zullen volgen!

Leden van de maatschap Radiologie in het Catharina ziekenhuis en collega artsassistenten, dank voor de support en de ruimte die jullie mij hebben gegeven om dit avontuur te volbrengen. Daarnaast ook bedankt voor alles dat jullie mij hebben bijgebracht op het gebied van de radiologie en de meer algemene dingen in het leven; het is kennis van onschatbare waarde. Als het goed is heeft deze thesis jullie geen nadeel opgeleverd, iets dat belangrijk voor me is. Het ga jullie goed en ik hoop jullie in de toekomst nog eens tegen te komen op congressen of bij andere gelegenheden.

Jaap, het eeuwige streven om jou te evenaren heeft me veel goeds opgeleverd, en een betere broer kan ik me niet wensen. Ik benijd je vermogen om een extreem drukke baan te combineren met het houden van Nina en die twee kleine frutsels, het zou mij niet lukken. Ik kan je niet genoeg bedanken voor je hulp bij het tot stand komen van de artikelen in deze thesis.

Roline, dank voor je hulp. Daarnaast vond ik het fijn dat ik jou af en toe ook nog kon helpen, oude kennis ophalen is altijd leuk. Ik hoop dat het je allemaal niet teveel afschrikt, je moet immers nog even door met studeren. Ik hoop dat ik je kan inspireren je ook te storten op onderzoek omdat ik denk dat je daardoor een nog betere dokter kunt worden.

Vrienden en familie die ik niet heb genoemd, ook jullie bedankt. Het leven zou niet zinvol zijn zonder jullie om me heen. Immers, werken is niet het belangrijkste in het leven, ook al laat ik misschien wel eens anders blijken..

Lieve Jette en Kaat, menig vrolijk filmpje maakte het avond- en weekendwerk draaglijk. Ik hoop dat ik jullie kan inspireren om later het beste uit jezelf te halen, op welke manier dan ook. 
Curriculum Vitae 


\section{Curriculum Vitae}

Joost Rutger Constantijn Lameijer was born on July $31^{\text {st }}, 1989$ in Zoetermeer, the Netherlands. After graduating from Stedelijk College Zoetermeer in 2007, he studied medicine at the University of Leiden.

After obtaining his medical degree in 2014 and after a short period at the cardiothoracic surgery department at the Catharina Hospital, he started his residency in radiology on January $2^{\text {nd }} 2016$.

In January 2017 he was approached by dr. Duijm and started writing the thesis you are now reading. This thesis also resulted in presentation at the European Congress of Radiology in 2017, 2019 and 2020 and at the Dutch Radiology Days (2017). 
List of publications 


\section{List of publications}

Severe arterial thromboembolism in patients with Covid-19

JRC Lameijer, J van Houte, MMG van Berckel, LR Canta, LSF Yo, MR Nijziel, GM Krietemeijer, SAM Troquay, MP Buise, J Hendriks

Epub August 8, 2020, J. Crit. Care. DOI:10.1016/j.jcrc.2020.08.002

Trends in delayed breast cancer diagnosis after recall at screening mammography JRC Lameijer, AC Voogd, MJM Broeders, RM Pijnappel, W Setz-Pels, L Strobbe, FH Jansen, VCG Tjan-Heijnen, LEM Duijm

Manuscript submitted and under review at the Eur. J. Radiol. (December 2020).

Fully automated postoperative ventilation in cardiac surgery patients: a randomised clinical trial

AJR de Bie, A Serpa Neto, DM van Meenen, AR Bouwman, AN Roos, JRC Lameijer, HHM Korsten, MJ Schultz, AJGH Bindels

Epub July 30th 2020, Br. J. Anaesth. DOI:10.1016/j.bja.2020.06.037

Frequency and diagnostic outcome of bilateral recall at screening mammography JRC Lameijer, J Nederend, AC Voogd, VCG Tjan-Heijnen, LEM Duijm.

Int. J. Cancer 148, 48-56 (2021). DOI:10.1002/ijc.33187

Delayed breast cancer diagnosis after repeated recall at biennial screening mammography, an observational follow-up study from the Netherlands

JRC Lameijer, RM Pijnappel, W Setz-Pels, MJM Broeders, VCG Tjan-Heijnen, LEM Duijm Br. J. Cancer 123, 325-332 (2020). DOI:10.1038/s41416-020-0870-2

Frequency and characteristics of contralateral breast abnormalities following recall at screening mammography

JRC Lameijer, AMP Coolen, AC Voogd, LJ Strobbe, MWJ Louwman, D Venderink, VCG Tjan-Heijnen, LEM Duijm

Eur. Radiol. 28, 4205-4214 (2019). DOI:10.1007/s00330-018-5532-x.

Characteristics of screen-detected cancers following concordant or discordant recalls at blinded double reading in biennial digital screening mammography.

AMP Coolen, JRC Lameijer, AC Voogd, MWJ Louwman, L Strobbe, VCG Tjan-Heijnen, LEM Duijm.

Eur. Radiol. 29(1), 337-344 (2019). DOI:10.1007/s00330-018-5586-9 
Frequency and characteristics of additionally detected ipsilateral breast lesions following recall at screening mammography

JRC Lameijer, AMP Coolen, J Nederend, AC Voogd, VCG Tjan-Heijnen, LEM Duijm

Breast. 42, 94-101 (2018). DOI:10.1016/j.breast.2018.08.104

Tumour characteristics of bilateral screen-detected cancers and bilateral interval cancers in women participating at biennial screening mammography.

RMG van Bommel, JRC Lameijer, AC Voogd, J Nederend, MWJ Louwman, W Setz-Pels, LJ Strobbe, VCG Tjan-Heijnen, LEM Duijm.

Eur. J. Radiol. 108, 215-221 (2018). DOI:10.1016/j.ejrad.2018.09.026

Incorporation of the technologist's opinion for arbitration of discrepant assessments among radiologists at screening mammography.

AMP Coolen, JRC Lameijer, AC Voogd, L Strobbe, MWJ Louwman, VCG Tjan-Heijnen, LEM Duijm

Breast Cancer Res. Treat. 171(1), 143-149 (2018). DOI:10.1007/s10549-018-4800-4.

Combined intravenous, topical and oral tranexamic acid administration in total knee replacement: Evaluation of safety in patients with previous thromboembolism and effect on hemoglobin level and transfusion rate.

JA Jansen, JRC Lameijer, BAM Snoeker

Knee. 24(5), 1206-1212 (2017). DOI:10.1016/j.knee.2017.07.004

The additional effect of post-operative oral tranexamic acid compared to standard pre-operative intravenous tranexamic acid use in three independent cohorts with 1103 primary total knee arthroplasties

JRC Lameijer, JA Jansen

Manuscript phase

Incidence of cardiovascular complications in knee arthroplasty patients before and after implementation of a ropivacaine local infiltration analgesia protocol: A retrospective study

JRC. Lameijer, F Verboom, J Grefkens, JA Jansen.

Knee. 23, 877-882 (2016). DOI:10.1016/j.knee.2016.05.009

The prognostic performance of the predisposition, infection, response and organ failure (PIRO) classification in high-risk and low-risk emergency department sepsis populations: comparison with clinical judgement and sepsis category.

B de Groot, JRC Lameijer, ER de Deckere, A Vis.

Emerg. Med J. 31(4), 292-300 (2014). DOI:10.1136/emermed-2012-202165 
High-sensitivity cardiac troponin $\mathrm{T}$ is an independent predictor of in hospital mortality in emergency department patients with suspected infection: a prospective observational derivation study.

B de Groot, RC Verdoorn, JRC Lameijer, J van der Velden.

Emerg. Med. J. 31(11), 882-888 (2014). DOI:10.1136/emermed-2013-202865 
